\title{
Diseases of Echinodermata. II. Agents metazoans (Mesozoa to Bryozoa)
}

\author{
Michel Jangoux \\ Laboratoire de Biologie marine (CP 160), Université Libre de Bruxelles, Ave F. D. Roosevelt 50, B-1050 Bruxelles, Belgium
}

\begin{abstract}
The only species of Mesozoa known to parasitize echinoderms is clearly pathogenic; it causes the regression of ovaries of infested ophiuroids. Symbiotic turbellarians have been reported for each echinoderm group; they mainly infest the gut and coelom of aspidochirote holothuroids and regular echinoids. Echinoderms generally act as second intermediary host for trematodes; the latter are known mostly from echinoids and ophiuroids which constitute the most frequent echinoderm prey for fishes. Records of echinoderm-infesting nematodes are rather scarce; they usually infest either the coelom or the gonads of their host. Many eulimid gastropods have been reported to parasitize echinoderms; however, most of them do not seem to seriously alter the echinoderm life cycle. They are no bivalves parasitic on echinoderms except a few species inhabiting the gut of holothuroids. Associations between echinoderms and sponges, cnidarians, entoprocts or bryozoans have been casually reported in the literature.
\end{abstract}

\section{INTRODUCTION}

The present paper is the second of a series of 4 that review the diseases of Echinodermata. It considers the disease agents belonging to the Mesozoa, Parazoa, Cnidaria, Acoelomata (Turbellaria and Trematoda), Nematoda, Mollusca (Gasteropoda and Bivalvia), Entoprocta and Bryozoa. As discussed in Part I (Jangoux 1987), I have adopted the definition of parasites proposed by Kinne (1980, p. 19) and used it in a very broad sense, considering disease agents (parasites sensu lato) to represent any kind of a harmful associate which affects, if even slightly, the echinoderm's tissues or internal fluids (i.e. coelomic and hemal fluids).

\section{DISEASES CAUSED BY METAZOANS}

Agents: Mesozoa

The Mesozoa, a small group of uncertain taxonomic affinity, comprise about 50 species of minute animals parasitic on marine invertebrates. One species, Rhopalura ophiocomae, parasitizes ophiuroids. Its most frequent host is the small cosmopolitan incubating amphiurid Amphipholis squamata (Caullery \& Mesnil 1901, Kozloff 1969, Rader 1982) but it may - if very rarely - also affect other ophiurid species, namely Ophiothrix fragilis and Ophiura albida (respectively Fontaine 1968, Bender 1972). $R$. ophiocomae is mostly known from European localities (Atlantic coast of France, North Sea, northwest Mediterranean Sea; for reviews see Kozloff 1969, Barel \& Kramers 1977), and also from 2 Pacific localities along the coast of Washington (Kozloff 1969, Rader 1982).

Structure and life cycle of Rhopalura ophiocomae were studied intensively at the begining of this century, mainly by Caullery \& Mesnil (1901) and Caullery \& Lavallée $(1908,1912)$ (Fig. 1). Mature adults of $R$. ophiocomae are free living. Adults, either male or female, develop in Amphipholis squamata and are emitted through the ophiuroid's bursal slits. Their life span is short (a few days) and they give rise to ciliated larvae. These infesting larvae penetrate the ophiuroid bursal slits and intimately contact the outer epithelium of the bursae. Soon afterwards, small parasitic plasmodia' occur within the epithelium. Subsequently, plasmodia migrate to the coelomic side of the bursae where they remain close to the ovaries. At that time plasmodia often protude into the coelomic cavity. They 


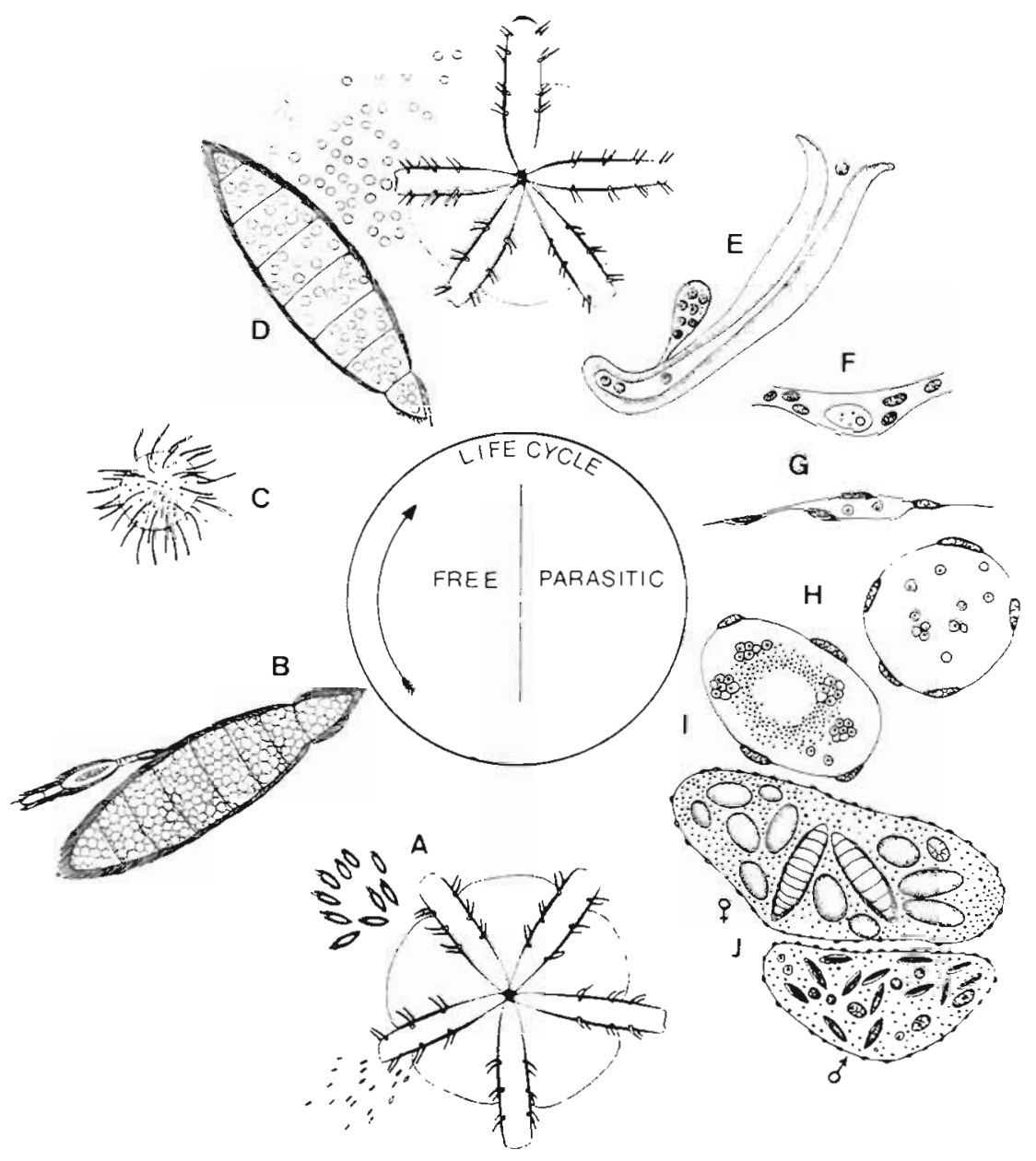

Fig. 1. Rhopalura ophiocomae. Life-cycle of a mesozoan parasite of the ophiuroid Amphipholis squamata (not to scale). (A) Male and female mesozoans emitted through the genital slits of an infested ophiuroid; (B) fecondation; (C) infesting mesozoan larvae; (D) release of infesting larvae from a female mesozoan; (E) infestation of ophiuroid genital slits $(F)$ penetration of the larvae in the ophiuroid bursal epithelium; ( $G$ to I) developing plasmodia; (J) male and female plasmodia. (After Caullery \& Lavallée 1912) are completely surrounded by an epithelial layer presumably formed by host mesothelium (Caullery \& Mesnil 1901, Rader 1982). Whether each plasmodium derived from a whole larva or from one or more cells of that larva is not known. The plasmodia grow and some of them move along the coelomic lining. Fully developed plasmodia consist of an enlarged cytoplasmic (?) mass surrounded by an epithelium of host origin. Each plasmodial mass contains numerous small nuclei (the 'plasmodic' or 'vegetative' nuclei), some germ cells (sometimes called 'agametes') and a few embryos at different developmental stages. These are either males or females, embryos of both sexes within the same plasmodium being exceptional. When mature, the plasmodium presumably disintegrates and numerous adult $R$. ophiocomae are emitted into the outer medium through the host's bursal slit.

The pathogenicity of Rhopalura ophiocomae is unquestionable. Its most obvious effect is the regression of host ovaries, while the testes - as noted by several authors - remain functional (Amphipholis squamata is hermaphroditic). The parasite does not consume the ovaries; these regress as soon as small plasmodia invade the bursal wall. Ovarian regression implies that infested ophiuroids never harbor incubated embryos. Other consequences of the disease are a decrease in the ophiuroid's regenerative abilities, as well as probably a decrease in its growth rate (Rader 1982).

\section{Agents: Parazoa}

There are only 2 sponge species known to parasitize echinoderms. Clark $(1896,1898)$ reported the occurrence of a Grantia-like species firmly attached to the outer body surface of several individuals of the holothuroid Synapta vivipara. The sponges always were seen at the base of the holothuroid buccal tentacles. Antarctic ophiuroids of the genus Ophiurolepis are very often parasitized by the sponge Iophon radiatus (Mortensen 1936, Fell 1961). The parasite fixes itself on the ophiuroid, and infestation is generally very extensive, the whole disc and the basal parts of the arms being involved.

As shown by Mortensen (1932), the bizarre sponge Microcordyla asteriae described by Zirpolo (1926) as an 
ectoparasite of the asteroid Coscinasterias tenuispina, actually represents a globiferous pedicellaria of the echinoid Sphaerechinus granularis. The pedicellariae probably were detached in a defensive reaction of $S$. granularis (globiferous pedicellariae of echinoids autotomize easily).

\section{Agents: Cnidaria}

Several sea anemones attach to the body surface of echinoderms. Gravier (1918) noted the accurrence of the actinid Sicyopus commensalis partly embedded in the body wall of the deep-sea holothuroid Pseudostichopus villosus. Kropp (1927) reported echinoids of the genus Diadema with the sea anemone Aiptasia tagetas firmly attached to their body surface near the anal cone. Other cnidarians may incidentally parasitize echinoderms, namely hydrozoans which live attached to the stem or the cirri of crinoids. Four crinoid-associated hydrozoans are known: Calycella syringa, Cuspidella sp., Lafoea fruticosa, and Stegopoma fastigiata (Clark 1921). A case of symbiosis between the hydrozoan Hydractinia vallini and several species of the Antarctic ophiuroid genus Theodoria has been reported by Smirnov \& Stepanyants (1980). This symbiosis is similar to the one between Antarctic ophiuroids and sponges. The single known case of hydrozoans living on asteroids was reported by Madsen (1961) who recorded unidentified athecate hydroids attached to the peristome of the deep-sea asteroid Eremicaster gracilis.

\section{Agents: Turbellaria}

While Turbellaria are mainly free-living, each order has developed representatives living in close association with other organisms. Symbiotic turbellarians were reviewed by Jennings (1971) (see also Stunkard \& Corliss 1951) who noted that echinoderms represent preferential shelters for turbellarians. Table 1 lists symbiotic turbellarians living with echinoderms; of the 68 species, 9 are Acoela, 58 Rhabdocoela $(52$ species belonging to the family Umagillidae) and 1 Polycladida. With very few exceptions (Euplana takewakii and Acholades asteris; respectively Kato 1935, Hickman \& Olsen 1955), almost all echinoderm-associated turbellarians live either within the digestive tract or within the coelomic cavity of their host. Symbiotic turbellarians have been reported for each echinoderm group, but most of these associates live in aspidochirote holothuroids (mainly Holothuriidae and Stichopodidae) or in regular echinoids. As noted in Table 1, massive turbellarian infestations occur rather frequently in echinoderms. There is, however, no information on the effect of parasitic Turbellaria on the echinoderm life cycle.

Gut-associated umagillids may either occur all along the digestive tract (Smith 1973) or be more or less restricted to some digestive areas (Barel \& Kramers 1971, Shinn 1981, Cannon 1982; see also Table 1). Holt \& Mettrick (1975) reported that Syndisyrinx franciscanus from the gut of Strongylocentrotus purpuratus feeds mostly on associated ciliates, harbored by the digestive tract of the echinoid. Snyder (1980) could determine neither beneficial nor detrimental effects due to the occurrence of gut-associated umagillids. He concluded that these symbiotes should be considered simply commensals. In contrast Shinn (1981) reported that the gut-associated umagillids always compete with their host for nutrients and thus may exert adverse effects. He noted that all the umagillids studied by him ingest intestinal host tissue - one of them subsisted entirely on that tissue (see also Cannon 1982). Shinn suggested that gut umagillids parasitise their host to varying degress. Giese (1958) noted that the infestation level of $S$. franciscanus in the gut of $S$. purpuratus remains constant throughout the year and does not differ whatever the size, sex or gonadal stage of the echinoid. In contrast, Wahlia pulchella inhabiting the intestine of Stichopus californicus displays a distinct annual cycle of infestation related to the annual feeding cycle of its host (worms do not occur in S. californicus in fall and winter when the host's viscera are resorbed) (Shinn 1986b). According to Shinn (1980, 1983b) egg capsules of the gut-associating $S$. franciscanus leave the host gut with fecal material. Embryogenesis within capsules lasts approximately 2 mo, and fully-formed embryos (infesting embryos) can survive in their capsule for about 10 additional mo (Fig. 2). Embryos hatch after the capsules were ingested by an echinoid. Hatching is induced by some property of the host's digestive fluid and performed presumably owing to a hatching enzyme secreted by the embryos (Shinn 1983b, 1986a).

Coelomic umagillids swim in the host's body cavity, seemingly without any particular intracoelomic location. Coelomic umagillids directly depend on their host for nutrition - they ingest the host's coelomic fluid together with coelomocytes (Jennings \& Mettrick 1968, Shinn 1983b) - or on other coelom-associated organisms such as ciliates (Mettrick \& Jennings 1969, Jennings 1980). Egg-capsules of intracoelomic umagillids of holothuroids frequently occur within brown bodies (Briot 1906a, b, Arvy 1957, Changeux 1961, Jespersen \& Lützen 1971, Shinn 1983b, 1985a). They are thought to be released into the outer medium through host evisceration (Changeux 1961, Jespersen \& Lützen 1971). Shinn (1985a) reported, however, that brown 
Table 1. Turbellarians associated with echinoderms (compiled from the sources indicated). Turbellarian species names according

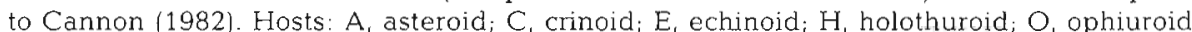

\begin{tabular}{|c|c|c|c|c|c|}
\hline Turbellarian & Host & Location in host & Remarks & Geographical area & Source \\
\hline \multicolumn{6}{|l|}{ I. Acoela } \\
\hline $\begin{array}{l}\text { Aechmalotus } \\
\text { pyrula }\end{array}$ & Eupyrgus scaber $(\mathrm{H})$ & $\begin{array}{l}\text { Digestive tract and } \\
\text { respiratory trees }\end{array}$ & - & $\begin{array}{l}\text { Barents Sea } \\
\text { (Murmansk coast) }\end{array}$ & Beklemishev (1915) \\
\hline $\begin{array}{l}\text { Aphanastoma } \\
\text { pallidum }\end{array}$ & Myriotrokus rinki $(\mathrm{H})$ & Digestive tract & - & $\begin{array}{l}\text { Barents Sea } \\
\text { (Murmansk coast) }\end{array}$ & Beklemishev (1915) \\
\hline $\begin{array}{l}\text { Aphanostoma } \\
\text { sanguineum }\end{array}$ & Chirodota laevis $(\mathrm{H})$ & $\begin{array}{l}\text { Posterior part of the } \\
\text { digestive tract }\end{array}$ & - & $\begin{array}{l}\text { Barents Sea } \\
\text { (Murmansk coast) }\end{array}$ & Beklemishev (1915) \\
\hline $\begin{array}{l}\text { Avagina } \\
\text { glandulifera }\end{array}$ & $\begin{array}{l}\text { Spatangus } \\
\text { purpureus (E) }\end{array}$ & Digestive tract & $\begin{array}{l}\text { Many echinoids } \\
\text { infested }\end{array}$ & $\begin{array}{l}\text { English Channel } \\
\text { (Plymouth) }\end{array}$ & Westblad (1953) \\
\hline Avagina incola & $\begin{array}{l}\text { Echinocardium } \\
\text { cordatum }(\mathrm{E})\end{array}$ & $\begin{array}{l}\text { Siphon (accessory } \\
\text { canal) }\end{array}$ & $\begin{array}{l}5 \% \text { of the echinoid } \\
\text { population infested }\end{array}$ & $\begin{array}{l}\text { NE Atlantic } \\
\text { (Millport) }\end{array}$ & Leiper $(1902,1904)$ \\
\hline Avagina incola & $\begin{array}{l}\text { Echinocardium flaves- } \\
\text { cens, Spatangus pur- } \\
\text { pureus (E) }\end{array}$ & Digestive tract & $\begin{array}{l}\text { Average infestation: } \\
50 \text { worms echinoid }\end{array}$ & $\begin{array}{l}\text { North Sea (Bonden, } \\
\text { Norway) }\end{array}$ & $\begin{array}{l}\text { Karling (in Westblad } \\
1948 \text { ) }\end{array}$ \\
\hline Avagina incola & $\begin{array}{l}\text { Echinocardium llaves- } \\
\text { cens }(E)\end{array}$ & Digestive tract & $\begin{array}{l}3 \text { to } 14 \text { worms } \\
\text { echinoid }{ }^{-1} \\
\text { (50 echinoids investi- } \\
\text { gated) }\end{array}$ & $\begin{array}{l}\text { North Sea } \\
\text { (Norwegian coast) }\end{array}$ & Westblad (1948) \\
\hline Avagina incola & $\begin{array}{l}\text { Spatangus } \\
\text { purpureus (E) }\end{array}$ & Digestive tract & - & $\begin{array}{l}\text { North Sea (Norwegian } \\
\text { coast), English } \\
\text { Channel (Plymouth) }\end{array}$ & Westblad $(1948,1953)$ \\
\hline Avagina vivipara & $\begin{array}{l}\text { Echinocardium } \\
\text { cordatum }(\mathrm{E})\end{array}$ & Esophagus & $\begin{array}{l}2 \text { to } 5 \text { worms } \\
\text { echinoid }^{-1} \\
\text { (18 infested } 68 \\
\text { investigated) }\end{array}$ & $\begin{array}{l}\text { SW Indian Ocean } \\
\text { (Ralph's Bay, } \\
\text { Tasmania) }\end{array}$ & Hickman (1956) \\
\hline Faerla echinocardi & $\begin{array}{l}\text { Echinocardium flaves- } \\
\text { cens }(\mathrm{E})\end{array}$ & Unspecified & - & $\begin{array}{l}\text { ? North Sea } \\
\text { (Norwegian coast) }\end{array}$ & Dorjes (1972) \\
\hline Meara stichopi & $\begin{array}{l}\text { Parastuchopus } \\
\text { tremulus }(\mathrm{H})\end{array}$ & $\begin{array}{l}\text { Anterior intestine; } \\
\text { coelomic cavity }\end{array}$ & $\begin{array}{l}1 \text { to } 8 \text { worms } \\
\text { holothuroid }^{-1}\end{array}$ & $\begin{array}{l}\text { North Sea (Norwegian } \\
\text { coast: Herdla, } \\
\text { Trondhjem.) }\end{array}$ & Westblad $(1926,1949)$ \\
\hline Meara stichopi & $\begin{array}{l}\text { Parastichopus } \\
\text { tremulus }(\mathrm{H})\end{array}$ & Esophagus & - & North Sea (Oslofjord) & $\begin{array}{l}\text { Jespersen \& Lutzen } \\
\text { (1.971) }\end{array}$ \\
\hline Meara stichopi & $\begin{array}{l}\text { Mesothuria } \\
\text { intestinalis }(\mathrm{H})\end{array}$ & Coelomic cavity & Single observation & $\begin{array}{l}\text { North Sea } \\
\text { (Norwegian coast) }\end{array}$ & Westblad $(1926,1949)$ \\
\hline Octocoelis chirodota & Chirodota laevis (H) & $\begin{array}{l}\text { Anterior part of } \\
\text { digestive tract }\end{array}$ & - & $\begin{array}{l}\text { Barents Sea } \\
\text { (Murmansk coast) }\end{array}$ & Beklemishev (1915) \\
\hline \multicolumn{6}{|c|}{ II. Rhabdoecoela (f. umagillidae) } \\
\hline Anoplodiera voluta & $\begin{array}{l}\text { Parastichopus } \\
\text { tremulus }(\mathrm{H})\end{array}$ & Digestive tract & $\begin{array}{l}\text { Up to } 90 \text { worms } \\
\text { holothuroid }\end{array}$ & $\begin{array}{l}\text { North Sea (Norwegian } \\
\text { coast: Herdla, Trond- } \\
\text { hjem) }\end{array}$ & Westblad $(1926,1930)$ \\
\hline Anoplodiera voluta & $\begin{array}{l}\text { Parastichopus } \\
\text { tremulus }(\mathrm{H})\end{array}$ & $\begin{array}{l}\text { Anterior part of diges- } \\
\text { tive tract }\end{array}$ & - & North Sea (Oslofjord) & $\begin{array}{l}\text { Jespersen \& Lutzen } \\
(1971)\end{array}$ \\
\hline Anoplodierasp. & $\begin{array}{l}\text { Holothuria } \\
\text { arenicola }(\mathrm{H})\end{array}$ & Pharynx & $\begin{array}{l}\text { Average infestation: } 7 \\
\text { worms holothuroid }{ }^{-1} \\
\text { (9 infested/12 investi- } \\
\text { gated) }\end{array}$ & $\begin{array}{l}\text { Tropical W Atlantic } \\
\text { (Bermuda) }\end{array}$ & Snyder $(1980)$ \\
\hline Anoplodiopsis gracilis & $\begin{array}{l}\text { Holothuria } \\
\text { forskals }(\mathrm{H})\end{array}$ & Coelomic cavity & $\begin{array}{l}\text { Up to } 9 \text { worms } \\
\text { holothuroids }{ }^{-1} \text { ( } 11 \text { in- } \\
\text { fested } / 47 \text { investi- } \\
\text { gated) (Wahl } 1906 \text { ) }\end{array}$ & $\begin{array}{l}\text { Mediterranean Sea } \\
\text { (Naples) }\end{array}$ & $\begin{array}{l}\text { Wahl }(1906,1909) \text {. } \\
\text { Westblad }(1953)\end{array}$ \\
\hline $\begin{array}{l}\text { Anoplodium } \\
\text { chirodotae }\end{array}$ & $\begin{array}{l}\text { Chirodota } \\
\text { pellucida }(\mathrm{H})\end{array}$ & Coelomic cavity & $\begin{array}{l}\text { Species of doubtful } \\
\text { generic affinty }\end{array}$ & White Sea & $\begin{array}{l}\text { Sabussow (1900, } \\
\text { quoted by Barel \& } \\
\text { Kramers, 1977) }\end{array}$ \\
\hline Anoplodium evelinae & $\begin{array}{l}\text { Unidentufied } \\
\text { holothuroid }\end{array}$ & Coelomic cavity & $\begin{array}{l}\text { Up to } 50 \text { worms } \\
\text { holothurold }\end{array}$ & $\begin{array}{l}\text { SW Atlantic (Brazil: } \\
\text { Santos Bay) }\end{array}$ & Marcus (1949) \\
\hline Anoplodium graff & $\begin{array}{l}\text { Holothuna } \\
\text { impatiens }(\mathrm{H})\end{array}$ & Coelomic cavity & - & $\begin{array}{l}\text { Mediterranean Sea } \\
\text { (Naples) }\end{array}$ & $\begin{array}{l}\text { Monticelli (1892), } \\
\text { Westblad (1953) }\end{array}$ \\
\hline Anoplodium hymanae & $\begin{array}{l}\text { Parastichopus } \\
\text { californicus }(\mathrm{H})\end{array}$ & Coelomic cavity & $\begin{array}{l}1 \text { to } 51 \text { (average } 15 \text { ) } \\
\text { worms holothuroid } \\
\text { ( } 25 \text { infested } / 27 \text { inves- } \\
\text { tigated) }\end{array}$ & $\begin{array}{l}\text { NE Pacific (Washing- } \\
\text { ton coast: Cowlitz } \\
\text { Bay) }\end{array}$ & $\begin{array}{l}\text { Shinn (1983a; see also } \\
\text { Shinn 1985b) }\end{array}$ \\
\hline
\end{tabular}


Table 1 (continued)

\begin{tabular}{|c|c|c|c|c|c|}
\hline Turbellarian & Host & Location in host & Remarks & Geographical area & Source \\
\hline $\begin{array}{l}\text { Anoplodum } \\
\text { longiductum }\end{array}$ & Actinopygasp. (H) & Unspecified & - & $\begin{array}{l}\text { SW Indian ocean } \\
\text { (Madagascar: } \\
\text { Nossy-Bé) }\end{array}$ & Hyman (1960) \\
\hline $\begin{array}{l}\text { Anoplodium } \\
\text { mediale }\end{array}$ & $\begin{array}{l}\text { Stichopus } \\
\text { japonicus }(\mathrm{H})\end{array}$ & Coelomic cavity & - & $\begin{array}{l}\text { NW Pacific (Japan: } \\
\text { Hiroshima) }\end{array}$ & Ozaki (1932) \\
\hline $\begin{array}{l}\text { Anoplodium } \\
\text { myriotrochi }\end{array}$ & $\begin{array}{l}\text { Myriotrochus } \\
\text { rincki }(\mathrm{H})\end{array}$ & Digestive tract & Infestation frequent & $\begin{array}{l}\text { Arctic Seas } \\
\text { (Spitzbergen) }\end{array}$ & $\begin{array}{l}\text { Barel \& Kramers } \\
\text { (1977) }\end{array}$ \\
\hline Anoplodium parasita & $\begin{array}{l}\text { Holothuna tubulosa, } \\
\text { Holothuria poli and } \\
\text { Holothuria stellati }(\mathrm{H})\end{array}$ & $\begin{array}{l}\text { Coelomic cavity; rare- } \\
\text { ly digestive tract or } \\
\text { respiratory trees }\end{array}$ & $\begin{array}{l}\text { 1-4 worms } \\
\text { holothuroid } \\
\text { fested/2 } 16 \text { investj- } \\
\text { gated) (Changeux) }\end{array}$ & $\begin{array}{l}\text { Mediterranean Sea } \\
\text { (Banyuls, Naples, } \\
\text { Trieste) }\end{array}$ & $\begin{array}{l}\text { Schneider (1858), } \\
\text { Monticelli (1892), } \\
\text { Briot (1906b), Wahl } \\
\text { (1906), Westblad } \\
\text { (1953), Changeux } \\
\text { (1961) }\end{array}$ \\
\hline Anoplodium ramosum & $\begin{array}{l}\text { Stichopus } \\
\text { variegatus }(\mathrm{H})\end{array}$ & $\begin{array}{l}\text { Unspecified } \\
\text { (endoparasitic) }\end{array}$ & - & $\begin{array}{l}\text { SW Indian Ocean } \\
\text { (Madagascar: } \\
\text { Nossi-Bé) }\end{array}$ & Hyman (1960) \\
\hline Anoplodium stichopi & $\begin{array}{l}\text { Parastichopus } \\
\text { tremulus }(\mathrm{H})\end{array}$ & Coelomic cavity & $\begin{array}{l}\text { Up to } 30 \text { worms } \\
\text { holothuroid }{ }^{-1} \\
\text { (Westblad) }\end{array}$ & $\begin{array}{l}\text { North Sea } \\
\text { (Norwegian coast) }\end{array}$ & $\begin{array}{l}\text { Bock (1926), Westblad } \\
\text { (1926), Jespersen \& } \\
\text { Lützen (1971) }\end{array}$ \\
\hline $\begin{array}{l}\text { Anoplodium } \\
\text { tubiferum }\end{array}$ & $\begin{array}{l}\text { Holothuria } \\
\text { forskali }(\mathrm{H})\end{array}$ & Digestive tract & - & $\begin{array}{l}\text { English Channel } \\
\text { (Plymouth) }\end{array}$ & Westblad (1953) \\
\hline 'Anoplodium'sp.' & $\begin{array}{l}\text { Leptosynapta bergen- } \\
\text { sis, Leptosynapta } \\
\text { galliennei, Leptosy- } \\
\text { napta inhaerens }(\mathrm{H})\end{array}$ & Digestive tract & Rather frequent & $\begin{array}{l}\text { NE Atlantic } \\
\text { (Plymouth, Roscoff) }\end{array}$ & $\begin{array}{l}\text { Cuénot (1912), Barel \& } \\
\text { Kramers (1970, 1977), } \\
\text { Kramers (1971) }\end{array}$ \\
\hline Bicladus metacrini & $\begin{array}{l}\text { Metacrinus } \\
\text { rotundus }(\mathrm{C})\end{array}$ & Digestive tract & $\begin{array}{l}\text { 'Occur in enormous } \\
\text { number' }\end{array}$ & $\begin{array}{l}\text { N Pacific (Japan: } \\
\text { Sagami Sea) }\end{array}$ & Kaburaki (1925) \\
\hline $\begin{array}{l}\text { Cleistogamia } \\
\text { heronensis }\end{array}$ & $\begin{array}{l}\text { Holothuria atra, } \\
\text { Holothuna leucospilo- } \\
\text { ta }(\mathrm{H})\end{array}$ & $\begin{array}{l}\text { Anterior to midpart of } \\
\text { digestive tract }\end{array}$ & - & $\begin{array}{l}\text { Great Barrier Reef } \\
\text { (Australia) }\end{array}$ & Cannon (1982) \\
\hline $\begin{array}{l}\text { Cleistogamia } \\
\text { holothuriana }\end{array}$ & $\begin{array}{l}\text { Actinopyga } \\
\text { mauritiana }(\mathrm{H})\end{array}$ & Digestive tract & $\begin{array}{l}50 \text { worms in a single } \\
\text { indjvidual (Faust) }\end{array}$ & $\begin{array}{l}\text { NE Indian Ocean } \\
\text { (Andaman Islands) }\end{array}$ & $\begin{array}{l}\text { Faust }(1924,1927) \\
\text { Baer }(1938)\end{array}$ \\
\hline $\begin{array}{l}\text { Cleistogamia } \\
\text { holothunana }\end{array}$ & $\begin{array}{l}\text { Actinopyga } \\
\text { echinites }(\mathrm{H})\end{array}$ & $\begin{array}{l}\text { Unspecified } \\
\text { (endoparasitic) }\end{array}$ & - & $\begin{array}{l}\text { SW Indian Ocean } \\
\text { (Madagascar: } \\
\text { Nossi-Bé) }\end{array}$ & Hyman (1960) \\
\hline $\begin{array}{l}\text { Cleistogamia } \\
\text { longicirrus }\end{array}$ & $\begin{array}{l}\text { Stichopus chloronotus, } \\
\text { Stichopus horrens, } \\
\text { Stichopus variegatus } \\
\text { (H) }\end{array}$ & $\begin{array}{l}\text { Anterior to midpart of } \\
\text { digestive tract }\end{array}$ & - & $\begin{array}{l}\text { Great Barrier Reef } \\
\text { (Australia) }\end{array}$ & Cannon (1982) \\
\hline Cleistogamia louftia & Holothuria sp. & $\begin{array}{l}\text { Unspecified } \\
\text { (endoparasitic) }\end{array}$ & - & Red Sea & $\begin{array}{l}\text { Khalil (1938, quoted } \\
\text { by Stunkard \& Corliss } \\
\text { 1951) }\end{array}$ \\
\hline Cleistogamia pallis & Bohadschıa argus $(\mathrm{H})$ & $\begin{array}{l}\text { Anternor to midpart of } \\
\text { digestive tract }\end{array}$ & - & $\begin{array}{l}\text { Great Barrier Reef } \\
\text { (Australia) }\end{array}$ & Cannon (1982) \\
\hline Cleistogamia pulchra & $\begin{array}{l}\text { Actinopyga echinites, } \\
\text { Actinopyga lecanora, } \\
\text { Actinopyga miliaris } \\
\text { (H) }\end{array}$ & $\begin{array}{l}\text { Midpart of digestive } \\
\text { tract }\end{array}$ & - & $\begin{array}{l}\text { Great Barrier Reef } \\
\text { (Australia) }\end{array}$ & Cannon (1982) \\
\hline $\begin{array}{l}\text { Cleistogamia } \\
\text { pyriformis }\end{array}$ & $\begin{array}{l}\text { Holothuna } \\
\text { impatiens }(\mathrm{H})\end{array}$ & $\begin{array}{l}\text { Antenor part of } \\
\text { digestive tract }\end{array}$ & - & $\begin{array}{l}\text { Great Barrier Reef } \\
\text { (Australia) }\end{array}$ & Cannon (1982) \\
\hline Desmote inops & $\begin{array}{l}\text { Florometra } \\
\text { serratissima (C) }\end{array}$ & Digestive tract & $\begin{array}{l}10 \text { to } 30 \text { worms } \\
\text { crinoid } d^{-1}(49 \text { infested/ } \\
60 \text { investigated) }\end{array}$ & $\begin{array}{l}\text { NE Pacific (British } \\
\text { Columbia: satellite } \\
\text { Channel) }\end{array}$ & Kozloff (1965) \\
\hline Desmote vorax & $\begin{array}{l}\text { Heliometra } \\
\text { glacialis (C) }\end{array}$ & $\begin{array}{l}\text { Unspecified } \\
\text { (endoparasitic) }\end{array}$ & $\begin{array}{l}1 \text { to } 20 \text { worms crinoid }{ }^{-1} \\
\text { ( } 9 \text { infested } / 100 \text { inves- }^{-} \\
\text {tigated) }\end{array}$ & $\begin{array}{l}\text { Barents Sea } \\
\text { (Kola Bay) }\end{array}$ & Beklemishev (1916) \\
\hline $\begin{array}{l}\text { Fallacohospes } \\
\text { inchoatus }\end{array}$ & $\begin{array}{l}\text { Florometra } \\
\text { serratissima (C) }\end{array}$ & Digestive tract & $\begin{array}{l}2 \text { to } 15 \text { worms crinoid }{ }^{-1} \\
\text { (59 infested } / 60 \text { inves- } \\
\text { tigated) }\end{array}$ & $\begin{array}{l}\text { NE Pacific (British } \\
\text { Columbia: satellite } \\
\text { Channel) }\end{array}$ & Kozloff (1965) \\
\hline Macrogynium ovalis & $\begin{array}{l}\text { Isostichopus } \\
\text { badionotus }(\mathrm{H})\end{array}$ & $\begin{array}{l}\text { Coelomic cavity; di- } \\
\text { gestive tract }\end{array}$ & $\begin{array}{l}15 \text { worms } \\
\text { holothuroid }{ }^{-1} \text { (average } \\
\text { number): } 36 \\
\text { holothuroids investi- } \\
\text { gated (Snyder) }\end{array}$ & $\begin{array}{l}\text { Tropical W Atlantic } \\
\text { (Bermuda) }\end{array}$ & $\begin{array}{l}\text { Meserve (1934), } \\
\text { Snyder (1980) }\end{array}$ \\
\hline
\end{tabular}


Table 1 (continued)

\begin{tabular}{|c|c|c|c|c|c|}
\hline Turbellanan & Host & Location in host & Remarks & Geographical area & Source \\
\hline $\begin{array}{l}\text { Monticellina } \\
\text { longituba }{ }^{2}\end{array}$ & $\begin{array}{l}\text { Holothuria tmpatiens, } \\
\text { Holothuria poli }(\mathrm{H})\end{array}$ & Coelomic cavity & - & $\begin{array}{l}\text { Mediterranean Sea } \\
\text { (Naples) }\end{array}$ & Westblad (1953) \\
\hline Notothrix inquilina & $\begin{array}{l}\text { Mensamaria } \\
\text { thompsoni }(\mathrm{H})\end{array}$ & $\begin{array}{l}\text { Digestive tract } \\
\text { (anterior part) }\end{array}$ & $\begin{array}{l}\text { Up to } 22 \text { worms } \\
\text { holothuroid }{ }^{-1}(121 \\
\text { investigated } / 51 \\
\text { infested) }\end{array}$ & Tasmania & Hickman (1955) \\
\hline Ozametra arborum & $\begin{array}{l}\text { Stichopus } \\
\text { japonicus (H) }\end{array}$ & Digestive tract & - & $\begin{array}{l}\text { NW Pacific (Japan: } \\
\text { Hiroshima) }\end{array}$ & Ozaki (1932) \\
\hline Ozametrasp. & $\begin{array}{l}\text { Parastichopus } \\
\text { californicus (H) }\end{array}$ & Digestive tract & - & $\begin{array}{l}\text { Pacific coast of } \\
\text { NAmerica }\end{array}$ & $\begin{array}{l}\text { Kozloff in Shinn } \\
\text { (1983a) }\end{array}$ \\
\hline $\begin{array}{l}\text { Paranotothrix } \\
\text { queenslandensis }\end{array}$ & $\begin{array}{l}\text { Actinopyga echinites, } \\
\text { Actinopyga miliaris, } \\
\text { Bohadschia argus, } \\
\text { Holothuria atra, } \\
\text { Holothuria hilla, } \\
\text { Holothuria impatiens, } \\
\text { Holothuria leucospilo- } \\
\text { ta, Stichopus } \\
\text { chloronotus, Stichopus } \\
\text { horrens, Strchopus } \\
\text { variegatus, Thelonota } \\
\text { ananas (H) }\end{array}$ & $\begin{array}{l}\text { Posterior part of } \\
\text { digestive tract }\end{array}$ & - & $\begin{array}{l}\text { Great Barrier Reef } \\
\text { (AustraLia) }\end{array}$ & Cannon (1982) \\
\hline Seritia elegans & $\begin{array}{l}\text { Parastichopus } \\
\text { tremulus (H) }\end{array}$ & $\begin{array}{l}\text { Digestive tract } \\
\text { (anterior part) }\end{array}$ & Rather frequent & $\begin{array}{l}\text { North Sea } \\
\text { (Norwegian coast) }\end{array}$ & $\begin{array}{l}\text { Westblad (1926, 1953), } \\
\text { Jespersen \& Lützen } \\
\text { (1971) }\end{array}$ \\
\hline Seritia striata & $\begin{array}{l}\text { Stichopus } \\
\text { mollis (H) }\end{array}$ & $\begin{array}{l}\text { Digestive tract } \\
\text { (anterior part) }\end{array}$ & - & Tasmania & Hickman (1955) \\
\hline Syndesmis alcalai & $\begin{array}{l}\text { Heterocentrotus } \\
\text { mammillatus }(\mathrm{E})\end{array}$ & $\begin{array}{l}\text { Digestive tract and } \\
\text { coelomic cavity }\end{array}$ & - & $\begin{array}{l}\text { NW Pacific (Philippi- } \\
\text { nes: Sumilon Island) }\end{array}$ & $\begin{array}{l}\text { Komschlies \& Vande } \\
\text { Vusse (1980a) }\end{array}$ \\
\hline Syndesmis compacta & $\begin{array}{l}\text { Echinometra } \\
\text { oblonga }(\mathrm{E})\end{array}$ & $\begin{array}{l}\text { Digestive tract and } \\
\text { coelomic cavity }\end{array}$ & - & $\begin{array}{l}\text { NW Pacific (Philippi- } \\
\text { nes: Cebu Province) }\end{array}$ & $\begin{array}{l}\text { Komschlies \& Vande } \\
\text { Vusse (1980b) }\end{array}$ \\
\hline $\begin{array}{l}\text { Syndesmis } \\
\text { dendrastromum }\end{array}$ & $\begin{array}{l}\text { Dendraster } \\
\text { excentricus (E) }\end{array}$ & Digestive tract & $\begin{array}{l}\text { Up to } 23 \text { worms } \\
\text { echinoid }{ }^{-1} \text { (Smith); } \\
\text { worms consistently } \\
\text { present in large } \\
\text { number (Orihel) }\end{array}$ & $\begin{array}{l}\text { E Pacific (California; } \\
\text { Washington State) }\end{array}$ & $\begin{array}{l}\text { Stunkard \& Corliss } \\
\text { (1950, 1951), Orihel } \\
\text { (1952), Smith (1973), } \\
\text { Shinn (1981) }\end{array}$ \\
\hline Syndesmis echinorum & $\begin{array}{l}\text { Echinus acutus, } \\
\text { Echinus esculentus, } \\
\text { Paracentrotus lividus, } \\
\text { Psammechinus mi- } \\
\text { crotuberculatus, } \\
\text { Psammechinus } \\
\text { miliaris, } \\
\text { Sphaerechinus } \\
\text { granularis, Strongy- } \\
\text { locentrotus } \\
\text { droebachiensis (E) }\end{array}$ & $\begin{array}{l}\text { Digestive tract and } \\
\text { coelomic cavity }\end{array}$ & $\begin{array}{l}\text { Infestation rate highly } \\
\text { variable (see Barel \& } \\
\text { Kramers 1977) }\end{array}$ & European Seas & $\begin{array}{l}\text { Silliman (1881), Fran- } \\
\text { çois (1886), Cuénot } \\
\text { (1891), Shipley (1901), } \\
\text { Briot (1906b), West- } \\
\text { blad (1926), Barel \& } \\
\text { Kramers (1970, 1977), } \\
\text { Lama Seco \& Rodri- } \\
\text { guez Babio (1978) }\end{array}$ \\
\hline $\begin{array}{l}\text { Syndesmis aff. } \\
\text { echinorum }\end{array}$ & $\begin{array}{l}\text { Strongylocentrotus } \\
\text { droebachiensis, Stron- } \\
\text { gylocentrotus pallidus } \\
\text { (E) }\end{array}$ & Digestive tract & - & $\begin{array}{l}\text { NE Pacific (Washing- } \\
\text { ton: San Juan Island) }\end{array}$ & Shinn (1981) \\
\hline Syndesmis glandulosa & $\begin{array}{l}\text { Diadema setosum, } \\
\text { Echinothrix } \\
\text { calamaris }(\mathrm{E})\end{array}$ & $\begin{array}{l}\text { Digestive tract and } \\
\text { coelomic cavity }\end{array}$ & - & $\begin{array}{l}\text { SW Indian Ocean } \\
\text { (Madagascar: Nossi- } \\
\text { Bé) }\end{array}$ & $\begin{array}{l}\text { Hyman (1960), } \\
\text { Komschlies \& Vande } \\
\text { Vusse (1980a) }\end{array}$ \\
\hline $\begin{array}{l}\text { Syndesmis } \\
\text { mammillata }\end{array}$ & $\begin{array}{l}\text { Echinometra } \\
\text { oblonga }(\mathrm{E})\end{array}$ & $\begin{array}{l}\text { Digestive tract and } \\
\text { coelomuc cavity }\end{array}$ & - & $\begin{array}{l}\text { NW Pacafic (Philippi- } \\
\text { nes: Negros Oriental } \\
\text { Province) }\end{array}$ & $\begin{array}{l}\text { Komschlies \& Vande } \\
\text { Vusse (1980a) }\end{array}$ \\
\hline $\begin{array}{l}\text { Syndesmis } \\
\text { philippinensis }\end{array}$ & $\begin{array}{l}\text { Echinometra } \\
\text { oblonga }(\mathrm{E})\end{array}$ & $\begin{array}{l}\text { Digestive tract and } \\
\text { coelomic cavity }\end{array}$ & - & $\begin{array}{l}\text { NW Pacific (Philippi- } \\
\text { nes: Negros Oriental } \\
\text { Province) }\end{array}$ & $\begin{array}{l}\text { Komschlies \& Vande } \\
\text { Vusse (1980a) }\end{array}$ \\
\hline 'Syndesmus'sp. & $\begin{array}{l}\text { Evechinus chloroticus, } \\
\text { Helocidaris erythro- } \\
\text { gramma (E) }\end{array}$ & Digestive tract & - & New Zealand & McRae (1959) \\
\hline
\end{tabular}


Table 1 (continued)

\begin{tabular}{|c|c|c|c|c|c|}
\hline Turbellarian & Host & Location in host & Remarks & Geographical area & Source \\
\hline $\begin{array}{l}\text { Syndisyrinx } \\
\text { antillarum }\end{array}$ & $\begin{array}{l}\text { Diadema antillarum } \\
\text { (E) }\end{array}$ & Coelomic cavity & $\begin{array}{l}60 \text { worms echinoid }{ }^{-1} \\
\text { (average number; } \\
3 \text { infested } / 9 \text { invest- } \\
\text { gated) (Snyder) }\end{array}$ & $\begin{array}{l}\text { Tropical Atlantic loff } \\
\text { Flonda: Bermuda) }\end{array}$ & $\begin{array}{l}\text { Powers (1935), Stunk- } \\
\text { ard \& Corliss (1951). } \\
\text { Mettrick \& Jennings } \\
\text { (1969), Snyder (1980) }\end{array}$ \\
\hline $\begin{array}{l}\text { Syndisyrinx } \\
\text { antillarum }\end{array}$ & $\begin{array}{l}\text { Lytechinus } \\
\text { variegatus }(\mathrm{E})\end{array}$ & $\begin{array}{l}\text { Digestive tract and } \\
\text { coelomic cavity }\end{array}$ & $\begin{array}{l}\text { Up to } 205 \text { worms } \\
\text { echinoid }{ }^{-1}(475 \text { inves- } \\
\text { tigated } 350 \text { infested) }\end{array}$ & Jamaica & $\begin{array}{l}\text { Nappi \& Crawford } \\
\text { (1984) }\end{array}$ \\
\hline $\begin{array}{l}\text { Syndisyrinx } \\
\text { antillarum }\end{array}$ & $\begin{array}{l}\text { Echinometrá } \\
\text { viridis }(\mathrm{E})\end{array}$ & $\begin{array}{l}\text { Digestive tract and } \\
\text { coelomic cavity }\end{array}$ & $\begin{array}{l}\text { Up to } 5 \text { worms } \\
\text { echinold }{ }^{-1} \text { ( } 219 \text { inves- } \\
\text { tigated } / 87 \text { infested) }\end{array}$ & Jamaica & $\begin{array}{l}\text { Nappi \& Crawford } \\
(1984)\end{array}$ \\
\hline $\begin{array}{l}\text { Syndisyranx } \\
\text { atriovillosa }\end{array}$ & $\begin{array}{l}\text { Spatangus } \\
\text { purpureus (E) }\end{array}$ & Digestive tract & - & $\begin{array}{l}\text { English Channel } \\
\text { (Plymouth) }\end{array}$ & Westblad (1953) \\
\hline $\begin{array}{l}\text { Syndisyrinx } \\
\text { franciscanus }\end{array}$ & $\begin{array}{l}\text { Strongylocentrotus } \\
\text { franciscanus, Strongy- } \\
\text { locentrotus pur- } \\
\text { puratus, Strongy- } \\
\text { locentrotus } \\
\text { droebachiensis, Stron- } \\
\text { gylocentrotus } \\
\text { pallidus, Lytechinus } \\
\text { anamesus (E) }\end{array}$ & Digestive tract & $\begin{array}{l}\text { Often up to } 30 \text { worms } \\
\text { in infested echinoid } \\
\text { (Lehman, Shinn) }\end{array}$ & $\begin{array}{l}\text { Pacific coast of } N \\
\text { America (California, } \\
\text { Washington) }\end{array}$ & $\begin{array}{l}\text { Lehman (1946), } \\
\text { Stunkard \& Corliss } \\
\text { (1951), Giese (1958), } \\
\text { Jennings \& Mettrick } \\
\text { (1968), Barnes (1969), } \\
\text { Mettrick \& Jennings } \\
\text { (1969), Mettrick \& } \\
\text { Boddington (1972), } \\
\text { Holt \& Mettrick } \\
\text { (1975), Shinn (1981, } \\
\text { 1983b) }\end{array}$ \\
\hline $\begin{array}{l}\text { Syadisyrinx } \\
\text { franciscanus }\end{array}$ & $\begin{array}{l}\text { Allocentrotus } \\
\text { fragilis (E) }\end{array}$ & Digestive tract & $\begin{array}{l}\text { Maximum } 3 \text { worms } \\
\text { echinold }{ }^{-1} \text { ( } 5 \text { infested/ } \\
75 \text { investigated) } \\
\text { (Giese) }\end{array}$ & $\begin{array}{l}\text { NE Pacific (off Califor- } \\
\text { nian coast) }\end{array}$ & $\begin{array}{l}\text { Giese (1958), Hyman } \\
(1960)\end{array}$ \\
\hline $\begin{array}{l}\text { Syndisyrinx } \\
\text { franciscanus }\end{array}$ & $\begin{array}{l}\text { Lytechinus } \\
\text { variegatus }(E)\end{array}$ & $\begin{array}{l}\text { Digestive tract and } \\
\text { coelomic cavity }\end{array}$ & $\begin{array}{l}29 \text { worms echinoidd }^{-1} \\
\text { (average number) }\end{array}$ & $\begin{array}{l}\text { Tropical W Atlantic } \\
\text { (Jamaica) }\end{array}$ & $\begin{array}{l}\text { Jennings \& Mettrick } \\
\text { (1968), Jones \& Can- } \\
\text { ton (1970) }\end{array}$ \\
\hline Syndisyrinx pallida & $\begin{array}{l}\text { Echinocardium } \\
\text { cordatum (E) }\end{array}$ & Digestive tract & $\begin{array}{l}1 \text { to } 4 \text { worms } \\
\text { echinoid }{ }^{-1}(10 \text { in- } \\
\text { fested } 68 \text { investi- } \\
\text { gated) }\end{array}$ & $\begin{array}{l}\text { Tasmania (Ralph's } \\
\text { Bay) }\end{array}$ & Hickman (1955) \\
\hline Syndisyrinx punicea & $\begin{array}{l}\text { Heliociaris erythro- } \\
\text { gramma. Amblyp- } \\
\text { neustes ovum (E) }\end{array}$ & Digestive tract & $\begin{array}{l}\text { Infestation very fre- } \\
\text { quent; up to } 18 \text { worms } \\
\text { echinoid }{ }^{-1}\end{array}$ & $\begin{array}{l}\text { SE Indian Ocean (Tas- } \\
\text { mania: Ralph's Bay) }\end{array}$ & Hickman (1956) \\
\hline Umagilla forkalensis & $\begin{array}{l}\text { Holothuria } \\
\text { forskali }(\mathrm{H})\end{array}$ & Digestive tract & $\begin{array}{l}\text { Up to } 14 \text { worms } \\
\text { holothuroid }{ }^{-1}(29 \mathrm{in} \text { - } \\
\text { fested } / 47 \text { investi- } \\
\text { gated) (Wahl 1909) }\end{array}$ & $\begin{array}{l}\text { Mediterranean Sea } \\
\text { (Naples); North Sea } \\
\text { (Norwegian coast); } \\
\text { English Channel (Ply- } \\
\text { mouth) }\end{array}$ & $\begin{array}{l}\text { Wahl }(1906,1909), \\
\text { Westblad (1953) }\end{array}$ \\
\hline Wahlia macrostylifera & $\begin{array}{l}\text { Isostichopus } \\
\text { tremulus (H) }\end{array}$ & Digestive tract & $\begin{array}{l}\text { Infestation rather } \\
\text { frequent }\end{array}$ & $\begin{array}{l}\text { North Sea } \\
\text { (Norwegian coast) }\end{array}$ & $\begin{array}{l}\text { Westblad }(1926,1930) \text {, } \\
\text { Jespersen \& Lützen } \\
(1971)\end{array}$ \\
\hline Wahlia macrostylufera & $\begin{array}{l}\text { Parastichopus } \\
\text { badionotus }(\mathrm{H})\end{array}$ & $\begin{array}{l}\text { Digestive tract and } \\
\text { coelomic cavity }\end{array}$ & $\begin{array}{l}15 \text { worms holo- } \\
\text { thuroid }{ }^{-1} \text { (average } \\
\text { number) ( } 33 \text { infested/ } \\
36 \text { investigated) }\end{array}$ & $\begin{array}{l}\text { Tropical W Atlantic } \\
\text { (Bermuda) }\end{array}$ & Snyder (1980) \\
\hline Wahlia pulchella & $\begin{array}{l}\text { Stichopus } \\
\text { californicus (H) }\end{array}$ & $\begin{array}{l}\text { Anterior part of inves- } \\
\text { tine }\end{array}$ & $\begin{array}{l}2 \text { to } 5 \text { worms } \\
\text { holothuroid }{ }^{-1} \text { (infesta- } \\
\text { tion level: } 62 \text { to } 100 \% \\
\text { in spring \& summer; } \\
0 \% \text { in fall and winter } \\
\text { when host's viscera } \\
\text { are resorbed) }\end{array}$ & $\begin{array}{l}\text { NE Pacific (coast of } \\
\text { Washington) }\end{array}$ & Shinn (1986b) \\
\hline Wahlia stichopi & $\begin{array}{l}\text { Stichopus chloronotus, } \\
\text { Stichopus horrens, } \\
\text { Thelonota ananas (H) }\end{array}$ & $\begin{array}{l}\text { Anterior to midpart of } \\
\text { digestive tract }\end{array}$ & - & $\begin{array}{l}\text { Great Barrier Reef } \\
\text { (Australia) }\end{array}$ & Cannon (1982) \\
\hline \multicolumn{6}{|c|}{ III. Rhabodocoela (f. acholadidae and pterastericolidae) } \\
\hline Acholades asteris & $\begin{array}{l}\text { Coscinasterias } \\
\text { calamaria (A) }\end{array}$ & $\begin{array}{l}\text { Encysted in tube feet } \\
\text { wall }\end{array}$ & $\begin{array}{l}20 \text { or more worms as- } \\
\text { teroid }{ }^{-1}(216 \text { infected/ } \\
267 \text { investigated) }\end{array}$ & $\begin{array}{l}\text { SW Indian Ocean } \\
\text { (Tasmania: D'Entre- } \\
\text { casteaux Channel) }\end{array}$ & $\begin{array}{l}\text { Hickman \& Olsen } \\
\text { (1955) }\end{array}$ \\
\hline
\end{tabular}


Table 1 (continued)

\begin{tabular}{|c|c|c|c|c|c|}
\hline Turbellanan & Host & Location in host & Remarks & Geographical area & Source \\
\hline $\begin{array}{l}\text { Pterastericola } \\
\text { australis }\end{array}$ & Patinella calcar (A) & Pyloric caeca & 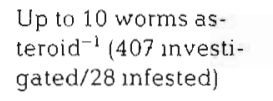 & $\begin{array}{l}\text { Hasting Point (New } \\
\text { South Wales, } \\
\text { Australia) }\end{array}$ & $\begin{array}{l}\text { Jennings \& Cannon } \\
\text { (1985) }\end{array}$ \\
\hline Pterastericola fedotovi & $\begin{array}{l}\text { Pteraster milhtaris, } \\
\text { Pteraster obscurus, } \\
\text { Pteraster pulvillus (A) }\end{array}$ & $\begin{array}{l}\text { Unspecified } \\
\text { (endoparasitic) }\end{array}$ & - & $\begin{array}{l}\text { Barents Sea (Mur- } \\
\text { mansk); White Sea } \\
\text { (Kandalaksha Bay) }\end{array}$ & $\begin{array}{l}\text { Beklemishev (1916), } \\
\text { Karling (1970) }\end{array}$ \\
\hline $\begin{array}{l}\text { Pterastericola } \\
\text { vivipara }\end{array}$ & Acanthaster planci $(\mathrm{A})$ & Pyloric caeca & $\begin{array}{l}\text { Infested asteroid may } \\
\text { have large number of } \\
\text { worms }\end{array}$ & $\begin{array}{l}\text { W Pacific (Australia: } \\
\text { central Great Barrier } \\
\text { Reef) }\end{array}$ & $\begin{array}{l}\text { Cannon (1978), Jen- } \\
\text { nings \& Cannon } \\
(1985)\end{array}$ \\
\hline $\begin{array}{l}\text { Triloborhynchus } \\
\text { astropectenis }\end{array}$ & $\begin{array}{l}\text { Astropecten } \\
\text { irregularis (A) }\end{array}$ & Pyloric caeca & $\begin{array}{l}5 \text { to } 10 \text { worms per py- } \\
\text { lonc caecum in in- } \\
\text { fested asteroid }\end{array}$ & $\begin{array}{l}\text { North Sea (Norwegian } \\
\text { and Swedish coasts)i } \\
\text { English Channel (Ply- } \\
\text { mouth) }\end{array}$ & $\begin{array}{l}\text { Bashirudin \& Karling } \\
\text { (1970), Jennings \& } \\
\text { Cannon (1985) }\end{array}$ \\
\hline $\begin{array}{l}\text { Triloborhynchus } \\
\text { psilastericola }\end{array}$ & $\begin{array}{l}\text { Psilaster } \\
\text { andromeda (A) }\end{array}$ & $\begin{array}{l}\text { Pyloric caeca, } \\
\text { coelomic cavity } \\
\text { (juvenule forms) }\end{array}$ & $\begin{array}{l}\text { Infestation frequent } \\
\text { (sometimes more than } \\
10 \text { worms asteroid }{ }^{-1} \text { ) }\end{array}$ & North Sea (Oslo fjord) & $\begin{array}{l}\text { Jespersen \& Lützen } \\
\text { (1972) }\end{array}$ \\
\hline \multicolumn{6}{|l|}{ IV. Polycladida } \\
\hline Euplana takewakii & $\begin{array}{l}\text { Ophioplocus } \\
\text { japonicus (O) }\end{array}$ & Bursae & $\begin{array}{l}20 \text { infested / } 200 \text { in- } \\
\text { vestigated }\end{array}$ & $\begin{array}{l}\text { NW Pacific (Japan: } \\
\text { Mitsui) }\end{array}$ & Kato (1935) \\
\hline
\end{tabular}

bodies containing egg capsules of the coelom-associating Anoplodium hymanae may pass out of intact hosts - the holothuroid Parastichopus californicus - through any of a series of pores that connect the coelom to the posterior end of the rectum. Embryogenesis of $A$. hymanae lasts about 1 mo, and embryos remain quiescent in their capsule until they are ingested by a holothuroid (developed embryos can survive in their

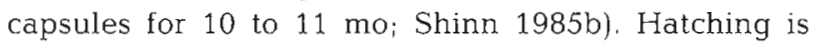
stimulated by some property of the host's digestive

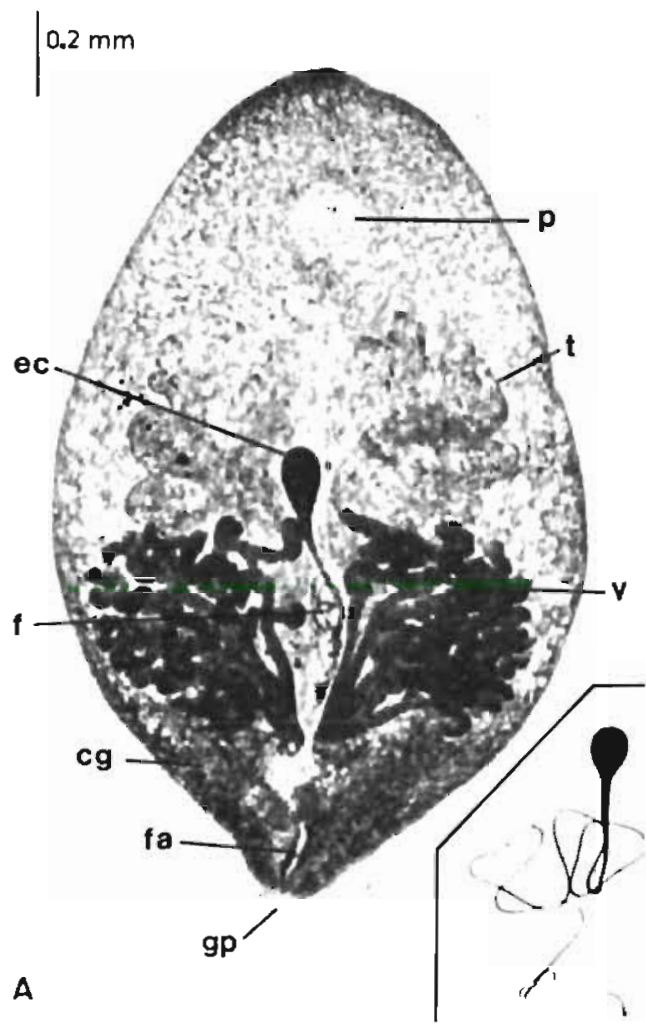

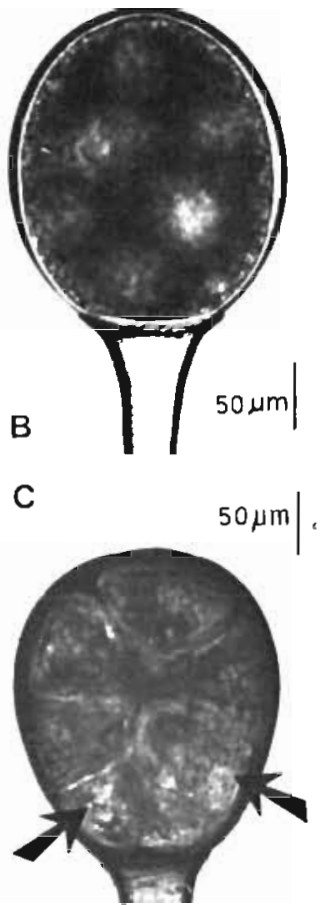

Fig. 2. Syndisyrinx franciscanus, a symbiotic turbellarian from the intestine of echinoids (Strongylocentrotus spp.). (A).Ventral view of a live adult individual. $\mathrm{cg}$ : cement glands; ec: bulb of egg capsule; f: filament of egg capsule; fa: female antrum; gp: location of common gonophore; $p$ : pharynx; $t$ : left testis; $v$ : vitellaria. Insert: egg capsule showing bulb and filament (B) Bulb of a newly produced egg capsule. (C) Bulb of a 2 mo old egg capsule containing 6 fully developed embryos (arrows). (After Shinn $1983 b\}$ 
Fig. 3. Anoplodium hymanae. Life cycle of a coelom-associated umagillid from the holothuroid Parastichopus californicus. (A) Release of umagillid egg capsules into the host's coelom; (B) ensheathment of egg capsules into brown bodies; (C) completion of embryos' development outside the host; (D) ingestion by the new host of egg capsules containing embryos; (E) hatching of larvae in the upper intestine; $(F)$ migration of larvae towards the respiratory trees; $(G)$ larvae penetrate the wall of the respiratory trees and enter the coelom. (After Shinn 1985b)

fluid. Larvae penetrate the wall of the posterior intestine or, more commonly, that of the respiratory trees to reach the coelom (Fig. 3). As demonstrated by Shinn (1985b), the size of A. hymanae infesting P. californicus varies seasonally and is correlated with the seasonal feeding behavior of the host.

Investigations by Shinn (1983b, 1985a, b, 1986b) on echinoderm-associated umagillids showed that hatchings are not adversely affected by the host's digestive fluids whatever the final location of the worms in the host. However, adult worms of coelom-inhabiting species are killed by the host's digestive fluid but appear to have some mean of avoiding attack by coelomocytes. Considering the number of species of umagillids that are reported to inhabit both the coelom and gut of the host (see Table 1), careful re-examination is needed to determine if the worms clearly are adapted to inhabiting very differents sites in their hosts, or whether the reports are the results of improper dissection techniques' (Shinn 1985b, p. 213).

Non-umagillid rhabdocoels associated with echinoderms have been reported only from asteroids (Table 1). The acholadid Acholades asteris was always found encysted in the connective tissue layer of the tube feet of Coscinasterias calamaria. Nothing is known on the life cycle of this aberrant rhabdocoel. All pterastericolids found thus far were associated with asteroid pyloric caeca on which they feed (feeding on energy-rich epithelial cells; Cannon 1975, 1978, Jennings \& Cannon 1985) (Fig. 4 \& 5). According to Jennings \& Cannon (1985), the occurrence of pterastericolids is independent of host size and sex. These workers noted that the worms neither affect the host's reproductive potential nor produce any marked damages to the asteroid's pyloric caeca. Digestion in
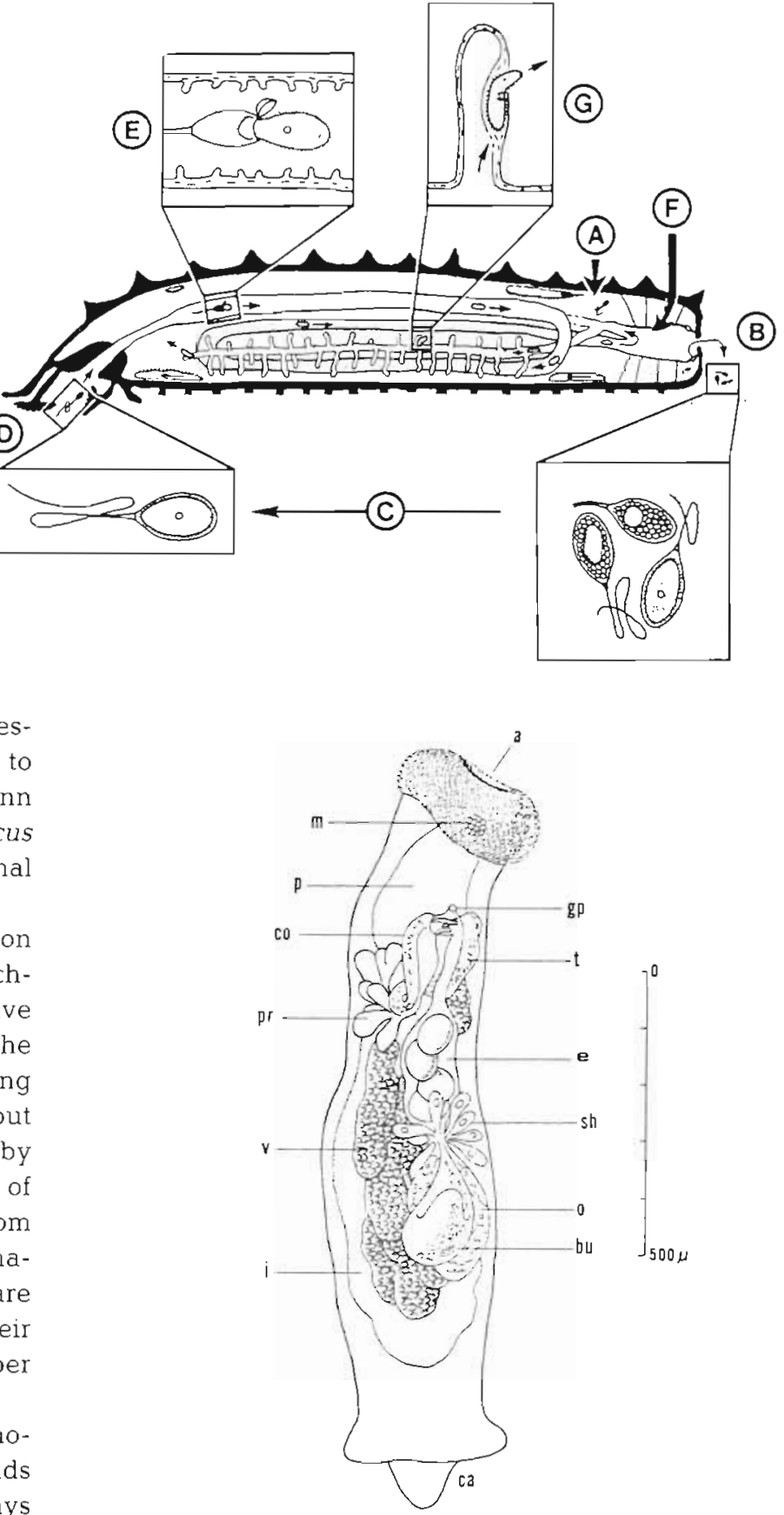

Fig. 4. Triloborhynchus psilastericola. Ventral view of a turbellarian parasite of the pyloric caeca of the asteroid Psilaster andromeda. a: entrance to apical organ; bu: bursa; ca: caudal adhesive disk; co: copulatory bulb; e: egg capsule in uterus; gp: common genital pore; i: intestine; $m$ : mouth; 0 : ovary; $p$ pharynx; pr: prostatic glands; sh; shell glands; t: testis; v: yolk glands. (After Jespersen \& Lützen 1972)

asteroid pterastericolids is predominantly intracellular (their gut is deprived of gastrodermal glands), and Jennings \& Cannon suggest this would be an adaptative simplification related to the particular diet of host 
storage and digestive cells, which provides all necessary dietary components plus the enzymes necessary for their digestion and assimilation' (p. 211). The only polyclad species known to be an echinoderm parasite, Euplana takewakii, feeds on ophiuroid gonads, the infested bursae always being castrated (Kato 1935).

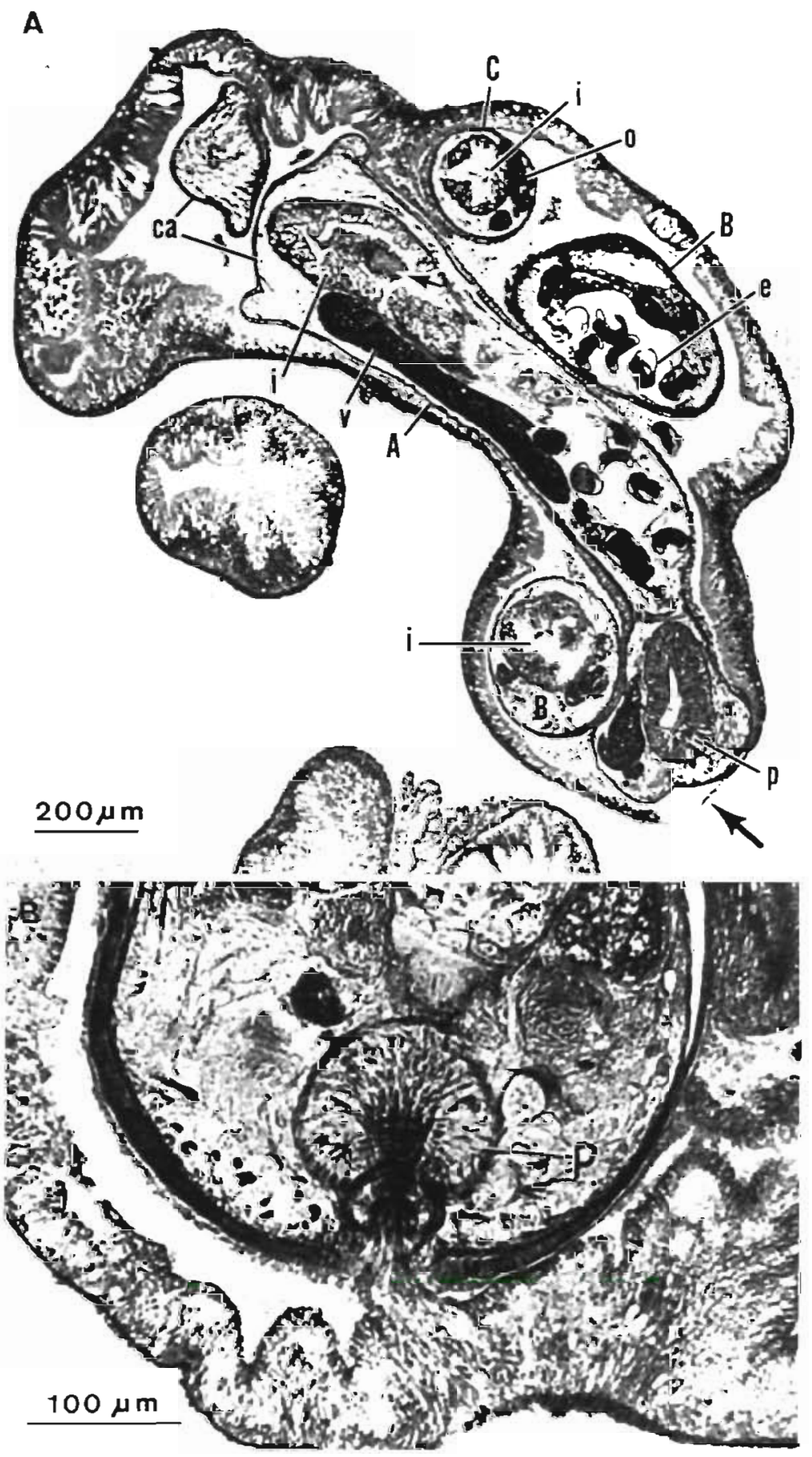

Fig. 5. Infestation of asteroid pyloric caeca by pterastericolid turbellarians. (A) Psilaster andromeda. Section through pyloric diverticulum containing 3 specimens $(A, B, C)$ of Triloborhynchus psilastericola. ca: caudal adhesive disk; e: egg capsule in uterus; $i$ : intestine; o: ovary; p: pharynx; v: yolk glands; large arrow: area of pyloric diverticulum demolished by specimen; small arrow: piece of ingested tissue from pyloric diverticulum. (B) Acanthaster planci. Section through a pyloric diverticulum showing an individual of Pterastericola vivipara ingesting pyloric tissues. P: pharynx. ([A] after Jespersen \& Lützen 1972; [B] after Cannon 


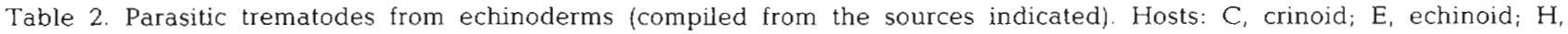
holothuroid; O, ophiuroid

\begin{tabular}{|c|c|c|c|c|c|c|}
\hline Trematode & Host & Location in host & Primary host & Remarks & Geographical area & Source \\
\hline $\begin{array}{l}\text { Diphterostomum } \\
\text { brusinae }\end{array}$ & $\begin{array}{l}\text { Antedon } \\
\text { mediterranea }(\mathrm{C})\end{array}$ & $\begin{array}{l}\text { Inside crinoid calyx } \\
\text { (within connective } \\
\text { tissue stnngs) }\end{array}$ & $\begin{array}{l}\text { Several species of } \\
\text { benthic fishes }\end{array}$ & $\begin{array}{l}1 \text { to } 15 \text { trematodes } \\
\text { crinoid }^{-1} \text {; furst in- } \\
\text { termediary host } \\
\text { would be a gas- } \\
\text { tropod mollusc } \\
\text { (Nassa sp. Natica } \\
\text { sp.) }\end{array}$ & $\begin{array}{l}\text { Mediterranean Sea } \\
\text { (Marseille) }\end{array}$ & $\begin{array}{l}\text { Prévot (1966a; see } \\
\text { also Palombi 1930) }\end{array}$ \\
\hline $\begin{array}{l}\text { Fellodistomum } \\
\text { fellis }^{1}\end{array}$ & $\begin{array}{l}\text { Ophiura albida, } \\
\text { Ophiura sarsi }(O)\end{array}$ & $\begin{array}{l}\text { In wall of digestive } \\
\text { sac }\end{array}$ & $\begin{array}{l}\text { Fishes (Anarrhicas } \\
\text { lupus, Platessa } \\
\text { platessa; Mor- } \\
\text { tensen) }\end{array}$ & $\begin{array}{l}1 \text { to } 13 \text { trematodes } \\
\text { ophiuroid }{ }^{-1} \text {; the } \\
\text { first intermediary } \\
\text { host is bivalve } \\
\text { Nucula nucula } \\
\text { (Chubrik) }\end{array}$ & $\begin{array}{l}\text { Barents Sea (Kola } \\
\text { Bay); North Sea } \\
\text { (Gullmarfjord) }\end{array}$ & $\begin{array}{l}\text { Tauson (1917), } \\
\text { Mortensen (1921a), } \\
\text { Chubrik (1952, see } \\
\text { also Barel \& Kra- } \\
\text { mers 1977) }\end{array}$ \\
\hline $\begin{array}{l}\text { Himasthla } \\
\text { leptosoma }\end{array}$ & $\begin{array}{l}\text { Leptosynapta } \\
\text { galliennei, Lep- } \\
\text { tosynapta in- } \\
\text { haerens }(\mathrm{H})\end{array}$ & $\begin{array}{l}\text { In body wall, at } \\
\text { base of buccal ten- } \\
\text { tacles; sometimes } \\
\text { within coelomic } \\
\text { brown bodies }\end{array}$ & $\begin{array}{l}\text { Sea birds (Tringa } \\
\text { variabilis, Calidns } \\
\text { leucophoea) }\end{array}$ & $\begin{array}{l}\text { Alternative inter- } \\
\text { mediary hosts: } \\
\text { bivalve } \\
\text { Scrobicularia } \\
\text { tenuis, polychete } \\
\text { Arenicola marina, } \\
\text { sipunculid Phas- } \\
\text { colosoma vulgare } \\
\text { (Cuénot 1912) }\end{array}$ & $\begin{array}{l}\text { NE Atlantic (Ar- } \\
\text { cachon, Roscoff) }\end{array}$ & $\begin{array}{l}\text { Cuénot (1892, } \\
\text { 1912), Timon- } \\
\text { David (1938) }\end{array}$ \\
\hline $\begin{array}{l}\text { 'Metacercaria' } \\
\text { psammechini }\end{array}$ & $\begin{array}{l}\text { Psammechinus } \\
\text { microtuberculatus, } \\
\text { Sphaerechinus } \\
\text { granularis(E) }\end{array}$ & $\begin{array}{l}\text { In muscles of Aris- } \\
\text { totle s s lantern }\end{array}$ & $\begin{array}{l}\text { Presumably } \\
\text { echinold-eating } \\
\text { fishes of the family } \\
\text { Labridae }\end{array}$ & $\begin{array}{l}\text { Infestation may be } \\
\text { very heavy }\end{array}$ & $\begin{array}{l}\text { Mediterranean Sea } \\
\text { (Banuyls, } \\
\text { Marseille) }\end{array}$ & $\begin{array}{l}\text { Timon-David } \\
(1934,1938)\end{array}$ \\
\hline $\begin{array}{l}\text { Monorchis } \\
\text { monorchis }\end{array}$ & $\begin{array}{l}\text { Antedon } \\
\text { mediterranea }(\mathrm{C})\end{array}$ & $\begin{array}{l}\text { Inside crinoid calyx } \\
\text { (within connective } \\
\text { tissue strings) }\end{array}$ & $\begin{array}{l}\text { Sparid fishes, in } \\
\text { particular Spondy- } \\
\text { liosoma cantharus }\end{array}$ & $\begin{array}{l}5 \text { to } 60 \text { trematodes } \\
\text { crinoid }{ }^{-1}(17 \text { in- } \\
\text { fested } / 151 \text { investi- } \\
\text { gated) }\end{array}$ & $\begin{array}{l}\text { Mediterranean Sea } \\
\text { (Marselle) }\end{array}$ & Prévot $(1966 a, b)$ \\
\hline $\begin{array}{l}\text { Ridrosia } \\
\text { ophiurae }\end{array}$ & Ophiura sarsi (O) & In gonads & - & - & $\begin{array}{l}\text { North Sea (Trond- } \\
\text { hjem fjord) }\end{array}$ & Mortensen (1933a) \\
\hline $\begin{array}{l}\text { Paralepidapedon } \\
\text { hoplognathi }\end{array}$ & $\begin{array}{l}\text { Anthocidaris } \\
\text { crassispina }(\mathrm{E})\end{array}$ & $\begin{array}{l}\text { Mostly in gonads; } \\
\text { also in muscles of } \\
\text { Aristotle's lantern } \\
\text { and in ampullae of } \\
\text { tube feet }\end{array}$ & $\begin{array}{l}\text { Fish Hoplognathus } \\
\text { punctatus }\end{array}$ & $\begin{array}{l}1 \text { to } 66 \text { trematodes } \\
\text { echinoid }{ }^{-1}(22 \text { in- } \\
\text { fested } / 29 \text { investi- } \\
\text { gated) }\end{array}$ & Misaki (Japan) & $\begin{array}{l}\text { Shimazu \& Shim- } \\
\text { ura } 1984\end{array}$ \\
\hline $\begin{array}{l}\text { Proctoeces } \\
\text { maculatus }\end{array}$ & $\begin{array}{l}\text { Anthocidans } \\
\text { crassispina, Diade- } \\
\text { ma setosum, } \\
\text { Hemicentrotus } \\
\text { pulcherrimus (E) }\end{array}$ & In gonads & - & - & Misaki (Japan) & $\begin{array}{l}\text { Shimazu \& Shim- } \\
\text { ura (1984) }\end{array}$ \\
\hline Protoecessp. & $\begin{array}{l}\text { Strongylocentrotus } \\
\text { intermedius }(\mathrm{E})\end{array}$ & In gonads & - & $\begin{array}{l}\text { Gastropod Haliotis } \\
\text { discus hannai is al- } \\
\text { temative inter- } \\
\text { mediary host }\end{array}$ & $\begin{array}{l}\text { Japan Sea (off } \\
\text { Maehama, } \\
\text { Hokkaido) }\end{array}$ & Shimazu (1979) \\
\hline $\begin{array}{l}\text { ?Tetrarhynchus } \\
\text { holothuriae }\end{array}$ & Molpadia sp. $(\mathrm{H})$ & Body waill (?) & - & - & $\begin{array}{l}\text { NE Indian Oceãn } \\
\text { (Malaysian coast) }\end{array}$ & Shipley (1903) \\
\hline $\begin{array}{l}\text { Zoogonoides } \\
\text { viviparus }\end{array}$ & $\begin{array}{l}\text { Ophiura albida, } \\
\text { Ophiothrix fragilis, } \\
\text { Leptosynapta } \\
\text { galliennei, Lep- } \\
\text { tosynapta in- } \\
\text { haerens }(\mathrm{O}, \mathrm{H})\end{array}$ & $\begin{array}{l}\text { In gonads and } \\
\text { coelom wall of } \\
\text { ophiuroids; in body } \\
\text { wall of } \\
\text { holothuroids (at } \\
\text { base of buccal ten- } \\
\text { tacles) }\end{array}$ & - & $\begin{array}{l}\text { Might also occur in } \\
\text { Mysis sp. }\end{array}$ & $\begin{array}{l}\text { NE Atlantic (Ar- } \\
\text { cachon, Roscoff) }\end{array}$ & $\begin{array}{l}\text { Cuénot (1892, } \\
\text { 1912) }\end{array}$ \\
\hline $\begin{array}{l}\text { Zoogonoides } \\
\text { viviparus }\end{array}$ & $\begin{array}{l}\text { Ophiura albida; } \\
\text { rarely Ophiura tex- } \\
\text { turata and Ophiura } \\
\text { robusta (O) }\end{array}$ & $\begin{array}{l}\text { Mostly between } \\
\text { am vertebrae } \\
\text { (natural infesta- } \\
\text { tion); also within } \\
\text { disc (gonads, water } \\
\text { vascular system, } \\
\text { mesenteries) (ex- } \\
\text { perimental infesta- } \\
\text { tion) }\end{array}$ & $\begin{array}{l}\text { Fishes: posterior } \\
\text { intestine and rec- } \\
\text { tum of plaice, } \\
\text { flounder, dab and } \\
\text { long rough dab } \\
\text { from Øresund }\end{array}$ & $\begin{array}{l}\text { First intermediary } \\
\text { host is gastropod } \\
\text { Buccinum un- } \\
\text { datum, } O \text {. albida is } \\
\text { the most important } \\
\text { second intermedi- } \\
\text { ary host. } 1 \text { to } 30 \\
\text { trematodes } \\
\text { ophiuroid }{ }^{-1} \text {; up to } \\
250 \text { in experimen- } \\
\text { tally infested ones }\end{array}$ & $\begin{array}{l}\text { North Sea } \\
\text { (Kattegat, } \\
\text { Øresund) }\end{array}$ & Køie $\{1976\}$ \\
\hline
\end{tabular}


Table 2 (continued)

\begin{tabular}{|c|c|c|c|c|c|c|}
\hline Trematode & Host & Location in host & Primary host & Remarks & Geographical area & Source \\
\hline Zoogonus mirus & $\begin{array}{l}\text { Arbacia lixula, Pa- } \\
\text { racentrotus lividus, } \\
\text { Sphaerechinus } \\
\text { granularis (E) }\end{array}$ & $\begin{array}{l}\text { In muscles of Aris- } \\
\text { totle's lantern }\end{array}$ & $\begin{array}{l}\text { Fishes: Labrus } \\
\text { merula (natural in- } \\
\text { festation), Blennius } \\
\text { gattorugire (ex- } \\
\text { perimental infesta- } \\
\text { tion) }\end{array}$ & $\begin{array}{l}1 \text { to } 30 \text { trematodes } \\
\text { echinoid }{ }^{-1} \text {; heavy } \\
\text { intestation with } P \text {. } \\
\text { lividus, slight in- } \\
\text { lestation with } \\
\text { A. Lixula }\end{array}$ & $\begin{array}{l}\text { Mediterranean Sea } \\
\text { (Banyuls, } \\
\text { Marseille) }\end{array}$ & $\begin{array}{l}\text { Timon-David } \\
(1933,1934,1936, \\
1938)\end{array}$ \\
\hline Zoogonus rubellus & $\begin{array}{l}\text { Arbacia } \\
\text { punctulata (E) }\end{array}$ & $\begin{array}{l}\text { Presumably in } \\
\text { muscles of Aris- } \\
\text { totle's lantern }\end{array}$ & $\begin{array}{l}\text { Eel (natural infes- } \\
\text { tation); toadfish } \\
\text { (experimental in- } \\
\text { festation) }\end{array}$ & $\begin{array}{l}\text { First intermediary } \\
\text { host gastropod } \\
\text { Nassa obsaleta; } \\
\text { usual second inter- } \\
\text { mediary host: } \\
\text { polychete Nereis } \\
\text { virens. Experimen- } \\
\text { tal use of A. punc- } \\
\text { tulata as alterna- } \\
\text { tive second inter- } \\
\text { mediary host was } \\
\text { partly successful }\end{array}$ & $\begin{array}{l}\text { NW Atlantic } \\
\text { (Woods Hole) }\end{array}$ & $\begin{array}{l}\text { Stunkard (1941; } \\
\text { see also Stunkard } \\
1938 \text { ) }\end{array}$ \\
\hline Zoogonus sp. & $\begin{array}{l}\text { Psammechinus } \\
\text { miliaris }(\mathrm{E})\end{array}$ & $\begin{array}{l}\text { In muscles of Aris- } \\
\text { totle's lantern }\end{array}$ & - & $\begin{array}{l}1 \text { to } 36 \text { trematodes } \\
\text { echinoid }\end{array}$ & $\begin{array}{l}\text { North Sea } \\
\text { (Boulogne, } \\
\text { Wimereux) }\end{array}$ & Stunkard (1941) \\
\hline $\begin{array}{l}{ }^{1} \text { Previously identifi } \\
{ }^{2} \text { The parasite has b } \\
{ }^{3} \text { Described as ency } \\
{ }^{4} \text { Identified by Cuér }\end{array}$ & $\begin{array}{l}\mathrm{d} \text { by Tauson (1917) as } \\
\text { en tentatively ascribe } \\
\text { ed larvae of cestode } \\
(1892,1912) \text { as Cer }\end{array}$ & $\begin{array}{l}\text { Adolescaria ophiur } \\
\text { d to trematodes by } \\
\text { Shipley 1903) } \\
\text { caria capriciosa }\end{array}$ & Lortensen; it causes d & estruction of infested & gonads & \\
\hline
\end{tabular}

\section{Agents: Trematoda}

Trematodes reported from echinoderms are listed in Table 2. Unidentifed metacercariae were noted by Schneider (1858), in the body cavity of Holothuria tubulosa; by Schurig (1906), in the gut of a deep-sea echinoid; by Ohshima (1911), in stomach and mesenchyme of a planktonic holothuroid larva; by Mortensen (1921b), in gonads of the Japanese echinoid Mespilia globulus; and by Johnson (1971), in gonads of Strongylocentrotus purpuratus.

Echinoderms generally act as second intermediary host (Fig. 6). The echinoderm's reaction to invading cercariae or to encysted metacercariae is largely unknown. According to Prévot (1966a) host tissues form a 'xenocyst' of dense connective tissue around metacercariae (Fig. 7), but Køie (1976) reported that infested ophiuroids do not respond to trematode cysts. Effects of metacercariae on their echinoderm host appear to be rather unimportant. According to Køie (1976), heavily infested Ophiura albida tend to autotomize their arms. This is presumably linked to the cysts' location at the joints between the arm vertebrae. One may also suggest that, when heavily infested, the jaw muscles of echinoids become less functional (Table 2; Zoogonus mirus and Zoogonus sp.); thus the cysts may affect echinoid feeding.

The location of metacercarian cysts (in muscles or within the body wall) may partly explain why relatively few species of echinoderm-infesting trematodes have been recorded. Whatever the cause, it seems rather obvious that echinoderms are very suitable intermediary hosts for marine digenic trematodes. Not only do echinoderms occur frequently in very dense populations, but some of their representatives also form part of the diet of many fishes. As seen in Table 2, most echinoderm-infesting trematodes are known from echinoids and ophiuroids which constitute the most frequent echinoderm prey for fishes. The role of echinoderms as potential vectors of trematode-caused fish diseases requires further attention.

\section{Agents: Nematoda}

Rather few nematodes have been reported to occur in echinoderms (e.g. Fig. 8). In addition to the species listed in Table 3, unidentified - and presumably undescribed - nematodes were found inside the host's body (mostly the coelomic cavity): Antarctic asteroids Hymenaster perspicuus and Diplasterias luetkeni (see Ludwig 1903); echinoids Echinus esculentus and Brissopsis Jyrifera (respectively Shipley 1901, Brattström 1946); holothuroids Leptosynapta spp., Holothuria spp. and Asia lefevrei (respectively Monticelli 1892, Briot 1906a, Hérouard 1923); and North Sea ophiuroids Asteron:x loveni and Ophiura albida (respectively Jungersen 1912, Mortensen 1921a). 
Fig. 6. Fellodistomum fellis. Lifecycle of a marine digenic trematode with 2 intermediary hosts: bivalve mollusc Nucula tenuis and ophiuroid Ophiura sarsi. (A) Redia; (B) cercaria; (C) metacercaria; (D) late metacercaria and adult worm. (After Chubrik 1952)
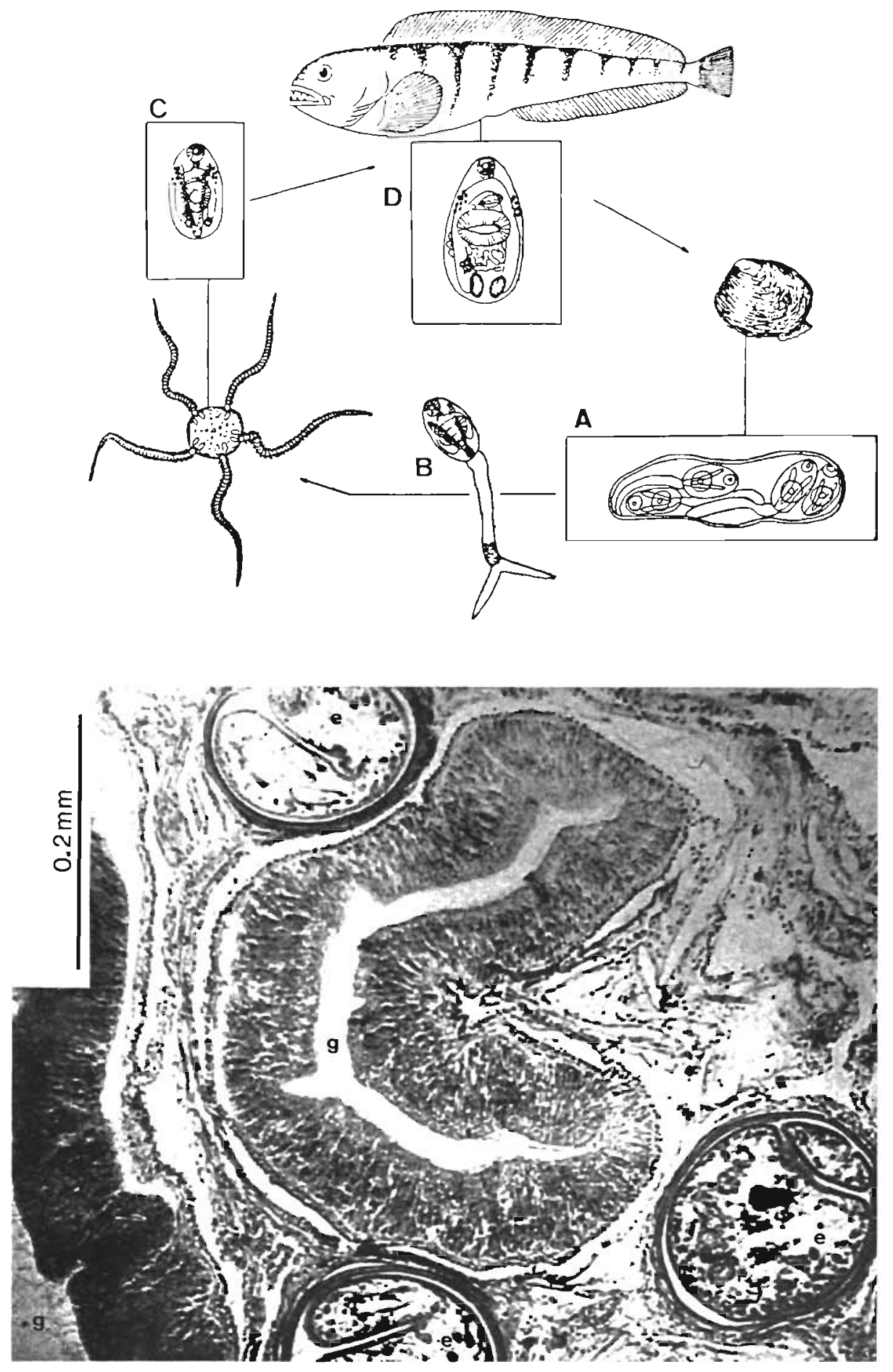

Fig. 7. Monorchis monorchis (Trematoda). Metacercariae encysted within connective tissue strings of the calyx of the comatulid crinoid Antedon mediterranca. e: encysted metacercariae; g: gut of the crinoid. (After Prévot 1966a)
Intense infestations by juvenile nematodes also occurred within the digestive wall of the abyssal holothuroids Kolga hyalina, Trochostoma thompsoni and Elpidia glacialis (Danielssen \& Koren 1882, Massin pers. comm.).

As seen from Table 3 echinoderm-associated nematodes are mostly juveniles. Echinoderms presum- ably act as intermediary host, the primary host being fishes. This was suggested by Ward (1933) and demonstrated by Pearse \& Timm (1971) who identified the primary host of the echinoid parasite Echinocephalus pseudouncinatus as the California horned shark Heterodontus francisci. Host reactions were noted only by Pearse \& Timm (1971) who reported the encystment 

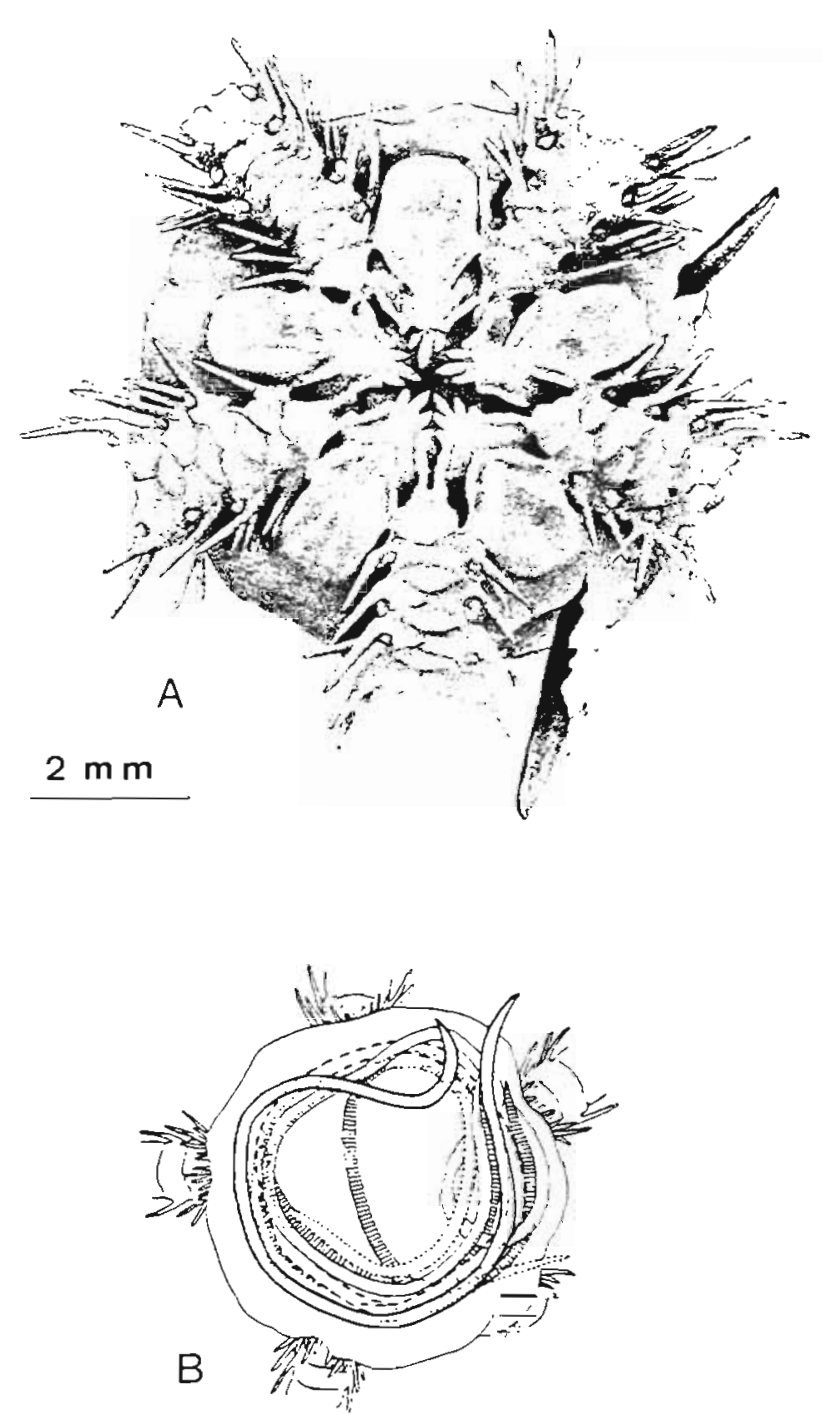

\section{$5 \mathrm{~m} \mathrm{~m}$}

Fig. 8. Thalassonema ophioctinis, a nematode parasite of the ophiuroid Ophiocten amitinum. (A) Oral view of ophiuroid showing ends of nematode protruding through the wall of disc; (B) 5 nematodes coiled within the ophiuroid body cavity. (After Ward 1933)

of juvenile nematodes within echinoid gonads. The cyst is host-produced and made of dense connective tissue. Effects of nematodes on their hosts are obvious when the worms destroy the echinoderm's body wall. an injury reported by Ludwig (1903), Ward (1933) and Rubstov (1977). Another, less conspicuous, effect was noted by Pearse \& Timm (1971) on gonads of Centrostephanus coronatus: growing juvenile nematodes progressively invaded the gonadal tubules (small juveniles are confined to the gonad wall) and negatively affected host gametogenesis. Gametogenesis is suppressed in the infested tubules, especially above the parasite, viz. in the oral or distal part of the tubule. Pearse \& Timm suggested that encysted juveniles block the passage through the tubules of some hormonal substance that regulates echinoid gametogenesis. Hagen (1985)implied that infestation of Strongylocentrotus droebachiensis by the nematode Philotrema sp. (= Echinomermella sp.) could be lethal for the echinoid upon hatching of the juvenile nematodes.

\section{Agents: Mollusca, Gastropoda}

Gastropods living symbiotically with echinoderms belong almost exclusively to the family Eulimidae. According to Waren (1984) there are about 800 species (43 genera) of extant eulimids of which all except 2 are associated with echinoderms. Table 4 lists both ectoand endoparasitic eulimids (species classified as ectoparasites clearly behave as parasites or entertain morphological relations with their host which imply parasitism).

Most ectoparasitic eulimids live attached to the echinoderm's body surface, by either their snout or their proboscis (Vaney 1915, Warén 1984). They feed on the host's tissues or fluids using their proboscis which penetrates more or less deeply into the echinoderm's body wall or crosses it to reach the coelomic cavity, the water-vascular system, or the hemal system. However, unattached ectoparasites also occur, e.g. Pulicicochlea calamaris and Vitreobalcis temnopleuricola which browse over the epidermis of the echinoids Echinothrix calamaris and Temnopleurus toreumaticus (Ponder \& Gooding 1978, Fujioka 1985, respectively) and Peastilifer nitidulus which moves over the entire body surface of Holothuria atra, periodically puncturing the body wall of its host (Hoskin \& Cheng 1970).

Some attached ectoparasitic eulimids are said to feed exclusively on echinoderm dermal tissues. Among them are those belonging to the gallicole genus Stilifer (Tullis \& Cheng 1971, Warén 1980a) (Fig. 9), as well as representatives of the genera Pelseneeria (Koehler \& Vaney 1908) and Monogamus (Lützen 1976). These authors reported that the proboscis is inserted into the dermis but they did not discuss the way in which the dermal tissue is ingested. Dermaltissue-feeding eulimids may induce conspicuous host reactions (Lüzen 1976): the formation of swollen areas which are basically disorganized outgrowths of the connective tissue upon which the parasite feed (Fig. 10).

Fluid-feeding ectoparasitic eulimids have also been reported (e.g. Warén 1981c). According to Bacci (1948) 
Table 3. Parasitic nematodes from echinoderms (compiled from the sources indicated). Hosts: A, asteroid; E, echinoid; O, ophiuroid

\begin{tabular}{|c|c|c|c|c|c|}
\hline Nematode & Host & Location in host & Remarks & Geographical area & Source \\
\hline Ananus asteroideus & $\begin{array}{l}\text { Diplopteraster } \\
\text { perigrinator }(\mathrm{A})\end{array}$ & Coelomic cavity & $\begin{array}{l}\text { One nematode in } \\
\text { each asteroid arm }\end{array}$ & $\begin{array}{l}\text { Antarctic seas (off } \\
\text { Kerguelen Islands) }\end{array}$ & Rubstov (1977) \\
\hline $\begin{array}{l}\text { Echinocephalus } \\
\text { pseudouncinatus }\end{array}$ & $\begin{array}{l}\text { Arbacia } \\
\text { punctulata (E) }\end{array}$ & Gonad & $\begin{array}{l}\text { Only juvenile } \\
\text { nematode observed }\end{array}$ & $\begin{array}{l}\text { NW Atlantic } \\
\text { (Woods Hole) }\end{array}$ & $\begin{array}{l}\text { Hopkins (1935), } \\
\text { Millemann (1951) }\end{array}$ \\
\hline $\begin{array}{l}\text { Echinocephalus } \\
\text { pseudouncinatus }\end{array}$ & $\begin{array}{l}\text { Centrostephanus } \\
\text { coronata }(\mathrm{E})\end{array}$ & Gonads & $\begin{array}{l}\text { Most infested } \\
\text { echinoids had sev- } \\
\text { eral juvenile } \\
\text { nematodes in each } \\
\text { of their } 5 \text { gonads } \\
\text { ( } 142 \text { infested/213 } \\
\text { investigated) }\end{array}$ & $\begin{array}{l}\text { E Pacific (Southern } \\
\text { California: Santa } \\
\text { Catalina Island) }\end{array}$ & $\begin{array}{l}\text { Pearse \& Timm } \\
\text { (1971) }\end{array}$ \\
\hline $\begin{array}{l}\text { Marimermis } \\
\text { kerguelensi }\end{array}$ & $\begin{array}{l}\text { Hippasteria } \\
\text { hyadesi }(\mathrm{A})\end{array}$ & Coelomic cavity & - & $\begin{array}{l}\text { Antarctic seas (off } \\
\text { Kerguelen Islands) }\end{array}$ & $\begin{array}{l}\text { Rubstov \& Platono- } \\
\text { va (1974) }\end{array}$ \\
\hline $\begin{array}{l}\text { Onchaleimus } \\
\text { echini }\end{array}$ & $\begin{array}{l}\text { Echinus } \\
\text { esculentus (E) }\end{array}$ & Digestive tract & - & - & Leydig (1854) \\
\hline Philometra grayi & $\begin{array}{l}\text { Echinus } \\
\text { esculentus (E) }\end{array}$ & Coelomic cavity & $\begin{array}{l}1 \text { to } 4 \text { nematodes } \\
\text { echinoid }{ }^{-1} \text { infesta- } \\
\text { tion relatively rare }\end{array}$ & Around British Isles & $\begin{array}{l}\text { Gemmil (1901), } \\
\text { Gemmil \& von Lin- } \\
\text { stow (1902), Irving } \\
\text { (1910), Ritchie } \\
\text { (1910, see also } \\
\text { Barel \& Kramers } \\
\text { 1977) }\end{array}$ \\
\hline Philometrasp. & $\begin{array}{l}\text { Strongylocentrotus } \\
\text { droebachiensis (E) }\end{array}$ & Coelomic cavity & $\begin{array}{l}\text { Infestation level: } \\
2030 \%\end{array}$ & $\begin{array}{l}\text { North Sea (Vest- } \\
\text { fjorden, Norway) }\end{array}$ & Hagen $(1983,1985)$ \\
\hline $\begin{array}{l}\text { Thalassonema } \\
\text { ephiacanthis }\end{array}$ & $\begin{array}{l}\text { Ophiacantha an- } \\
\text { taretica }(\mathrm{O})\end{array}$ & Coelomic cavity & - & Antarctic Seas & Rubstov (1985) \\
\hline $\begin{array}{l}\text { Thalassonema } \\
\text { ophioctinis }\end{array}$ & $\begin{array}{l}\text { Ophiocten } \\
\text { amitium }(\mathrm{O})\end{array}$ & Coelomic cavity & $\begin{array}{l}1 \text { to } 5 \text { juvenile } \\
\text { nematodes } \\
\text { ophiuroid }{ }^{-1} \text { ( } 4 \text { in- } \\
\text { fested } / 37 \text { investi- } \\
\text { gated) }\end{array}$ & $\begin{array}{l}\text { SW Indian Ocean } \\
\text { (South Africa: } \\
\text { Glendower } \\
\text { Beacon) }\end{array}$ & Ward (1933) \\
\hline
\end{tabular}

the proboscis of Melanella comatulicola reaches the coelomic canal of its crinoid host's arm and sucks up coelomic fluid. Cabioch et al. (1978) found that Balcis alba - a temporary holothuroid ectoparasite - penetrates the host's body wall via its proboscis. Aquarium observations have shown that the proboscis does not seek out a specific organ or tissue. It moves actively within the holothuroid coelomic cavity and pumps off coelomic fluid. Aquarium observations further revealed that the point of penetration of the proboscis is not restricted to any part of the body surface. In the field however, it was invariably located immediately below the buccal tentacles. Smith (1984) observed that the proboscis of $B$. alba is unfolded when penetrating the holothuroid integument, and that the proboscis epithelium releases secretory material which appears to bring about a rapid loosening of the host's connective tissue. Fluid-feeding was inferred also with Echineulima spp., Ophieulima minima and Peastilifer edulis, as the proboscis of individuals of these species was observed inserted into the host's body cavity

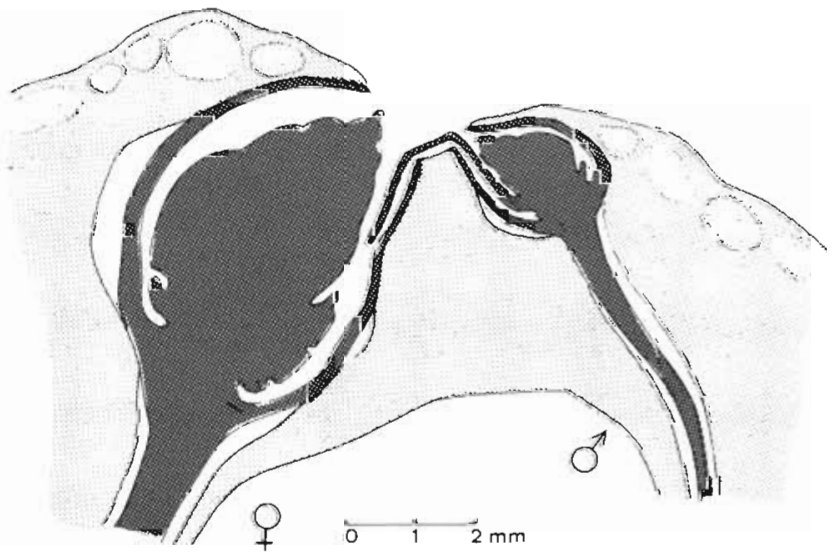

Fig. 9. Stilifer linckiae. Position of 2 specimens of a parasitic gastropod in a gall in the arm of the asteroid Linckia laevigata. (After Lützen 1972a)

(respectively Lützen \& Nielsen 1975, Warén \& Sibuet 1981, Hoskin \& Warén 1983). Egloff (1966) and Warén (1980a) reported that the proboscis of adult Thyca crys- 
Table 4. Parasitic gastropods from echinoderms (compiled from the sources indicated). Species names of gastropods according to Warén (1984)

\begin{tabular}{|c|c|c|c|c|c|}
\hline Gastropod & Host & Location in host & Remarks & Geographical area & Source \\
\hline \multicolumn{6}{|l|}{ I. Parasites of crinoids } \\
\hline $\begin{array}{l}\text { Annulobalcis } \\
\text { marshalli }\end{array}$ & $\begin{array}{l}\text { Crotalometra } \\
\text { rustica }\end{array}$ & $\begin{array}{l}\text { Attached between } \\
\text { arm ossicles }\end{array}$ & $\begin{array}{l}2 \text { specimens known } \\
\text { from single host }\end{array}$ & $\begin{array}{l}\text { New Zealand (off } \\
\text { Mayor Island) }\end{array}$ & Warén (1981a) \\
\hline Balcis devians & Antedon bifida & $\begin{array}{l}\text { Attached to base of } \\
\text { pinnule }\end{array}$ & $\begin{array}{l}\text { Only } 1 \text { specimen } \\
\text { found }\end{array}$ & North Sea (Plymouth) & Fretter (1955) \\
\hline Eulima ptilocrinida & Ptilocrinus pinnalus & $\begin{array}{l}\text { Proboscis deeply in- } \\
\text { serted in side of the } \\
\text { crinoid calix }\end{array}$ & - & $\begin{array}{l}\text { NE Pacific (off British } \\
\text { Columbia) }\end{array}$ & Bartsch $(1907)$ \\
\hline Goodingia varicosa & $\begin{array}{l}\text { Capillaster } \\
\text { multiradiatus }\end{array}$ & $\begin{array}{l}\text { Attached to aboral } \\
\text { side of arms }\end{array}$ & $\begin{array}{l}4 \text { specimens known } \\
\text { from } 2 \text { hosts }\end{array}$ & $\begin{array}{l}\text { NE Indian Ocean } \\
\text { (New Guinea) }\end{array}$ & Lützen $(1972 b)$ \\
\hline $\begin{array}{l}\text { Melanella } \\
\text { comatulicola }\end{array}$ & $\begin{array}{l}\text { Antedon } \\
\text { mediterraneas }\end{array}$ & $\begin{array}{l}\text { Attached to pinnules, } \\
\text { also to calyx or anal } \\
\text { cone }\end{array}$ & $\begin{array}{l}1 \text { to } 18 \text { gastropods } \\
\text { crinoid }{ }^{-1} \text { ( } 27 \text { infested/ } \\
65 \text { investigated) }\end{array}$ & $\begin{array}{l}\text { Mediterranean Sea } \\
\text { (Naples, Banyuls) }\end{array}$ & $\begin{array}{l}\text { Graff (1874); Bacci } \\
(1948) ; \text { Changeux } \\
(1956)\end{array}$ \\
\hline $\begin{array}{l}\text { Mucronalia } \\
\text { capillastericola }\end{array}$ & $\begin{array}{l}\text { Capillaster } \\
\text { multiradiatus }\end{array}$ & $\begin{array}{l}\text { Attached to the oral } \\
\text { side of arms }\end{array}$ & - & $\begin{array}{l}\text { Indian Ocean (Red } \\
\text { Sea, Singapore) }\end{array}$ & $\begin{array}{l}\text { Bartsch }(1909), \text { Fishel- } \\
\text { son }(1973,1974)\end{array}$ \\
\hline $\begin{array}{l}\text { Tropiometricola } \\
\text { sphaeroconchus }\end{array}$ & $\begin{array}{l}\text { Tropiometra afra } \\
\text { macrodiscus }\end{array}$ & Galls on arms & - & Japan Sea (Honshu) & $\begin{array}{l}\text { Habe }(1974,1976) \\
\text { Warén }(1981 \mathrm{~b})\end{array}$ \\
\hline \multicolumn{6}{|c|}{ II. Parasites of holothuroids } \\
\hline Balcis acicula & Stichopus chloronotus & $\begin{array}{l}\text { Body surface or } \\
\text { coelomic cavity }\end{array}$ & - & $\begin{array}{l}\text { Tropical W Pacific } \\
\text { (Fiji, Hawaii, Palao) }\end{array}$ & Habe (1952) \\
\hline Balcis alba & $\begin{array}{l}\text { Neopentadactyla } \\
\text { mixta }\end{array}$ & $\begin{array}{l}\text { Body surtace, near } \\
\text { tentacles }\end{array}$ & $\begin{array}{l}\text { Up to } 6 \text { gastropods on } \\
\text { single host (aquarium } \\
\text { observation) }\end{array}$ & $\begin{array}{l}\text { NE Atlantic } \\
\text { (Irish coast) }\end{array}$ & Cabioch et al (1978) \\
\hline Balcis catalinensis & Holothuria arenicola & $\begin{array}{l}\text { Body surface or } \\
\text { stomach }\end{array}$ & $\begin{array}{l}\text { Stomach of infested } \\
\text { hosts harbors } 9 \text { to } 26 \\
\text { gastropods according } \\
\text { to holothuroid size; } \\
\text { percentage of infesta- } \\
\text { tion } 66 \text { to } 100 \% \text { de- } \\
\text { pending on locality }\end{array}$ & $\begin{array}{l}\text { Tropical E Pacific } \\
\text { (Mexico: Bay of La } \\
\text { Paz) }\end{array}$ & Brand \& Ley (1980) \\
\hline Balcis intermedia & Holothuria glaberrima & $\begin{array}{l}\text { Firmly attached to out- } \\
\text { er body surface }\end{array}$ & $\begin{array}{l}1 \text { to } 3 \text { gastropods } \\
\text { holothuroid }{ }^{-1}(12 \text { in- } \\
\text { lested } / 35 \text { investi- } \\
\text { gated) }\end{array}$ & $\begin{array}{l}\text { Tropical E Pacific } \\
\text { (Mexico: Vera Cruz) }\end{array}$ & Caso $(1968)$ \\
\hline Diacolax Cucumariae & Cucumaria mendax & $\begin{array}{l}\text { Parasite protrudes } \\
\text { outside host body with } \\
\text { its rostrum deeply in- } \\
\text { serted into the } \\
\text { holothuroid's coelomic } \\
\text { cavity }\end{array}$ & $\begin{array}{l}\text { Only } 1 \text { specimen } \\
\text { known }\end{array}$ & $\begin{array}{l}\text { Southern Atlantic } \\
\left(51>10^{\prime} \mathrm{S}, 64>15^{\prime} \mathrm{W}\right)\end{array}$ & Mandahl-Barth (1945) \\
\hline Enteroxenos bouvieri & Holothuria atra & Coelomic cavity & - & $\begin{array}{l}\text { Tropical W Pacific } \\
\text { (New Caledonia) }\end{array}$ & Risbec (1953) \\
\hline $\begin{array}{l}\text { Enteroxenos } \\
\text { oestergeni }\end{array}$ & $\begin{array}{l}\text { Parastichopus tre- } \\
\text { mulus }\end{array}$ & $\begin{array}{l}\text { Mostly hanging in } \\
\text { coelomic cavity, } \\
\text { attached to esopha- } \\
\text { gus, rarely to stomach } \\
\text { or intestine. Some live } \\
\text { free in coelomic cavity }\end{array}$ & $\begin{array}{l}5 \text { gastropods } \\
\text { holothuroid }{ }^{-1} \text { (average } \\
\text { number) (537 in- } \\
\text { fested/1515 investi- } \\
\text { gated) (Lutzen) }\end{array}$ & $\begin{array}{l}\text { North Sea } \\
\text { (Scandinavian coast) }\end{array}$ & $\begin{array}{l}\text { Bonnevie (1902), Oes- } \\
\text { tergren (1938), Lüzen } \\
(1979)\end{array}$ \\
\hline $\begin{array}{l}\text { Enteroxenos } \\
\text { parastichopoli }\end{array}$ & $\begin{array}{l}\text { Parastichopus } \\
\text { californicus }\end{array}$ & $\begin{array}{l}\text { Hanging in coelomic } \\
\text { cavity, attached to } \\
\text { esophagus }\end{array}$ & $\begin{array}{l}\text { Ca } 3 \text { gastropods } \\
\text { holothuroid }{ }^{-1} \text { (average } \\
\text { number) ( } 37 \text { infested/ } \\
244 \text { investigated) } \\
\text { (Lutzen) }\end{array}$ & $\begin{array}{l}\text { NE Pacific (Washing- } \\
\text { ton: Puget Sound) }\end{array}$ & $\begin{array}{l}\text { Tikasingh (1961, } \\
\text { 1962), Kuncaid (1964), } \\
\text { Lutzen (1979) }\end{array}$ \\
\hline Entocolax chirodotae & Chrodata pellucida & $\begin{array}{l}\text { Hanging in coelomic } \\
\text { cavity, attached to } \\
\text { body wall (anterior } \\
\text { part) }\end{array}$ & - & Sea of Japan & Skarlato $(1951)$ \\
\hline Entocolax ludwign & Myriotrochus rinki & $\begin{array}{l}\text { Hanging in coelomic } \\
\text { cavity, attached to } \\
\text { body wall (anterior } \\
\text { part) }\end{array}$ & - & $\begin{array}{l}\text { Behring Sea } \\
\text { (Lorenz Bay) }\end{array}$ & Volgt (1888) \\
\hline
\end{tabular}


Table 4 (continued)

\begin{tabular}{|c|c|c|c|c|c|}
\hline Gastropod & Host & Location in host & Remarks & Geographical area & Source \\
\hline $\begin{array}{l}\text { Entocolax } \\
\text { numskykorsacovi }\end{array}$ & $\begin{array}{l}\text { Myriotrochus } \\
\text { mitsukurii }\end{array}$ & $\begin{array}{l}\text { Hanging in coelomic } \\
\text { cavity, attached to in- } \\
\text { testine }\end{array}$ & - & Sea of Japan & $\begin{array}{l}\text { Ivanov (1945a; quoted } \\
\text { from Lützen 1979) }\end{array}$ \\
\hline Entocolax schiemenzi & Chirodota pisami & $\begin{array}{l}\text { Hanging in coelomic } \\
\text { cavity, attached to } \\
\text { body wall }\end{array}$ & $\begin{array}{l}2 \text { infested } \\
\text { holothuroids observed } \\
(1 \text { gastropod } \\
\left.\text { holothuroid }{ }^{-1}\right)\end{array}$ & $\begin{array}{l}\text { SE Pacific } \\
\text { (Chile: Calbuco) }\end{array}$ & $\begin{array}{l}\text { Ludwig }(1897,1898) \\
\text { Voigt (1901) }\end{array}$ \\
\hline $\begin{array}{l}\text { Entocolax } \\
\text { schwanwitschi }\end{array}$ & $\begin{array}{l}\text { Myriotrochus } \\
\text { eurycyclus }\end{array}$ & $\begin{array}{l}\text { Hanging in coelomic } \\
\text { canty, attached to in- } \\
\text { testine }\end{array}$ & $\begin{array}{l}\text { 1 to } 22 \text { gastropods } \\
\text { holothuroid }{ }^{-1}(10 \% \text { of } \\
\text { investigated hosts in- } \\
\text { fested; Heding \& } \\
\text { Mandahl-Barth) }\end{array}$ & Barents sea (Kola Bay) & $\begin{array}{l}\text { Schwanwitsch }(1914), \\
\text { Heding \& Mandahl- } \\
\text { Barth (1938). } \\
\text { Andersen (1971) }\end{array}$ \\
\hline Entocolax trochodotae & Trochodota purpurea & $\begin{array}{l}\text { Hanging in coelomic } \\
\text { cavity, attached to } \\
\text { body wall (anterior } \\
\text { part) }\end{array}$ & - & $\begin{array}{l}\text { SW Atlantic (Falkland } \\
\text { Islands) }\end{array}$ & Heding (1934) \\
\hline Entoconcha mirabilis & Oestergrenia digitata & $\begin{array}{l}\text { Hanging in coelomic } \\
\text { cavity, attached to } \\
\text { ventral hemal vessel } \\
\text { of intestine }\end{array}$ & - & Mediterranean Sea & $\begin{array}{l}\text { Baur (1864) (see also } \\
\text { Koehler 1895, Lützen } \\
\text { 1979) }\end{array}$ \\
\hline Peastilifer edulis & Holothuria edulis & $\begin{array}{l}\text { Attached to body } \\
\text { surface }\end{array}$ & - & $\begin{array}{l}\text { Tropical W Pacific } \\
\text { (Great Barrier Reef) }\end{array}$ & $\begin{array}{l}\text { Hoskin \& Warén } \\
\text { (1983) }\end{array}$ \\
\hline Peastilifer nitidula & Holothuria atra & Free on body surface & $\begin{array}{l}1 \text { to } 5 \text { gastropods } \\
\text { holothurold }{ }^{-1}(200 \mathrm{in} \text { - } \\
\text { fested } / 400 \text { investi- } \\
\text { gated) }\end{array}$ & $\begin{array}{l}\text { Tropical W Pacific } \\
\text { (Hawai, NE } \\
\text { Australia, New } \\
\text { Caledonia) }\end{array}$ & $\begin{array}{l}\text { Hoskin \& Cheng } \\
\text { (1970); Hoskin \& } \\
\text { Warén (1983) }\end{array}$ \\
\hline Pisolamia brychius & $\begin{array}{l}\text { Oneirophanta } \\
\text { mutabilis }\end{array}$ & $\begin{array}{l}\text { Attached to body } \\
\text { surface }\end{array}$ & $\begin{array}{l}26 \text { gastropods col- } \\
\text { lected from } 17 \text { infested } \\
\text { holothuroids (111 in- } \\
\text { vestigated) }\end{array}$ & $\begin{array}{l}\text { NE Atlantic (Bay of } \\
\text { Biscay, deep sea) }\end{array}$ & $\begin{array}{l}\text { Bouchet \& Lützen } \\
(1976,1980)\end{array}$ \\
\hline Prostifer subpellucida & $\begin{array}{l}\text { Bohadschia argus, } \\
\text { Holothuria sp. }\end{array}$ & Galls in body wall & - & $\begin{array}{l}\text { NE Indian Ocean } \\
\text { (N Australia: Yonge } \\
\text { Reef) }\end{array}$ & Warén (1980b) \\
\hline Scalaribalcis angulata & $\begin{array}{l}\text { Holothuria } \\
\text { cinerascens }\end{array}$ & Galls in body wall & - & $\begin{array}{l}\text { SE Pacific } \\
\text { (Easter Island) }\end{array}$ & $\begin{array}{l}\text { Mandahl-Barth } \\
\text { (1949), Warén (1980b) }\end{array}$ \\
\hline Thyomicola americana & $\begin{array}{l}\text { Eupentacta } \\
\text { quinquesemita, } \\
\text { Eupentacta pseudo- } \\
\text { quinquesemita }\end{array}$ & $\begin{array}{l}\text { Hanging in coelomic } \\
\text { cavity, attached to } \\
\text { posterior intestine }\end{array}$ & $\begin{array}{l}\text { Overall incidence of } \\
\text { infestation: } 41 \% \text { ( } 1 \text { to } \\
\text { several hundred para- } \\
\text { sites host }{ }^{-1} \text {. Wright; in- } \\
\text { festation highly vari- } \\
\text { able according to the } \\
\text { host populations, } \\
\text { Byrne) }\end{array}$ & $\begin{array}{l}\text { NE Pacific (US and } \\
\text { Canadian coasts) }\end{array}$ & $\begin{array}{l}\text { Tikasing (1961). } \\
\text { Wright (1974), Byme } \\
\text { (1985) }\end{array}$ \\
\hline Thyonicola dogieli & $\begin{array}{l}\text { Cucumaria miniata, } \\
\text { Cucumaria japonica, } \\
\text { Cucumaria obunca }\end{array}$ & $\begin{array}{l}\text { Hanging in coelomic } \\
\text { cavity, attached to } \\
\text { postenor intestine }\end{array}$ & - & NE Pacific (?) & $\begin{array}{l}\text { lvanov (1945b; quoted } \\
\text { from Lützen 1979) }\end{array}$ \\
\hline $\begin{array}{l}\text { Thyonicola morten- } \\
\text { seni }\end{array}$ & Thyone serrata & $\begin{array}{l}\text { Hanging in coelomic } \\
\text { cavity, attached to } \\
\text { posterior intestine }\end{array}$ & $\begin{array}{l}\text { About } 40 \text { gastropods } \\
\text { in a single holothuroid }\end{array}$ & $\begin{array}{l}\text { SE Indian Ocean (off } \\
\text { Cape of Good Hope) }\end{array}$ & Mandahl-Barth (1941) \\
\hline $\begin{array}{l}\text { Gasterosiphon } \\
\text { deimatis }\end{array}$ & Deima blackei & $\begin{array}{l}\text { In coelomic cavity: } \\
\text { proboscis penetrates } \\
\text { the intestine hemal } \\
\text { system while siphon } \\
\text { opens to outer } \\
\text { medium across the } \\
\text { host's body wall }\end{array}$ & $\begin{array}{l}\text { Only } 2 \text { specimens } \\
\text { known from a single } \\
\text { host }\end{array}$ & $\begin{array}{l}\text { NE Indian Ocean } \\
\text { (Bay of Bengal) }\end{array}$ & $\begin{array}{l}\text { Koehler \& Vaney } \\
(1903,1905)\end{array}$ \\
\hline $\begin{array}{l}\text { Megadenus canth- } \\
\text { arelloides }\end{array}$ & Stichopus chloronotus & $\begin{array}{l}\text { Presumably attached } \\
\text { to digestive wall or } \\
\text { body wall }\end{array}$ & $\begin{array}{l}\text { Only } 2 \text { specimens } \\
\text { known from a single } \\
\text { host }\end{array}$ & $\begin{array}{l}\text { Tropical Indian Ocean } \\
\text { (Aldabra) }\end{array}$ & $\begin{array}{l}\text { Humphreys \& Lützen } \\
(1972)\end{array}$ \\
\hline $\begin{array}{l}\text { Megadenus } \\
\text { holothuricola }\end{array}$ & Holothuria mexicana & $\begin{array}{l}\text { Attached to wall of } \\
\text { respiratory trees }\end{array}$ & $\begin{array}{l}\text { Only } 2 \text { specimens } \\
\text { known from a single } \\
\text { host }\end{array}$ & $\begin{array}{l}\text { Tropical Atlantic } \\
\text { (Bahamas) }\end{array}$ & Rosén (1910) \\
\hline $\begin{array}{l}\text { Megadenus } \\
\text { oneirophantae }\end{array}$ & $\begin{array}{l}\text { Oneirophanta } \\
\text { mutabilis }\end{array}$ & Swellings in intestine & $\begin{array}{l}\text { The } 2 \text { hosts investi- } \\
\text { gated had } 3 \text { and } 9 \\
\text { gastropods }\end{array}$ & $\begin{array}{l}\text { North Atlantic (deep } \\
\text { sea) }\end{array}$ & $\begin{array}{l}\text { Bouchet \& Lützen } \\
(1980)\end{array}$ \\
\hline
\end{tabular}


Table 4 (continued)

\begin{tabular}{|c|c|c|c|c|c|}
\hline Gastropod & Host & Location in host & Remarks & Geographical area & Source \\
\hline $\begin{array}{l}\text { Megadenus } \\
\text { voeltzkowj }\end{array}$ & Holothuria pardalis & $\begin{array}{l}\text { Attached to peri-eso- } \\
\text { phagial ring (presum- } \\
\text { ably water-vascular } \\
\text { ring) }\end{array}$ & $\begin{array}{l}\text { Only } 1 \text { specimen } \\
\text { known }\end{array}$ & $\begin{array}{l}\text { Tropical W Indian } \\
\text { Ocean (Zanzıbar) }\end{array}$ & $\begin{array}{l}\text { Schepman \& Nier- } \\
\text { strasz }(1914)\end{array}$ \\
\hline Megadenus sp. & Holothuna atra & Cloaca & $\begin{array}{l}1 \text { to } 3 \text { gastropods } \\
\text { holothuroid }{ }^{-1} \text { ( } 8 \text { in- } \\
\text { fested } / 1359 \text { investi- } \\
\text { gated) }\end{array}$ & NE Indian Ocean & Jones \& James $(1970)$ \\
\hline Melanella muelleriae & $\begin{array}{l}\text { Actinopyga mauritia- } \\
\text { na, Holothuria per- } \\
\text { vicax, Holothuria } \\
\text { cinarescens, } \\
\text { Holothuria arenicola }\end{array}$ & $\begin{array}{l}\text { Projecting from body } \\
\text { wall }\end{array}$ & $\begin{array}{l}\text { Some individuals in- } \\
\text { fested }\end{array}$ & $\begin{array}{l}\text { Central Indian Ocean } \\
\text { (Aldabra) }\end{array}$ & Sloan et al. (1979) \\
\hline $\begin{array}{l}\text { Molpadicola } \\
\text { orientalis }\end{array}$ & Molpadiasp. & Coelomic cavity & - & $\begin{array}{l}\text { Okhotsk Sea } \\
\text { (deep sea) }\end{array}$ & Grusov $(1957)$ \\
\hline Mucronalia variabilis & Synapta ooplax & $\begin{array}{l}\text { Free on host body sur- } \\
\text { face, or in host diges- } \\
\text { tive tract }\end{array}$ & - & $\begin{array}{l}\text { SW Indian Ocean } \\
\text { (Zanzibar) }\end{array}$ & $\begin{array}{l}\text { Vaney (1913), Schep- } \\
\text { man \& Nierstrasz } \\
\text { (1914) }\end{array}$ \\
\hline $\begin{array}{l}\text { Paedophorus } \\
\text { dicoelobius }\end{array}$ & Eupyrgus pacificus & $\begin{array}{l}\text { In Polian vesicles or } \\
\text { respiratory trees }\end{array}$ & $\begin{array}{l}12 \text { gastropods col- } \\
\text { lected from } 3 \text { infested } \\
\text { holothuroids ( } 80 \mathrm{in}- \\
\text { vestigated) }\end{array}$ & $\begin{array}{l}\text { NW Pacific (Peter the } \\
\text { Great Bay) }\end{array}$ & Ivanov $(1933,1937)$ \\
\hline \multicolumn{6}{|l|}{ III. Parasites of echinoids } \\
\hline $\begin{array}{l}\text { Euchinewima } \\
\text { eburnea }\end{array}$ & $\begin{array}{l}\text { Chaetodiadema } \\
\text { granulatum. Astropy- } \\
\text { ga radiata, Astropyga } \\
\text { pulvinata, Heterocen- } \\
\text { trotus mammillatus, } \\
\text { Heterocentrotus } \\
\text { trigonana }\end{array}$ & $\begin{array}{l}\text { Attached to oral side } \\
\text { of body surface }\end{array}$ & $\begin{array}{l}1 \text { to } 4 \text { gastropods } \\
\text { echinoid }^{-1}\end{array}$ & Tropical Indo-Pacific & $\begin{array}{l}\text { Lützen \& Nielsen } \\
(1975)\end{array}$ \\
\hline Euchineulima mittrei & $\begin{array}{l}\text { Echinothrix diadema, } \\
\text { Echinothrix calamaris, } \\
\text { Diadema setosum, } \\
\text { Diadema mexicanum, } \\
\text { Diadema savignyi }\end{array}$ & $\begin{array}{l}\text { Attached to oral side } \\
\text { of body surface }\end{array}$ & $\begin{array}{l}1 \text { to } 6 \text { gastropods } \\
\text { echinoid }\end{array}$ & Circumtropical & $\begin{array}{l}\text { Lützen \& Nielsen } \\
(1975)\end{array}$ \\
\hline Euchineulima ponderi & Parasalenia gratiosa & Attached to peristome & $\begin{array}{l}\text { Only } 2 \text { specimens } \\
\text { from single host. }\end{array}$ & $\begin{array}{l}\text { Tropical W Pacific } \\
\text { (Great Barrier Reef: } \\
\text { Lizard Island) }\end{array}$ & Warén (1980a) \\
\hline $\begin{array}{l}\text { Luetzenia } \\
\text { asthenosoma }\end{array}$ & Asthenosomasp. & Attached to peristome & $\begin{array}{l}\text { Only } 2 \text { specimens } \\
\text { trom single host }\end{array}$ & $\begin{array}{l}\text { SW Pacific (Australua: } \\
\text { New South Wales) }\end{array}$ & Warén (1980b) \\
\hline Megadenus cysticola ${ }^{1}$ & Stylocidaris tiara & $\begin{array}{l}\text { Galls in primary } \\
\text { spines }\end{array}$ & $\begin{array}{l}1 \text { to } 7 \text { gastropods } \\
\text { echinoid }\end{array}$ & $\begin{array}{l}\text { E Indian Ocean } \\
\text { (off Ceylon) }\end{array}$ & $\begin{array}{l}\text { Koehler }(1924,1927) \\
\text { Koehler \& Vaney } \\
(1925)\end{array}$ \\
\hline $\begin{array}{l}\text { Monogamus } \\
\text { entopodia }\end{array}$ & Echinometra mathaei & Tube feet wall & $\begin{array}{l}21 \text { gastropods from } 10 \\
\text { infested echinolds }\end{array}$ & $\begin{array}{l}\text { Red Sea (Gulf of } \\
\text { Aqaba) }\end{array}$ & Lutzen (1976) \\
\hline $\begin{array}{l}\text { Monogamus } \\
\text { interspinea }\end{array}$ & Echinometra mathael & Buried in skin & $\begin{array}{l}2 \text { gastropods from } 2 \\
\text { infested echinoids ( } 55 \\
\text { investigated) }\end{array}$ & $\begin{array}{l}\text { SW Indian Ocean } \\
\text { (Ambona) }\end{array}$ & Lützen (1976) \\
\hline $\begin{array}{l}\text { Monogamus } \\
\text { parasaleniae }\end{array}$ & Parasalenia gratiosa & Galls in spines & $\begin{array}{l}2 \text { gastropods from } \\
\text { single host }\end{array}$ & $\begin{array}{l}\text { Tropical Pacific } \\
\text { (Tonga Islands) }\end{array}$ & Warén $(1980 \mathrm{~b}\}$ \\
\hline 'Mucronalia'sp. & $\begin{array}{l}\text { Stylocidaris tiara, } \\
\text { Stereocidaris indica }\end{array}$ & $\begin{array}{l}\text { Attached to body sur- } \\
\text { face, producing con- } \\
\text { spicuous test deforma- } \\
\text { tions }\end{array}$ & - & $\begin{array}{l}\text { E Indian Ocean (Cey- } \\
\text { lon, Bay of Bengal) }\end{array}$ & Koehler (1927) \\
\hline Pelseenaria media & Echunus affinis & $\begin{array}{l}\text { Attached to body sur- } \\
\text { face }\end{array}$ & - & $\begin{array}{l}\text { NE Atlantic (off } \\
\text { Azores: deep sea) }\end{array}$ & $\begin{array}{l}\text { Koehler \& Vaney } \\
(1908)\end{array}$ \\
\hline Pelseenaria minor & Echinus affinis & $\begin{array}{l}\text { Attached to body sur- } \\
\text { face }\end{array}$ & - & $\begin{array}{l}\text { North Sea (Banc de } \\
\text { Seine) }\end{array}$ & $\begin{array}{l}\text { Koehler \& Vaney } \\
(1908)\end{array}$ \\
\hline Pelseenaria profunda & Genocidaris maculata & $\begin{array}{l}\text { Attached to body sur- } \\
\text { face }\end{array}$ & $\begin{array}{l}11 \text { echinoids infested } \\
\text { (several hundred in- } \\
\text { vestigated) }\end{array}$ & $\begin{array}{l}\text { NE Atlantic (off } \\
\text { Azores: deep sea) }\end{array}$ & $\begin{array}{l}\text { Koehler \& Vaney } \\
(1908)\end{array}$ \\
\hline
\end{tabular}


Table 4 (continued)

\begin{tabular}{|c|c|c|c|c|c|}
\hline Gastropod & Host & Location in host & Remarks & Geographical area & Source \\
\hline Pelseenaria stilifera & $\begin{array}{l}\text { Strongylocentrotus } \\
\text { droebachiensis, } \\
\text { Echinus esculentus }\end{array}$ & $\begin{array}{l}\text { Attached to body } \\
\text { surface }\end{array}$ & $\begin{array}{l}4 \text { gastropods from } \\
\text { single host (Ankel) }\end{array}$ & $\begin{array}{l}\text { Baltuc Sea } \\
\text { (Kristinenberg) }\end{array}$ & $\begin{array}{l}\text { Ankel (1938), } \\
\text { Montensen (1940) }\end{array}$ \\
\hline Pulicochlea calamaris & Echinothrix calamaris & Free on body surface & $\begin{array}{l}\text { Rather frequent infes- } \\
\text { tation }\end{array}$ & $\begin{array}{l}\text { Tropical W Pacific } \\
\text { (Hawai, Papua New } \\
\text { Guinea, New } \\
\text { Caledonia) }\end{array}$ & $\begin{array}{l}\text { Ponder \& Gooding } \\
(1978)\end{array}$ \\
\hline Pulicochlea fusca & Diadema setosum & Free on body surface & $\begin{array}{l}\text { Numerous gastropods } \\
\text { collected }\end{array}$ & $\begin{array}{l}\text { Tropical W Pacific } \\
\text { (Papua New Guinea } \\
\text { and adjacent islands) }\end{array}$ & $\begin{array}{l}\text { Ponder \& Gooding } \\
(1978)\end{array}$ \\
\hline Robillardia cernica & $\begin{array}{l}\text { Echinometra mathaei, } \\
\text { Echinometra insularis }\end{array}$ & $\begin{array}{l}\text { Attached to wall } \\
\text { of rectum }\end{array}$ & $\begin{array}{l}1 \text { to } 2 \text { gastropods } \\
\text { echinoid }{ }^{-1} \text { (54 in- } \\
\text { fested } / 185 \text { investi- } \\
\text { gated) }\end{array}$ & $\begin{array}{l}\text { Indian Ocean (Red } \\
\text { Sea, Mauritius, Am- } \\
\text { boina); SW Pacific } \\
\text { (Easter Island) }\end{array}$ & $\begin{array}{l}\text { Gooding \& Lützen } \\
(1973)\end{array}$ \\
\hline Sabinella infrapatula & Ogmocidaris benhami & $\begin{array}{l}\text { Attached to body sur- } \\
\text { face, close to periproct }\end{array}$ & $\begin{array}{l}\text { Only } 1 \text { individual } \\
\text { found }\end{array}$ & $\begin{array}{l}\text { SW Pacific (New Zea- } \\
\text { land: off Major Island) }\end{array}$ & Warén (1981a) \\
\hline Sabinella troglodytes ${ }^{2}$ & Eucidaris tribuloides & $\begin{array}{l}\text { Galls in primary } \\
\text { spines }\end{array}$ & $\begin{array}{l}\text { Infestation relatively } \\
\text { rare }(33 \text { infested } / 1467 \\
\text { nnvestigated) } \\
\text { (McPherson) }\end{array}$ & $\begin{array}{l}\text { Tropical Atlantic } \\
\text { (Cape Verde Islands, } \\
\text { Florida) }\end{array}$ & $\begin{array}{l}\text { Thiele (1925), Pilsbry } \\
\text { (1956), McPherson } \\
\text { (1968) }\end{array}$ \\
\hline $\begin{array}{l}\text { Trochostilifer } \\
\text { mortenseni }\end{array}$ & Prionocidaris australis & $\begin{array}{l}\text { Galls in primary } \\
\text { spines }\end{array}$ & $\begin{array}{l}1 \text { gall with } 2 \text { gas- } \\
\text { tropods in each in- } \\
\text { fested echinoid }\end{array}$ & $\begin{array}{l}\text { Tropical W Pacific } \\
\text { (New Caledonia) }\end{array}$ & Warén (1980b) \\
\hline $\begin{array}{l}\text { Vitreobalcis } \\
\text { temnopleunicola }\end{array}$ & $\begin{array}{l}\text { Temnopleurus } \\
\text { toreumaticus }\end{array}$ & $\begin{array}{l}\text { Attached to body } \\
\text { surface }\end{array}$ & $\begin{array}{l}\text { Infestation rate varied } \\
\text { from } 5.3 \text { to } 50 \% \text { de- } \\
\text { pending on host popu- } \\
\text { lation and season }\end{array}$ & Inland Sea (Japan) & $\begin{array}{l}\text { Fujioka \& Habe } \\
\text { (1983), Fujioka (1984, } \\
\text { 1985) }\end{array}$ \\
\hline \multicolumn{6}{|l|}{ IV. Parasites of asteroids } \\
\hline Apicalia palmipedis & Palmipes rosaceus & $\begin{array}{l}\text { Attached to body sur- } \\
\text { face (oral side) }\end{array}$ & $\begin{array}{l}1 \text { to } 2 \text { gastropods per } \\
\text { infested asteroid }\end{array}$ & $\begin{array}{l}\text { NW Indian Ocean } \\
\text { (Ceylan, Singapore) }\end{array}$ & $\begin{array}{l}\text { Koehler (1910), } \\
\text { Koehler \& Vaney } \\
\text { (1912), Warén (1981b) }\end{array}$ \\
\hline $\begin{array}{l}\text { Asterolamia } \\
\text { cingulatus }\end{array}$ & Craspidaster hesperus & $\begin{array}{l}\text { Attached to side of } \\
\text { body (marginal plates) }\end{array}$ & - & $\begin{array}{l}\text { NW Pacific } \\
\text { (Hong Kong) }\end{array}$ & Warén (1980b) \\
\hline Asterolamia hians & Astropecten indicus & $\begin{array}{l}\text { Attached to aboral } \\
\text { body surface, among } \\
\text { paxillae }\end{array}$ & - & $\begin{array}{l}\text { Tropical Pacific (Great } \\
\text { Barrier Reef) }\end{array}$ & Warén (1980b) \\
\hline Asterophila japonica & $\begin{array}{l}\text { Pedicellaster magis- } \\
\text { ter, Ctenodiscus cris- } \\
\text { patus, Leptasterias } \\
\text { polans, Leptasterias } \\
\text { arctica }\end{array}$ & $\begin{array}{l}\text { Coelomic cavity } \\
\text { attached to the body } \\
\text { wall }\end{array}$ & $\begin{array}{l}10 \text { to } 29 \% \text { asteroids } \\
\text { infested depending on } \\
\text { locality (Hoberg et al.) }\end{array}$ & $\begin{array}{l}\text { N Pacific (off Japan, } \\
\text { Asiabc coast, Alaska) }\end{array}$ & $\begin{array}{l}\text { Randall \& Heath } \\
\text { (1911), Grusov (1965), } \\
\text { Hoberg et al (1980) }\end{array}$ \\
\hline $\begin{array}{l}\text { Paramegadenus } \\
\text { arrhynchus }\end{array}$ & $\begin{array}{l}\text { Anthenoides } \\
\text { rugulosus }\end{array}$ & $\begin{array}{l}\text { Open gall on body } \\
\text { surface (aboral side) }\end{array}$ & - & $\begin{array}{l}\text { Tropical W Pacific } \\
\text { (Philippines: near } \\
\text { Cebu) }\end{array}$ & $\begin{array}{l}\text { Kanazawa \& Habe } \\
\text { (1979), Warén (1980b) }\end{array}$ \\
\hline $\begin{array}{l}\text { Paramegadenus } \\
\text { scutellicola }\end{array}$ & Stellaster incei & On tube feet & - & $\begin{array}{l}\text { Tropıcal W Pacifıc } \\
\text { (Great Barrier Reef) }\end{array}$ & Warén (1980b) \\
\hline Parvioris equestris & Stellaster incei & $\begin{array}{l}\text { Attached to body sur- } \\
\text { face (marginal plates) }\end{array}$ & - & $\begin{array}{l}\text { Indo-West Pacific (An- } \\
\text { daman Islands, Java } \\
\text { Sea, Great Barrier } \\
\text { Reef) }\end{array}$ & $\begin{array}{l}\text { Koehler (1910), } \\
\text { Koehler \& Vaney } \\
\text { (1912). Warén (1981b) }\end{array}$ \\
\hline Parvioris mortoni $3^{3}$ & Archaster typicus & $\begin{array}{l}\text { Attached to body sur- } \\
\text { face (aboral or lateral } \\
\text { side) }\end{array}$ & $\begin{array}{l}1 \text { to } 4 \text { gastrcpods } \\
\text { asteroid }{ }^{-1} \text { ( } 75 \text { infested/ } \\
396 \text { investigated) }^{-1}\end{array}$ & $\begin{array}{l}\text { NW Pacific } \\
\text { (Hong Kong) }\end{array}$ & $\begin{array}{l}\text { Morton (1976), } \\
\text { Warén (1981b) }\end{array}$ \\
\hline Stilifer astericola & Heliaster cumingi & Gall in body wall & $\begin{array}{l}\text { Up to } 5 \text { gastropods } \\
\text { asteroid }^{-1}\end{array}$ & E Pacific (Galapagos) & Lützen (1972a) \\
\hline Stilifer inflatus & Linckia laevigata & Gall in body wall & $\begin{array}{l}\text { Only } 1 \text { specimen } \\
\text { known }\end{array}$ & $\begin{array}{l}\text { Tropical W Pacific } \\
\text { (Great Barrier Reef) }\end{array}$ & Warén (1980a) \\
\hline Stilifer linckiae & Linckia multofora & Gall in body wall & $\begin{array}{l}1 \text { to } 2 \text { galls asteroid }{ }^{-1} \\
\text { ( } 54 \text { intested/665 inves- } \\
\text { tigated) (Davis) }\end{array}$ & $\begin{array}{l}\text { Tropical Indo-West } \\
\text { Pacific (Oman Sea, } \\
\text { Ceylan, Great Barrier } \\
\text { Reef, Hawai) }\end{array}$ & $\begin{array}{l}\text { Sarasin \& Sarasin } \\
\text { (1887), Davis (1967), } \\
\text { Tullis \& Cheng (1971), } \\
\text { Lutzen (1972a), Warén } \\
(1980 a)\end{array}$ \\
\hline
\end{tabular}


Table 4 (continued)

\begin{tabular}{|c|c|c|c|c|c|}
\hline Gastropod & Host & Location in host & Rematks & Geographical area & Source \\
\hline $\begin{array}{l}\text { Stilufer } \\
\text { ophidiastericola }\end{array}$ & $\begin{array}{l}\text { Ophidiaster cribranus, } \\
\text { Ophidiaster lorioli, } \\
\text { Ophidiaster confestus, } \\
\text { Ophidiaster granifor }\end{array}$ & Gall in body wall & - & $\begin{array}{l}\text { Tropical Indo-Pacific } \\
\text { (Indonesia to SW } \\
\text { Japan) }\end{array}$ & Habe $\{1976\}$ \\
\hline Stilifer ovoideus ${ }^{4}$ & $\begin{array}{l}\text { Certonardoa semire- } \\
\text { gularis, Ophidiaster } \\
\text { granifer, Tamaria } \\
\text { dubiosa }\end{array}$ & Gall in body wall & - & $\begin{array}{l}\text { Tropical Indo-Pacific } \\
\text { (Indonesia to SW } \\
\text { Japan) }\end{array}$ & $\begin{array}{l}\text { Hirase }(1927,1932) \\
\text { Lützen }(1972 a), \text { Habe } \\
(1976)\end{array}$ \\
\hline Stilifer utinomi & $\begin{array}{l}\text { Linckia guildingi, } \\
\text { Linckia la evigata }\end{array}$ & Gall in body wall & - & $\begin{array}{l}\text { Tropical W Pacific } \\
\text { (Great Barier Reef, SW } \\
\text { Japan) }\end{array}$ & $\begin{array}{l}\text { Habe (1952), } \\
\text { Lützen (1972a) }\end{array}$ \\
\hline Stilifer sp. & Ophıdiaster granifer & Gall in body wall & $\begin{array}{l}\text { Up to } 4 \text { gastropods as- } \\
\text { teroid }^{-1}(26 \text { investi- } \\
\text { gated } / 8 \text { infested })\end{array}$ & $\begin{array}{l}\text { Tropical W Pacific } \\
\text { (Guam) }\end{array}$ & $\begin{array}{l}\text { Yamaguchi \& Lucas } \\
\text { (1984) }\end{array}$ \\
\hline Thyca callista & $\begin{array}{l}\text { Phataria unifascialis, } \\
\text { Pharia pyramidata }\end{array}$ & $\begin{array}{l}\text { Attached to body } \\
\text { surface }\end{array}$ & $\begin{array}{l}1 \text { to } 3 \text { gastropods as- } \\
\text { teroid }{ }^{-1} \text {, infestation } \\
\text { rather rare }\end{array}$ & $\begin{array}{l}\text { Tropical E Pacific } \\
\text { (coast of Mexico and } \\
\text { central America) }\end{array}$ & $\begin{array}{l}\text { Berry (1959), Shasky } \\
\text { (1961), Bertsch (1975) }\end{array}$ \\
\hline Thyca cristallina & $\begin{array}{l}\text { Linckia multifora, } \\
\text { Linckia laevigata }\end{array}$ & $\begin{array}{l}\text { Attached to body } \\
\text { surface }\end{array}$ & $\begin{array}{l}\text { Infestation rate vari- } \\
\text { able: from } 14 \text { to } 62 \% \\
\text { dependirtg on } \\
\text { localities }\end{array}$ & $\begin{array}{l}\text { Tropical Indo-West } \\
\text { Pacific (Indonesia, } \\
\text { Papua New Guinea, } \\
\text { Great Barrier Reet, } \\
\text { Fiji) }\end{array}$ & $\begin{array}{l}\text { Egloff (1966). Elder } \\
\text { (1979), Warén (1980a), } \\
\text { Bouillon \& Jangoux } \\
\text { (1984) }\end{array}$ \\
\hline Thycd ectoconcha & $\begin{array}{l}\text { Linckia multifora, } \\
\text { Linckia guildingi }\end{array}$ & $\begin{array}{l}\text { Attached to body } \\
\text { surface }\end{array}$ & $\begin{array}{l}\text { Infestation rate ca } 3 \% \\
\text { (MacNae \& Kalk) }\end{array}$ & $\begin{array}{l}\text { Indian Ocean (Ceylon, } \\
\text { Mozambique coast) }\end{array}$ & $\begin{array}{l}\text { Sarasin \& Sarasin } \\
\text { (1887), MacNae \& } \\
\text { Kalk (1962) }\end{array}$ \\
\hline Thyca stellasteris & Stellaster equestris & $\begin{array}{l}\text { Attached to body } \\
\text { surface }\end{array}$ & - & $\begin{array}{l}\text { Indian Ocean (Anda- } \\
\text { man Islands, West } \\
\text { Australia, Red Sea) }\end{array}$ & $\begin{array}{l}\text { Koehler (1910), } \\
\text { Koehler \& Vaney } \\
\text { (1912), Warén (1980a) }\end{array}$ \\
\hline \multicolumn{6}{|c|}{ V. Parasites of ophiuroids } \\
\hline $\begin{array}{l}\text { Fuscapex } \\
\text { ophiocanthicola }\end{array}$ & Ophiocanthasp. & $\begin{array}{l}\text { Attached to body sur- } \\
\text { face (oral side), cover- } \\
\text { ing bursal slits }\end{array}$ & $\begin{array}{l}3 \text { gastropods from } \\
\text { single host }\end{array}$ & $\begin{array}{l}\text { SW Pacific (off Ker- } \\
\text { madec Islands, deep } \\
\text { sea) }\end{array}$ & Warén (1981a) \\
\hline Ophieulima armigeri & $\begin{array}{l}\text { Ophiomusium } \\
\text { armigerum }\end{array}$ & $\begin{array}{l}\text { Attached to body sur- } \\
\text { face (oral side), near } \\
\text { bursal slits }\end{array}$ & $\begin{array}{l}\text { Up to } 5 \text { gastropods } \\
\text { ophiuroid }{ }^{-1} \text { ( } 23 \text { in- } \\
\text { fested/more than } 3000 \\
\text { investigated) }\end{array}$ & $\begin{array}{l}\text { NW Atlantic } \\
\text { (off Virginia) }\end{array}$ & $\begin{array}{l}\text { Warén \& Carney } \\
\text { (1981) }\end{array}$ \\
\hline $\begin{array}{l}\text { Ophieulima } \\
\text { fuscoapicata }\end{array}$ & Ophiactis profundi & $\begin{array}{l}\text { Attic hed to body sur- } \\
\text { face (radial shields) }\end{array}$ & $\begin{array}{l}2 \text { gastropods from } \\
\text { single host }\end{array}$ & $\begin{array}{l}\text { SW Pacific (off Ker- } \\
\text { madec Islands, deep } \\
\text { sea) }\end{array}$ & Warén (1981a) \\
\hline Ophieulima minima & Ophiactis abyssicola & $\begin{array}{l}\text { Attached to body sur- } \\
\text { face (aboral side) }\end{array}$ & - & $\begin{array}{l}\text { N Atlantic (deep-sea: } \\
\text { off Ireland, off Iceland, } \\
\text { Bay of Biscay) }\end{array}$ & Warén \& Sibuet (1981) \\
\hline $\begin{array}{l}\text { Ophioarachuzicola } \\
\text { biformis }\end{array}$ & $\begin{array}{l}\text { Ophioarachna } \\
\text { incrassata }\end{array}$ & $\begin{array}{l}\text { Attached to body sur- } \\
\text { face (oral side of arm) }\end{array}$ & $\begin{array}{l}\text { Only } 1 \text { gastropod } \\
\text { found }\end{array}$ & $\begin{array}{l}\text { Tropical W Pacific } \\
\text { [Salomon Islands) }\end{array}$ & Warén (1980b) \\
\hline $\begin{array}{l}\text { Punctufera } \\
\text { ophiomoerae }\end{array}$ & Ophiomoeris projecta & $\begin{array}{l}\text { Open galls (aboral } \\
\text { side of the disc) }\end{array}$ & $\begin{array}{l}2 \text { gastropods from } \\
\text { single host }\end{array}$ & $\begin{array}{l}\text { SW Pacific (off Ker- } \\
\text { madec Islands: } \\
\text { deep sea) }\end{array}$ & Warén (1981a) \\
\hline $\begin{array}{l}{ }^{1} \text { Generic position unc } \\
{ }^{2} \text { Identified as Mucron } \\
\text { Identified as Eulima } \\
{ }^{3} \text { Identified as Stilifer }\end{array}$ & $\begin{array}{l}\text { ear (see Warén } 1980 \text { b) } \\
\text { hia nidorum by Pilsbry (1 } \\
\text { hoplandi by Morton ( } 197 \\
\text { lebensis by Hurase ( } 1927\end{array}$ & $\begin{array}{l}\text { 956) and McPherson (19 } \\
\text { 6) (see Warén 1981b) } \\
\text { 7, 1932) (see Warén } 1980\end{array}$ & 68) (see Warén 1980b) & & \\
\hline
\end{tabular}

tallina passes through the asteroid's body wall to reach the radial (water-vascular) canal. One may wonder, however, if the ambulacral or coelomic fluids together with coelomocytes can ensure sufficient nutrients for parasites. As noted by Lützen \& Nielsen (1975), additional predation upon internal organs presumably occurs. Other fluid-feeding eulimids insert their pro- boscis into the hemal lacunae of holothuroids (their hemal system has energy-rich contents). Such a symbiosis has been documented by Bouchet \& Lützen (1976, 1980) who studied relations between Pisolamia brychius and the deep-sea holothuroid Oneirophanta mutabilis (Fig. 11). Ectoparasitic gastropods may also feed directly on internal organs (i.e. digestive organs); 
Fig. 10. Monogamus entopodia. Male and female (with 3 egg capsules) of a parasitic gastropod in a transformed tube foot of the echinoid Echinometra mathaei. (After Lützen 1976)

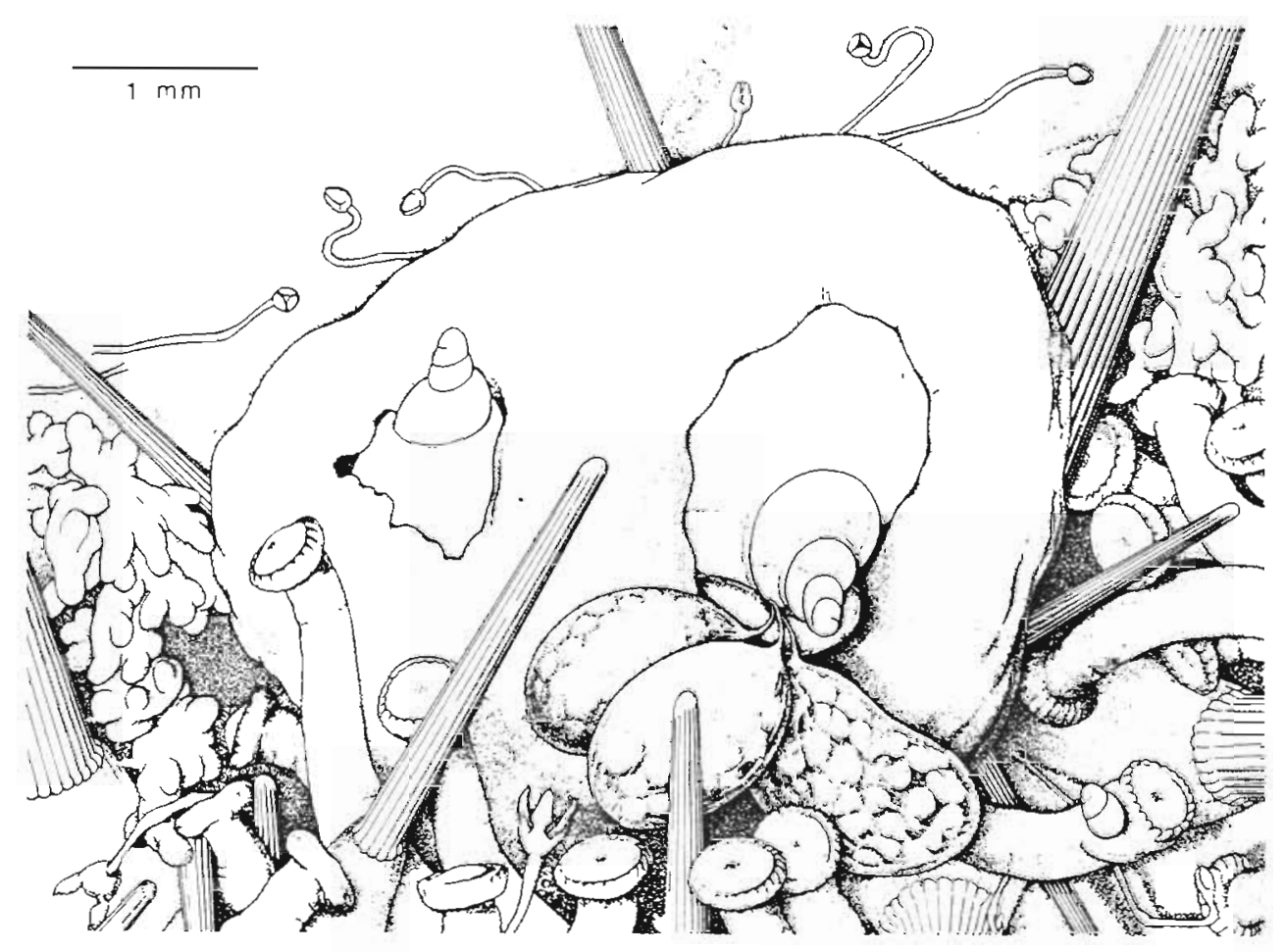

Fig. 11. Pisolamia brychius, a blood-sucking gastropod parasite of the deep-sea holothuroid Oneirophanta mutabilis. i: intestine of holothuroid; h: hemal vessel of holothuroid; P: proboscis; S: snout; t: tube-foot. (After Bouchet \& Lützen 1976)

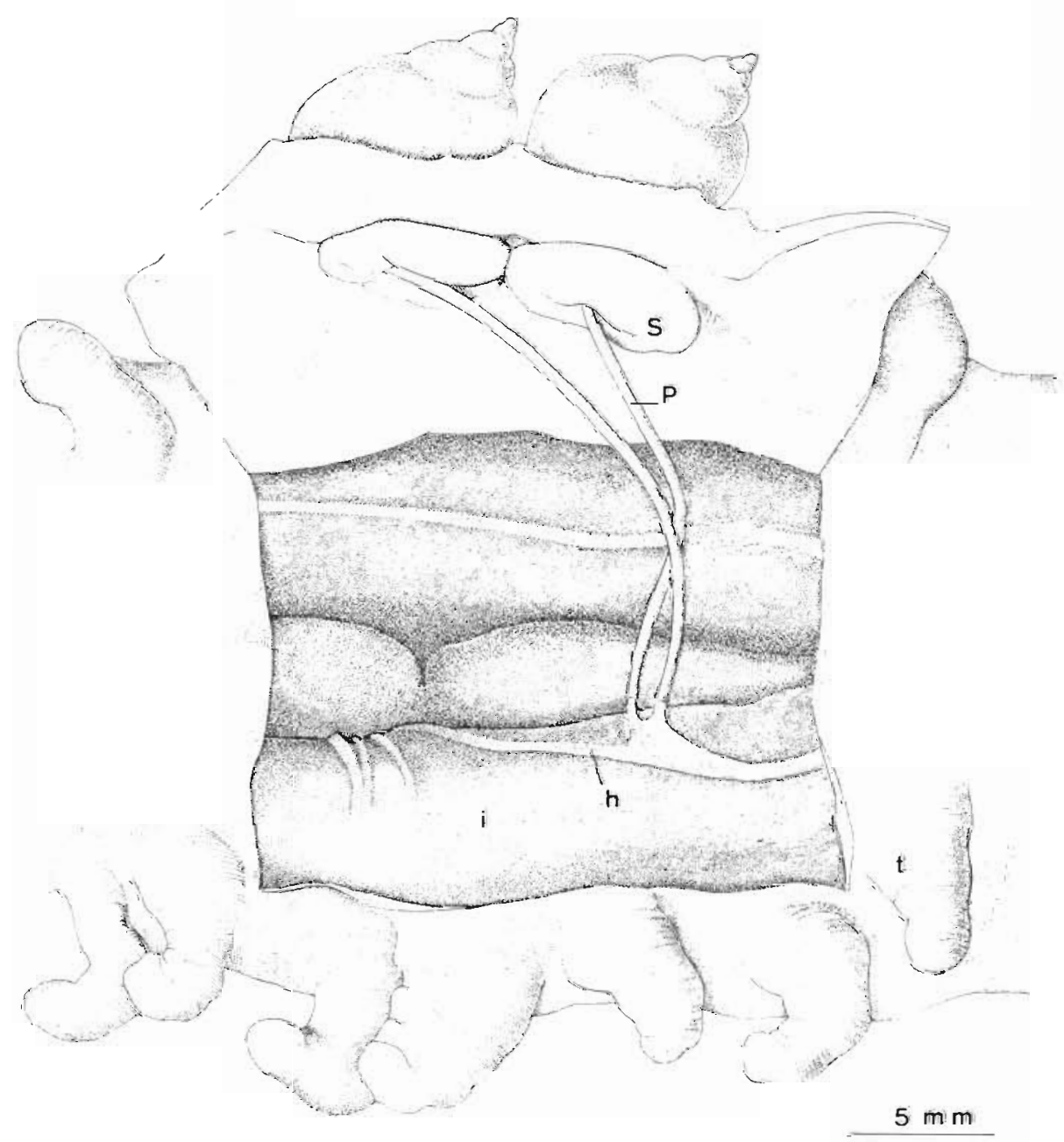


this has been suggested by Waren (1980b) for 2 species of Asterolamia.

Little information is available on the feeding biology of intradigestive eulimids. An unusual feeding habit was reported for 2 unattached species of holothuroidassociated snails, Mucronalia variabilis and Balcis catalinensis, symbiotic with Synapta ooplax and Holothuria arenicola (respectively Vaney 1913, Brand \& Ley 1980). The snails move freely on the body surface of their host but may enter the host's digestive tract in order to feed by puncturing the digestive wall. The presence of several individuals of $B$. catalinensis in the stomach of $H$. arenicola does not cause significant effects on the absorption efficiency of the host (Brand \& Ley 1980). Gooding \& Lützen (1973) provide evidence that Robillardia cernica, which inhabits the rectum of the echinoid Echinometra insularis, feeds on host gonads, using its elongated proboscis. Megadenus oneirophantae lives in cyst-like swellings in the digestive wall of a deep-sea holothuroid. According to Bouchet \& Lützen (1980), it supposedly feeds on content of the digestive hemal lacunae. A most unusual feeding habit is that of Megadenus cantharelloides: it attaches to the digestive wall of Stichopus chloronotus - the visceral mass of the parasite protruding into the digestive cavity - with its proboscis crossing both digestive wall and coelomic cavity and penetrating the host's body wall, in order to feed on dermal tissue (Humphreys \& Lützen 1972).

Oral feeding by intracoelomic eulimids has been inferred only for Gasterosiphon deimatis which inserts its proboscis into digestive hemal lacunae (Koehler \& Vaney 1903). Other intracoelomic forms (viz. the aberrant Entocolax and allied genera, i.e., the former Entoconchidae; e.g. Tikasingh \& Pratt 1961, Lützen 1968, 1979, Byme 1985) are believed to derive their energy from the host's coelomic fluid by direct absorption of nutrients through their body wall. Intracoelomic parasitic gastropods occur only in asteroids (eulimid genus Asterophila) and in holothuroids (eulimid genera Diacolax, Enteroxenox, Entoconcha, Gasterosiphon, Molpadicola, Paedophorus, Thyonicola) (Table 4; Fig. 12 \& 13). Most of them are attached to the coelomic side of either digestive tract or body wall of their host by a hollow stalk or by a siphon. Although some authors have suggested that feeding could take place through that duct (Heath 1910, Tikasingh 1962), such a hypothesis has not been accepted generally.

Harmful. effects of parasitic gastropods are not restricted to their feeding activities. Ectoparasitic eulimids may produce clearly definable attachment lesions (Lützen \& Nielsen 1975, Lützen 1976, Elder 1979). Host reactions produce conspicuous soft swellings of the dermal tissue in parasitized echinoid tube feet (Lützen 1976) and in infested crinoid pinnules

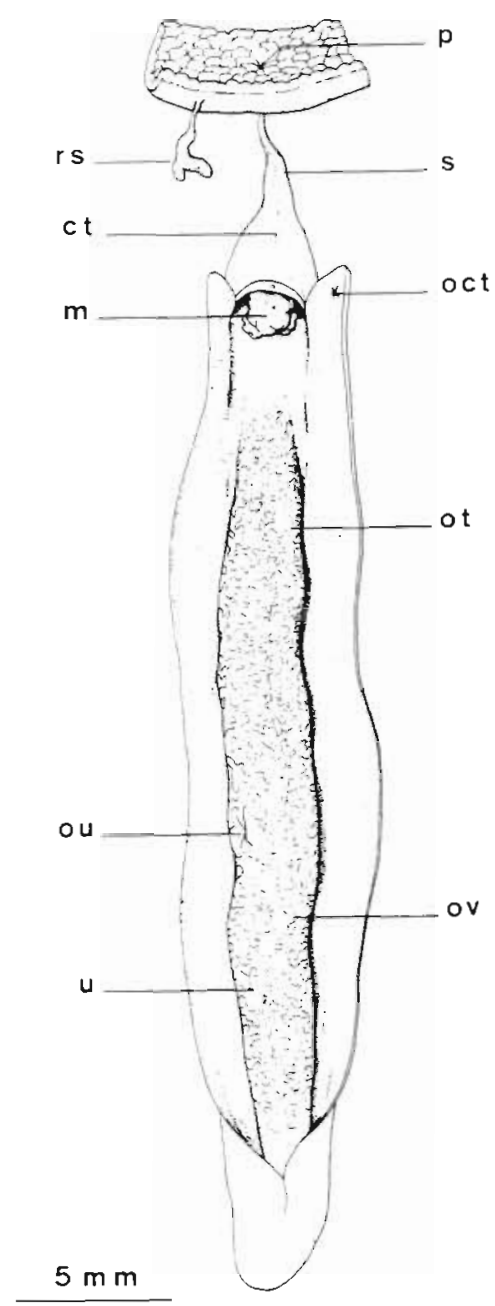

Fig. 12. Enteroxenos oestergreni, an intracoelomic gastropod parasite of the holothuroid Stichopus tremulus. ct: ciliated tubule; m: modified male implanted in receptaculum masculinum; : pit in the wall of host's esophagus; rs: remains of stalk of another individual; s: stalk; oct: opening of ciliated tubule; ot: ovarian tubules; ou: opening of uterus; ov: oviduct; u: uterus. (After Lutzen 1979)

(Bacci 1948, Fretter 1955). Gallicole eulimids (e.g. Stilifer spp., Puctifera ophiomoerae, Tropiometricola sphaeroconchus; Table 4) produce spectacular hard swellings or galls in the body wall of asteroids, ophiuroids and crinoids. These galls resemble those induced by myzostomids on crinoid arms. Whether or not they involve particular modifications of host skeleton has not been investigated. According to Davis (1967) S. linckiae suppresses the autotomizing capability of the asteroid arm in which it is located. Other gallicole species modify primary spines of cidaroid echinoids (Koehler \& Vaney 1925, Koehler 1927, Pilsbry 1956, Warén 1980b). In most cases the snails bore into the distal part of spines which then enlarges. Sometimes spine-dwelling gastropods appear to 


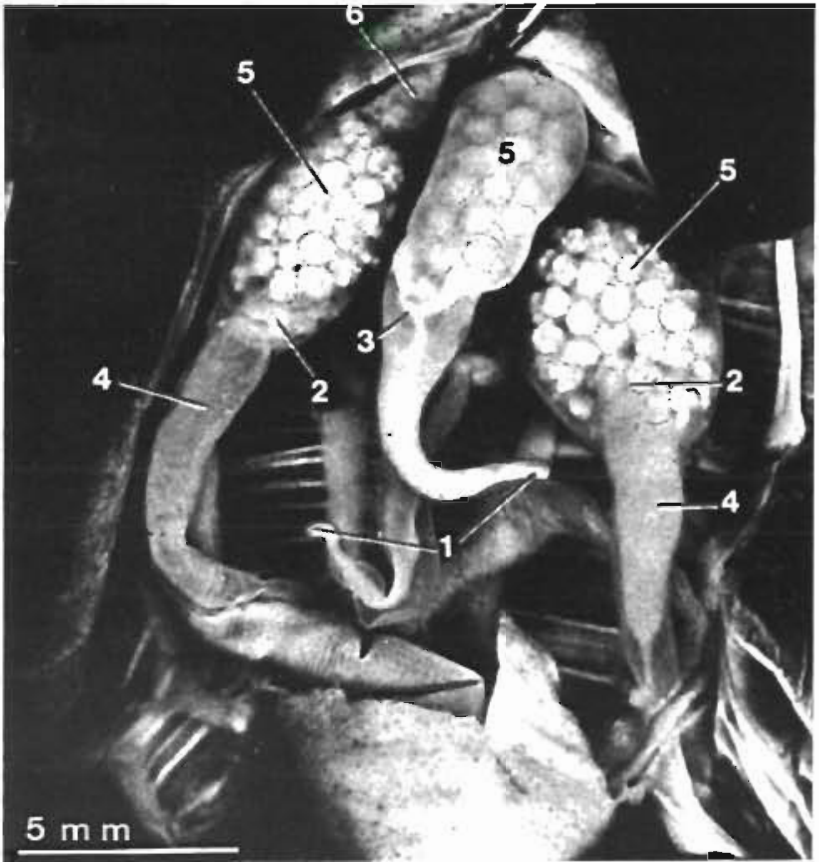

Fig. 13. Myriotrochus rinki. Holothuroid parasitized by 3 ovigerous specimens of the intracoelomic gastropod Entocolax ludwigi. 1: oral end; 2 : ovary; 3 : oviduct; 4 : part of the body containing intestine; 5 : pseudopallium with egg capsules; 6 : siphon. (After Lützen 1979)

induce a conspicuous regression of the host skeleton, the spine being reduced to its swollen basal part (Koehler \& Vaney 1925). Nothing is known of the feeding habits of these spine-associated eulimids. The host skeleton is also affected by non-gallicole species. Fishelson (1973, 1974) reported that Mucronalia capillastericola attaches to crinoid arms and causes a prononced twist and degeneration of the arm skeleton above the place of attachment. Koehler \& Vaney (1912) and Vaney (1913) drew attention to the particular gaps occurring in the marginal skeleton of asteroids infested by Parvioris equestris. According to them, the absence of marginal plates is the consequence of the early attachment of parasitic snails which had inhibited skeletal growth. Eulimids parasitizing cidaroid echinoids may induce conspicuous test swellings implying deformations of the test skeleton (Döderlein 1906, Koehler 1927) (Fig. 14). Pyriform test deformations caused by a Mucronalia-like species were reported by Mortensen (1943) for the echinoid Salmacis bicolor. According to Byrne (1985) the intracoelomic eulimid Thyonicola americana for the most part did not appear to affect its holothuroid host Eupentacta quinquesemita. She noted, however, that heavily parasitized hosts could be detected by their apparent inability to keep their tentacles fully retracted and that, in some cases of mass infestation, the parasites may inter-

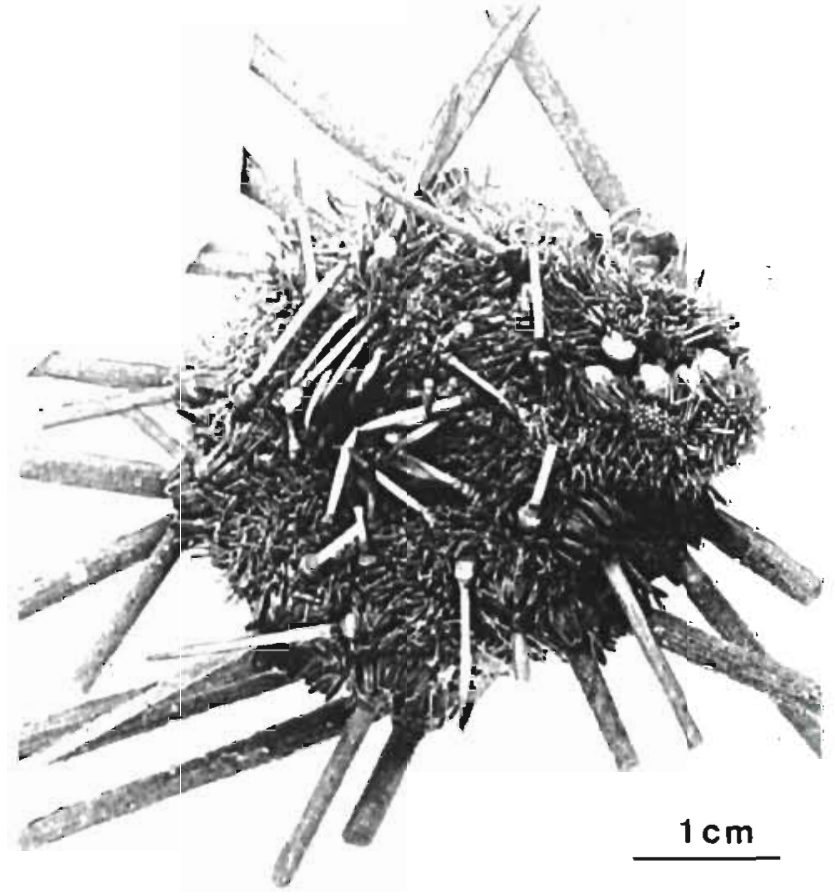

Fig. 14. Stereocidaris tricarinata. Oral view of cidaroid echinoid showing test deformations produced by parasitic gastropods (Stilifer sp.). (After Döderlein 1906)

fere with the use of the holothuroid's tentacles for suspension feeding.

That parasitic eulimids may produce partial castration of the host was considered by Gooding \& Lutzen (1973). They found the size of the gonads in echinoids infested by Robillardia cernica to be usually smaller than in uninfested echinoids. According to Heding \& Mandahl-Barth (1938), intracoelomic Entocolax spp. may castrate their host; in contrast Lützen (1979) reported that Enteroxenox oestergreni is not likely to influence the fecundity of the holothuroid Parastichopus tremulus.

Few host reactions have been reported from echinoderms parasitized by gastropods, except the induction of dermal swellings and galls. This does not imply of course that echinoderms do not react to snail infestations. A particular host-parasite relation must be noted, namely the constant presence of a host envelope surrounding the intracoelomic entoconchid eulimids from holothuroids (Vaney 1913, Tikasingh 1962, Wright 1974). This envelope consists of an outer mesothelial layer and of an inner connective tissue layer. Considering the unsolved question of entoconchid nutrition, it would be worth investigating whether or not host hemal lacunae occur within the inner layer of the envelope. A similar envelope was found around individuals of Asterophila japonica, an intracoelomic entoconchid from asteroids (Hoberg et al. 1980). The mesothelial cover surrounding intracoelomic gas- 
tropods should occur presumably around any part of the parasitic snail which permanently crosses the coelomic cavity (a mesothelial covering of the parasite proboscis has been noticed by Warén [1980b] for Asterolamia hians).

So far there are practically no data indicating that parasitism by eulimids can seriously alter the echinoderm life cycle. Eulimids do not - or only exceptionally - produce host castration, nor do they have any measurable effect on the biology of their host, not even when mass infestations occur. (It may be presumed, however, that eulimids involving skeletal deformations are rather constraining for the echinoderms.) All these facts suggest that the ecological consequences of parasitism due to eulimid gastropods may be quite limited for the echinoderms involved.

\section{Agents: Mollusca, Bivalvia}

Bivalves associated with echinoderms have been recorded almost exclusively from echinoids and holothuroids (Boss 1965). Most echinoid-associated bivalves are simply attached to the host's spines through byssal threads (e.g. Gage 1966, Barel \& Kramers 1977). However, Bernard $(1895,1896)$ described a species (Scioberetia australis) which lives in the brood pouches of the Antarctic spatangoid Abatus cavernosus. According to Bernard, only females of $A$. cavernosus without $S$. australis had developing embryos in their brood pouches. This might imply that the bivalves inhibit the development of embryos or prevent their settlement in brood pouches.

A few bivalve species live ectosymbiotically on synaptid holothuroids. They attach to the synaptid body surface through their spade-shaped creeping foot. It is generally agreed that creeping bivalves do not affect their host, except that they may slightly erode its skin (Anthony 1916, Popham 1940). Three species of endosymbiotic bivalves have been reported from holothuroids. There is almost no information on the relations between Holothuria fuscocineria and Entovalva major which is said to supposedly live in the holothuroid cloaca (Bruun 1938). Entovalva mirabilis and Cycladoconcha amboinensis inhabit small pouches dug into the digestive wall of synaptid holothuroids (respectively Voeltzkow 1890, Schepman \& Nierstrasz 1914; Spärck 1931). These 3 species are presumably typical suspension feeders.

\section{Agents: Entoprocta}

A few Loxosomatidae appear to be relatively common symbiotes of crinoids and ophiuroids, especially in polar and subpolar areas. Mortensen $(1910,1911)$ reported the occurrence of Loxosomella antedonis on cirri of Poliometra prolixa and Heliometra glacialis. L. antedonis appears to secrete a cement on the surface of the crinoid cirri and then attach to its host. The ophiuroid Amphiocnida pilosa often supports individuals of Loxosoma sp. attached to various places of the oral side of its disc and arms (Mortensen 1924). According to Moyano \& Wendt (1981) the entoproct Barentsia discreta may attach to the bivium of the Antarctic holothuroid Psolus charcoti.

\section{Agents: Bryozoa}

Bryozoans may be found firmly attached to the body surface of comatulid crinoids, mostly to their arms or cirri. They were recorded by Mortensen (1910) on Poliometra prolixa, and by Gautier (1959) on Leptometra phalangium. According to Gautier, about $25 \%$ of the crinoid population was infested 6 different species of bryozoans were associated with $L$. phalangium). Moyano \& Wendt (1981) report that up to 4 different species of Bryozoa were seen attached to the outer body surface of the Antarctic holothuroid Psolus charcoti.

Acknowledgements. I thank Drs. J. Jennings, O. Kinne, J. M. Lawrence, G. Shinn and A. Warén for information and criticism; Dr. C. Massin for helping with literature research; and N. Biot, Dr. G. Coppois, M. Doizé, and J. Harray for assisting in the preparation of the manuscript and illustrations.

\section{LITERATURE CITED}

Andersen, M. (1971). Echinodermata from Jørgen Brønlund Fjord, North Greenland. Meddr Gronland 184 (12): 1-18

Ankel, W. E. (1938). Beobachtungen an Prosobranchiern der schwedischen Westküste. Ark. Zool. 30 A (9): 1-27

Anthony, R. (1916). Contribution à l'étude de l'Entovolva (Synapticola) perrieri Malard, mollusque acéphale commensal des synaptes. Archs Zool. exp gén. 55: 375-391

Arvy, L. (1957). Contribution à la connaissance des 'corps bruns' des Holothuridae. C.r. hebd. Séanc. Acad. Sci., Paris 245: 2543-2545

Bacci, G. (1948). Melanella comatulicola (Graff), un gasteropodo parasita della Antedon mediterranea (Lam.). Boll. Zool. 15: 89-98

Baer, J. G. (1938). On the anatomy and systematic status of Cleistogamia holothuriana Faust, 1924. Rec. Indian Mus. 40: $159-168$

Barel, C. D., Kramers, P. G. (1970). Notes on associates of echinoderms from Plymouth and the coast of Brittany Proc. K. ned. Akad. Wet. (C) 73: 159-170

Barel, C. D., Kramers, P. G. (1977). A survey of the echinoderm associates of the north-east Atlantic area. Zool. Verh., Leiden 156: 1-159

Barnes, A. T (1969). Two endoparasitic turbellarians from California echinoids. Ph. D. thesis, Univ. of California, Santa Barbara 
Bartsch, P. (1907). A new parasitic mollusk of the genus Eulima. Proc. U.S. natn. Mus. 32: 555-556

Bartsch, P. (1909). Eulima capillastericola sp. nov. Vidensk. Meddr dansk naturh. Foren. 1909: 195

Bashirudin, M., Karling, T G. (1970). A new entocommensal turbellarian (Fam. Pterastericolidae) from the sea star Astropecten irregularis. Z. Morph. 67. 16-28

Baur, A. (1864). Beiträge zur Naturgeschichte der Synapta digitata. 3. Die Eingeweideschnecke (Helicosyrinx parasita) in der Leibeshöhle der Synapta digitata. Nova Acta Acad. Caesar Leop. Carol. 1864 (I, 3): 1-109

Beklemishev, V. N. (1915). On parasitic turbellarians from the Murmansk coast. I. Acoela. Trudy imp. St. Petersb. Obshch. Estest. (4) 43: 103-172. (Russian; French. summary)

Beklemishev, V N. (1916). On parasitic turbellarians from the Murmansk coast. II. Rhabdocoela. Trudy imp. St. Petersb. Obshch. Estest. (4) 45: 1-78. (Russiani French summary)

Bender, K. (1972). The orthonectid, Rhopalura ophiocomae (Giard), found in Ophiothrix fragilis (Abildgaard) and Ophiura albida (Forbes) from Norway. Sarsia 49: 29-32

Bernard, F. (1895). Sur un lamellibranche nouveau (Scioberetia australis) commensal d'un échinoderme. C.r. hebd. Séanc. Acad. Sci., Paris 121: 569-571

Bernard, F. (1896). Scioberetia australis, type nouveau de lamellibranche. Bull. scient. Fr. Belg. 27: 364-395

Berry, S. S. (1959). Notices of new eastern Pacific Mollusca. III. Leaflets. Malacologia 1: 109-114

Bertsch, H. (1975). New data on Thyca callista (Gastropoda. Capulidae). Veliger 18: 99-100

Bock, S. (1926). Anoplodium stichopi, ein neuer Parasit von der Westküste Skandinaviens. Zool. Bidr. Uppsala 10: $1-30$

Bonnevie, K. (1902). Enteroxenos oestergreni, ein neuer, in Holothurien schmarotzender Gastropode. Zool. Jb. (Anat. Ontogenie Tiere) 15: 731-792

Boss, K. J. (1965). Symbiotic erycinacean bivalves. Malacologia 3: 183-195

Bouchet, P., Lützen, J. (1976). Pisolamia, nouveau genre de gastéropode parasite de l'holothurie Oneirophanta mutabilis. C.r. hebd. Séanc. Acad. Sci., Paris 282: 1013-1016

Bouchet, P., Lützen, J. (1980). Deux gastéropodes parasites d'une holothurie élasipode. Bull. Mus. Hist. nat. Paris (4) 2 (A): $59-75$

Bouillon, J., Jangoux, M. (1984). Note sur l'association entre le mollusque parasite Thyca crystallina (Gould) et l'astérie Linckia laevigata (L.) (Echinodermata) sur le récif de l'île de Laing. Annls Soc. r. zool. Belg. 114: 249-256

Brand, T., Ley, E. M. (1980). On the newly discovered relationship between the parasitic gastropod Balcis catalinensis and its holothurian host Brandtothuria arenicola. Bull. Am. malac. Union 1980: 5-10

Brattström, H. (1946). Observations on Brissopsis lyrifera (Forbes) in the Gullmar Fjord. Ark. Zool. 37 A (18): 1-25

Briot. A. (1906a). Sur les corps bruns des holothuries. C.I Séanc. Soc. Biol. 60: 1156-1157

Briot, A. (1906b). Sur les turbellariés parasites des oursins (Syndesmis echinorum François). C.r. Séanc. Soc. Biol. 60: 1158-1159

Bruun, A. F. (1938). A new entocommensalistic bivalve, Entovalva major n. sp., from the Red Sea. Vidensk. Meddr dansk naturh. Foren. 102: 163-167

Byme, M. (1985). The life history of the gastropod Thyonicola americana Tikasingh, endoparasitic in a seasonally eviscerating host. Ophelia 24: 91-101

Cabioch, L., Grainger, J. N., Keegan, B. F., Könnecker, G.
(1978). Balcis alba (Da Costa). A temprorary ectoparasite on Neopentadactyla mixta Ostergren. In: McHusky, D. S., Berry, A. J. (ed.) Proc. 12th European Mar. Biol. Symp. Pergamon Press, Oxford, p. 237-241

Cannon, L. R. (1975). Observations on a parasitic turbellarian from Acanthaster planci. Proc. Crown-of-thorns Starfish Semin. (Brisbane, 1974). AGPS, Canberra, p. 39-54

Cannon, L. R. (1978). Pterastericola vivipara n. sp., a parasitic turbellarian (Rhabdocoela: Pterastericolidae) from the crown-of-thorns starfish, Acanthaster planci. Mem. Qd Mus. 18: 179-183

Cannon, L. R. (1982). Endosymbiotic umagillids (Turbellaria) from holothurians of the Great Barrier Reef. Zool. Scr. 11: $173-188$

Caso, M. E. (1968). Contribucion al estudio de los holothuroideos de Mexico. Un caso de parasitismo de Balcis intermedia (Cantraine) sobre Holothuria glaberrina Selenka. Anls Inst. Biol. Univ. Nac. Auton. Mexico 39: $31-40$

Caullery, M., Lavallée, A. (1908). La fécondation et le développement de l'oeuf des orthonectides. I. Rhopalura ophiocomae. Archs Zool. exp. gén. 8: 421-469

Caullery, M., Lavallée, A. (1912). Recherches sur le cycle évolutif des orthonectides. Les phases initiales de l'infestation expérimentale de l'ophiure Amphiura squamata par Rhopalura ophiocomae. Bull. scient. Fr. Belg. 46: 139-171

Caullery, M., Mesnil, F. (1901). Recherches sur les orthonectides. Archs Anat. microsc. Morph. exp. 4: 381-470

Changeux, J. P. (1956). Melanella comatulina (Graff) 1874. Vie Milieu 7: 105-106

Changeux, J. P. (1961). Contribution à l'étude des animaux associés aux holothurides. Vie Milieu 10 (Suppl.): 1-124

Chubrik, G. K. (1952). The larval stages of the trematode, Fellodistomum fellis Nicoli, 1909 from the echinoderms of Barents Sea. Zool. Zh. SSSR 31: 653-658. (Russian)

Clark, A. H. (1921). A monograph of the existing crinoids. I. The comatulids (Part 2). Bull. U.S. natn. Mus. 82: 1-795

Clark, H. L. (1896). Notes on the life history of Synapta vivipara Oerstedt. J. Inst. Jamaica 2: 278-282

Clark, H. L. (1898). Synapta vivipara: a contribution to the morphology of echinoderms. Mem. Boston Soc. nat. Hist. 5: $53-88$

Cuénot, L. (1891). Protozoaires commensaux et parasites des échinodermes. Rev. biol. Nord France 3: 285-300

Cuénot, L. (1892). Commensaux et parasites des échinodermes (deuxième note). Rev. biol. Nord France 5: 1-22

Cuénot, L. (1912). Contribution à la faune du Bassin d'Arcachon. V. Echinodermes. Bull. Stn biol. Arcachon 14: $17-116$

Danielssen, D. C., Koren, J. (1882). Holothuroidea. Res. Norweg. N. Atlantic Exped. 1876-1878 Zool. 6: 1-94

Davis, L. V. (1967). The suppression of autotomy in Linckia multifora (Lamarck) by a parasitic gastropod, Stilifer linckiae Sarasin. Veliger 9: 343-346

Döderlein, L. (1906). Die Echinoiden der deutschen TiefseeExpedition. Deutsche Tiefsee-Exped. 5: 61-290

Dorjes, J. (1972). Faerla echinocardii sp. n. und Diskussion der Gattungen Avagina Leiper und Faerla Westblad (Turbellaria, Acoela). Zool. Scr, 1: 185-189

Egloff, D. A. (1966). Commensalism and parasitism in the Thyca-Linckia association. Am. Zool. 6: 564

Elder, H. Y (1979). Studies on the host parasite relationship between the parasitic prosobranch Thyca crystallina and the asteroid starfish Linckia laevigata. J. Zool., Lond. 187 : 369-391

Faust, E. C. (1924). Cleistogamia holothuriana, a new type of holostome fluke. J. Parasit. 11: 121 
Faust, E. C. (1927). Studies on asiatic holostomes (Class Trematoda). I. An unusual holostome, Cleistogamia holothuriana Faust, 1924, from the Andaman Sea. Rec. Indian Mus. 29: 215-218

Fell, H. B. (1961). The fauna of the Ross Sea. Part I. Ophiuroidea. Mem. N.Z. oceanogr. Inst. 18: 1-79

Fishelson, L. (1973). Ecology of the crinoids of the northern Red Sea with emphasis on epi- and endozoic fauna associated with them. J. mar. biol. Ass. India 15: 461-473

Fishelson, L. (1974). Ecology of the northern Red Sea crinoids and their epi- and endozoic fauna. Mar. Biol. 26: 183-192

Fontaine, A. R. (1968). A new ophiuroid host for Rhopalura ophiocomae Giard (Orthonectida: Mesozoa). J. Parasit. 54: $1251-1252$

François, P. (1886). Sur le Syndesmis, nouveau type de turbellariés décrit par M. W. A. Sillimann. C. r. hebd. Séanc. Acad. Sci., Paris 103: 752-754

Fretter, V. (1955). Observations on Balcis devians (Monterosato) and Balcis alba (Da Costa). Proc. malac. Soc. Lond. 31: 137-144

Fujioka, Y. (1984). Intraspecific variation in Vitreobalcis temnopleuricola (Gastropoda: Eulimidae). Jap. J. Zool. 43: $132-141$

Fujioka, Y. (1985). Population ecological aspects of the eulimid gastropod Vitreobalcis temnopleuricola. Malacologia 26: 153-163

Fujioka, Y., Habe, T (1983). A new species of Vitreobalcis (Prosobranchia: Eulimidae) from the Inland Sea of Japan. Venus 42: 13-16

Gage, J. (1966). Observations on the bivalves Montacuta substriata and Montacuta ferruginosa, 'commensals' with spatangoids. J. mar. biol. Ass. U.K. 46: 49-70

Gautier, V. (1959). Sur quelques cas d'épibioses: bryozoaires sur Leptometra. Recl. Trav. Stn mar. Endoume 16 (26): $143-148$

Gemmill, J. F. (1901). On Echinonema grayi, a large nematode from the perivisceral cavity of the sea-urchin. Rep. Brit. Ass. Adv. Sci. 1901. 691-692

Gemmill, J. F., Linstow. O. von (1902). Ichthonema grayi Gemmill \& v. Linstow. Arch. Naturgesch. 68: 113-118

Giese, A. C. (1958). Incidence of Syndesmis in the gut of two species of sea urchins. Anat. Rec. 132: 441-442

Gooding, R. V., Lützen, J. (1973). Studies on parasitic gastropods from echinoderms. III. A description of Robillardia cernica Smith, 1889, parasitic in the sea urchin Echinometra Meuschen, with notes on its biology. Biol. Skr. Dan. Vid. Selsk. $20(4): 1-22$

Graff, L. von (1874). Stylina comatulina, ein neuer Schmarotzer der Comatula mediterranea. Z. wiss. Zool. 25 (Suppl.): 124-126

Gravier, C. J. (1918). Sur l'adaptation du pied au milieu ambiant chez les actinies des grands fonds sous-marins. C.r hebd. Séanc. Acad. Sci., Paris 167: 1009-1012

Grusov, E. N. (1957). A new endoparasitic mollusc, Molpadicola orientalis, gen. n., sp. n. (Family Paedophoropodidae). Zool. Zh. SSSR 36: 852-863. (Russian; English summary)

Grusov, E. N. (1965). The endoparasitic mollusk Asterophila japonica Randall and Heath (Prosobranchia: Melanellidae) and its relation to the parasitic gastropods. Malacologia 3: 111-181. (Russian; English summary)

Habe, $T$ (1952). Parasitic gastropods found in echinoderms from Japan. Publs Seto mar. biol. Lab. 2: 73-85

Habe, T. (1974). Five new gastropodous species parasitic to the Japanese echinoderms. Venus 32: 117-123

Habe, T (1976). Parasitic gastropods from echinoderms of Japan. Bull. natn. Sci. Mus. Tokyo (A) 2 (3): 157-168
Hagen, N. T (1983). Destructive grazing of kelp beds by sea urchins in Vestfjorden, northern Norway. Sarsia 68: $177-190$

Hagen, N. T. (1985). Sea urchin outbreaks and nematode epizootics in Vestfjorden, northern Norway. In: Keegan, B. F., O'Connor, B. D. (ed.) Proc. 5th int. Echinoderm Conf., Galway. Balkema, Rotterdam, p. 387

Heding, S. G. (1934). Entocolax trochodotae n. sp., a new endoparasitic gastropod. Vidensk. Meddr dansk naturh. Foren. 98: 207-214

Heding, S. G., Mandahl-Barth, G. (1938). Investigations on the anatomy and systematic position of the parasitic snail Entocolax Voigt. Meddr Gronland 108 (5): 1-40

Hérouard, H. (1923). Holothuries provenant des campagnes des yachts Princesse-Alice et Hirondelle II (1898-1915). Rés. Camp. scient. Monaco 66: 1-161

Hickman, V. V. (1955). Two new rhabdocoel turbellarians parasitic in Tasmanian holothuroids. Pap. Proc. r. Soc. Tasmania 89: 81-97

Hickman, V. V (1956). Parasitic Turbellaria from Tasmanian Echinoidea. Pap. Proc. r. Soc. Tasmania 90: 169-181

Hickman, V V., Olsen, A. M. (1955). A new turbellarian parasitic in the sea-star, Coscinasterias calamaria (Gray). Pap. Proc. r. Soc. Tasmania 89: 55-63

Hirase, S. (1927). On the structure of a parasitic gastropod, Stilifer celebensis Kükenthal. Jap. J. Zool. 1 (7); 8

Hirase, S. (1932). The adaptive modifications of the gastropod Stilifer celebensis Kükenthal, parasitic on the starfish Certonardoa semiregularis (Müller and Troschel). Proc. malāc. Soc. Lond. 20: 73-76

Hoberg, M. K., Feder, H. M., Jewett, S. C. (1980). Some aspects of the biology of the parasitic gastropod, Asterophila japonica Randall \& Heath (Prosobranchia: Mellanellidae), from southeastern Chukchi Sea and northeastern Bering Sea, Alaska. Ophelia 19: 73-77

Holt, P. A., Mettrick, D. F. (1975). Ultrastrucutral studies of the epidermis and gastrodermis of Syndesmis franciscana (Turbellaria: Rhabdocoela). Can. J. Zool. 53: 536-549

Hopkins, S. H. (1935). A larval Echinocephalus in a sea urchin. J. Parasit. $21 \quad 314-315$

Hoskin, G. P., Cheng, T C. (1970). On the ecology and microanatomy of the parasitic marine prosobranch Mucronalia nitidula (Pease, 1860). Mar. biol. Ass. India, Symp. Ser. 3 (3): 780-798

Hoskin, G. P., Warén, A. (1983). Peastilifer edulis, a new eulimid prosobranch, parasitic on an Indo-Pacific holothurian. Nautilus 97: 23-26

Humphreys, W. F., Lützen, J. (1972). Studies on parasitic gastropods from echinoderms. II. On the structure and biology of the parasitic gastropod, Megadenus cantharelloides n. sp. Biol. Skr. Dan. Vid. Selsk. 19 (1): 1-27

Hyman, L. H. (1960). New and known umagillid rhabdocoels trom echinoderms. Am. Mus. Novit. 1984: 1-14

Irving, J. (1910). Nemertine within test of sea-urchin. Naturalist, Hull 1910: 6

Ivanov, A. W. (1933). Ein neues endoparasitisches Mollusk, Paedophorus dicoelobius n. gen., n. sp. Zool. Anz. 104: 161-165

Ivanov, A. W. (1937). Die Organisation und die Lebensweise der parasitischen Molluske Paedophorus docoelobius A. Ivanov. Acta zool., Stockh. 18: 111-208

Ivanov, A. W. (1945a). Entocolax rimsky-korsakovi nov. sp., a new mollusc parasitic of Myriotrochus mitsukuri. Dokl. Akad. Nauk SSSR (foreign language edn) 48: 534-536

Ivanov, A. W. (1945b). A new endoparasitic mollusc Parentoxenos dogieli nov. gen., nov. sp. Dokl. Akad. Nauk SSSR (foreign language edn) 49: 450-452 
Jangoux, M. (1987). Diseases of echinodermata. I. Agents microorganisms and protistans. Dis. aquat. Org. 2: 147-162

Jennings, J. B. (1971). Parasitism and commensalism in Turbellaria. Adv. Parasit. 9: 1-32

Jennings, J. B. (1980). Nutrition in symbiotic Turbellaria. In: Smith, D. C., Tiffon, $Y$ (ed.) Nutrition in the lower Metazoa. Pergamon Press, Oxford, p. 45-56

Jennings, J. B., Cannon, L. R. G. (1985). Observations on the occurrence, nutritional physiology and respiratory pigment of three species of flatworms (Rhabdocoela: Pterastericolidae) entosymbiotic in starfish from temperate and tropical waters. Ophelia 24: 199-215

Jennings, J. B., Mettrick, D. F. (1968). Observations on the ecology, morphology and nutrition of the rhabdocoel turbellarian Syndesmis franciscana (Lehman, 1946) in Jamaica. Caribb. J. Sci. 8: 57-69

Jespersen, A., Lützen, J. (1971). On the ecology of the aspidochirote sea cucumber Stichopus tremulus (Gunnerus). Norw. J. Zool. 19: 117-132

Jespersen, A., Lützen, J. (1972). Triloborhynchus psilastericola n. sp., a parasitic turbellarian (Fam. Pterastericolidae) from the starfish Psilaster andromeda (Müller and Troschel). Z. Morph. 71: 290-298

Johnson, P. T. (1971). Studies on unhealthy-appearing urchins from Whites Point. Ann. Rep. Kelp. Habit. Impr. Project (1970-1971). Calif. Inst. Technol, Pasadena, p. 55-69

Jones, I., Canton, C. E. (1970). Additional observations on the distribution of Syndesmis franciscana in Caribbean. Caribb. J. Sci. 10: 71-72

Jones, S., James, D. B. (1970). On a stiliferid gastropod parasitic in the cloacal chamber of Holothuria atra. Proc. Symp. Mollusca Cochin 3: 799-804

Jungersen, H. F. (1912). Chordeuma obesum, a new parasitic copepod endoparasite in Asteronyx loveni. Rep. Brit. Ass. Adv. Sci. 1912: 505-506

Kaburaki, T. (1925). An intersting alloecoel infesting the alimentary canal of Metacrinus rotundus P. H. C. Annotnes zool. jap. 10: 299-310

Kanazawa, T., Habe, T (1979). Parasitic gastropod Paramegadenus arrhynchus (Ivanov) from off Mactan Isle near Cebu Island, Philippines. Venus 38: 150-152

Karling, T G. (1970). On Pterastericola fedotovi (Turbellaria). commensal in sea stars. Z. Morph. 67: 29-39

Kato, K. (1935). Discoplana takewakii sp. nov., a polyclad parasitic in the genital bursa of the ophiuran. Annotnes zool. jap. 15: 149-156

Khalil, M. (1938). Cleistogamia loutfia (Kahlil et Azim, 1937). Khalil, 1937: a redescription. J. Egypt. med. Ass. 21: 285-287

Kincaid, T. (1964). A gastropod parasitic on the holothurian, Parastichopus californicus (Stimpson). Trans. Am. microsc. Soc. 83: 373-376

Kinne, O (1980). Diseases of marine animals: general aspects. In: Kinne, O. (ed.) Diseases of marine animals, Vol. I General aspects; Protozoa to Gastropoda. Wiley, Chichester, p. 13-73

Koehler, R. (1895). Les mollusques parasites des holothuries. Le Naturaliste, Paris (2) 9 (200): 156-158, 169

Koehler, R. (1910). Asteroidea. II. Les astéries littorales. Trustees Indian Mus., Calcutta, Echinoderma of the Indian Museum 6: 1-191

Koehler, R. (1924). Anomalies, irrégularités et déformations du test chez les échinides. Annls Inst. océanogr., Paris 1 (5): $159-480$

Koehler, R. (1927). Echinoides. III. Echinides réguliers. Appendice: déformations provoquées chez certains cidaridés par les prosobranches parasites. Trustees Indian
Mus., Calcutta, Echinoderma of the Indian Museum 10: 131-142

Koehler, R., Vaney, C. (1903). Entosiphon deimatis, nouveau mollusque parasite d'une holothurie abyssale. Rev. suisse Zool. 11. 23-41

Koehler, R., Vaney, C. (1905). Holothuroidea. I. Les holothuries des mers profondes. Trustees Indian Mus., Calcutta, Echinoderma of the Indian Museum 3: 1-123

Koehler, R., Vaney, C. (1908). Description d'un nouveau genre de prosobranche parasite sur certains échinides (Pelseneeria nov. gen.). Bull. Inst. océanogr. Monaco 118 : $1-16$

Koehler, R., Vaney, C. (1912). Nouvelles formes de gastéropodes ectoparasites. Bull. scient. Fr. Belg. 46: 191-217

Koehler, R., Vaney, C. (1925). Un nouveau gastéropode producteur de galles sur les piquants du Dorocidaris tiara Anderson. C. r. hebd. Séanc. Acad. Sci., Paris 180: $1559-1563$

Køie, M. (1976). On the morphology and life-history of Zoogonoides viviparus (Olsson, 1868) Odhner, 1902 (Trematoda, Zoogonidae). Ophelia 15: 1-14

Komschlies, K. L., Vande Vusse, F. J. (1980a). Three new species of Syndesmis Silliman, 1881 (Turbellaria: Umagillidae) from Philippine sea urchins. J. Parasit. 66: 659-663

Komschlies, K. L., Vande Vusse, F. J. (1980b). Syndesmis compacta sp. nov and description of $S$. glandulosa Hyman 1960 (Turbellaria: Umagillidae) from Philippine sea urchins. J. Parasit. 66: 664-666

Kozloff, E. N. (1965). Desmote inops sp. n. and Fallacohospes inchoatus gen. and $\mathrm{sp}$. n., umagillid rhabdocoels from the intestine of the crinoid Florometra serratissima (A. H. Clark). J. Parasit. 51: 305-312

Kozloff, E. N. (1969). Morphology of the orthonectid Rhopalura ophiocomae. J. Parasit. 55: 171-195

Kramers, P. G. (1971). New records of the holothurians, Thyone serrifera Oestergren (Dendrochirotida) and Leptosynapta bergensis (Oestergren) (Apodida). Zool. Meded. Leiden 45: 193-195

Kropp, B. (1927). 'Commensalism' of a sea anemone and a sea urchin. Science 65: 423

Lama Seco, A., Rodriguez Babio, C. (1978). Estudio monografico de Syndesmis echinorum François, 1886 (Turbellaria, Rhabdocoela) endoparasito de equinoideos del litoral Gallego. Rev. Iber. Parasit. 38: 165-192

Lehman, H. E. (1946). A histological study of Syndisyrinx franciscanus, gen. et sp. nov., an endoparasitic rhabdocoel of the sea urchin, Strongylocentrotus franciscanus. Biol Bull. mar biol. Lab., Woods Hole 91: 295-311

Leiper, R. T. (1902). On an acoelous turbellarian inhabiting the common heart urchin. Nature, Lond. 66: 641

Leiper, R. T. (1904). On the turbellarian worm Avagina incola, with a note on the classification of the Proporidae. Proc. zool. Soc. Lond. 1904: 407-411

Leydig, F. (1854). Über einige Rundwürmer. Arch. Anat. Physiol. 1854: 291-295

Ludwig, H. (1897). Eine neue Schlauchschnecke aus der Leibeshöhle einer antarktischen Chirodota. Zool. Anz. 20: 248-249

Ludwig, H. (1898). Fauna chilensis. Die Holothurien der Sammlung Plate. Zool. Jb. 4 (Suppl.): 431-453

Ludwig, H. (1903). Seesterne. Rés. Voyage S. Y Belgica 1903: $1-72$

Lutzen, J. (1968). Unisexuality in the parasitic family Entoconchidae (Gastropoda: Prosobranchia). Malacologia 7: 7-15

Lützen, J. (1972a). Studies on parasitic gastropods from echinoderms. II. On Stilifer Broderip, with special refer- 
ence to the structure of the sexual apparatus and the reproduction. Biol. Skr Dan. Vid. Selsk. 19 (6): 1-18

Lützen, J. (1972b). Records of parasitic gastropods from crinolds, with description of a new genus, Goodingia (Gastropoda, Prosobranchia). Steenstrupia 2: 233-246

Lützen, J. (1976). On a new genus and two new species of Prosobranchia (Mollusca), parasitic on the tropical sea urchin Echinometra mathaei. Israel J. Zool. 25: 38-51

Lützen, J. (1979). Studies on the life history of Enteroxenos Bonnevie, a gastropod endoparasitic in aspidochirote holothurians. Ophelia 18: 1-51

Lützen, J., Nielsen, K. (1975). Contributions to the anatomy and biology of Echineulima n. gen. (Prosobranchia: Eulimidae), parasitic on sea urchins. Vidensk. Meddr dansk. naturh. Foren. 138: 171-199

MacNae, W., Kalk, M. (1962). The fauna and flora of sand flats at Inhaca Island, Moçambique. J. Anim. Ecol. 31: 93-128

McPherson, B. F. (1968). Contributions to the biology of the sea urchin Eucidaris tribuloides (Lamarck). Bull. mar. Sci. 18: 400-443

McRae, A. (1959). Evechinus chloroticus (Val.), an endemic New Zealand echinoid. Trans. r. Soc. N.Z. 86: 105-207

Madsen, E. J (1961). The Porcellanasteridae. A monographic revision of an abyssal group of sea-stars. Galathea Rep. 4 : 33-174

Mandahl-Barth, G. (1941). Thyonicola mortenseni n. gen., n. sp., eine neue parasitische Schnecke. Vidensk. Meddr dansk naturh. Foren. 104: 341-351

Mandahl-Barth, G. (1945). Diacolax cucumariae n. gen., n. sp., a new parasitic snail. Vidensk. Meddr dansk naturh. Foren. 109: 55-68

Mandahi-Barth, G. (1949). Mucronalia angulata n. sp. Un nouveau gastéropode parasite. J. Conch., Paris 89: $147-149$

Marcus, E. (1949). Turbellaria brasileiros (7). Bol. Fac. Filos. Cienc. Letr Univ. S. Paulo (Zool.) 14: 1-156

Meserve, F. G. (1934). A new genus and species of parasitic Turbellaria from a Bermuda sea cucumber. J. Parasit. 20: $270-276$

Mettrick, D. F., Boddington, M. J. (1972). Amino acid pools of Syndesmis franciscana (Turbellaria: Platyhelminthes) and host coelomic fluich. Can. J. Zool. 50: 411-413

Mettrick, D. F., Jennings, J. B. (1969). Nutrition and chemical composition of the rhabdocoel turbellarian Syndesmis franciscana, with notes on the taxonomy of S. antillarum. J. Fish. Res. Bd Can. 26: 2669-2679

Millemann, R. E. (1951). Echinocephalus pseudouncinatus n. sp., a nematode parasite of the abalone. J. Parasit. 37 : $435-439$

Monticelli, F. S. (1892). Notizia preliminare intorno ad alcuni inquilini degli Holothuroidea del Golfo di Napoli. Monitore zool. ital. 3: 249-256

Mortensen, T (1910). Report on the echinoderms collected by the Denmark-Expedition at North-East Greenland. Meddr Gronland 45: 239-302

Mortensen, T (1911). A new species of Entoprocta, Loxosomella antedonis, from north-east Greenland. Meddr Gronland 45: 399-406

Mortensen, T (1921a). Notes on some Scandinavian echinoderms with descriptions of two new species. Vidensk. Meddr dansk naturh. Foren. 72: 45-79

Mortensen, T (1921b). Studies on the development and larval forms of echinoderms. G. E. C. Gad, Copenhagen

Mortensen, I (1924). Echinoderms of New Zealand and the Auckland-Campbell Islands. II. Ophiuroidea. Vidensk. Meddr dansk naturh. Foren. 77: 91-177
Mortensen, T. (1932). Uber den angeblichen Kieselschwamm Microcordyla asteriae Zirpolo. Zool. Anz. 97: 197-204

Mortensen, T (1933). Ophiuroidea. Rep. Dan. Ingolf-Exped. 4 (8): $1-121$

Mortensen, T (1936). Echinoidea and Ophiuroidea. Discovery' Rep. 12: 199-348

Mortensen, T. (1940). A monograph of the Echinoidea. Part II (1) Aulodonta. C. A. Reitzel, Copenhagen

Mortensen, T (1943). A monograph of the Echinoidea. Part III (2) Camarodonta I. C.A. Reitzel, Copenhagen

Morton, B. (1976). Selective site segregation in Balcis shaplandi and Mucronalia fulvescens (Mollusca: Gastropoda: Aglossa) parasitic upon Archaster typicus (Echinodermata: Asteroidea). Malacol. Rev. 9: 55-61

Moyano, H. I., Wendt, A. (1981). Bryozoa epizoos de Psolus charcoti Vaney, 1907 (Holothuroidea, Psolidae). Inst. Antarct. Chil., Ser. cient. 27: 5-11

Nappi, A. J., Crawford, J A. (1984). The occurrence and distribution of a syndesmid (Turbellaria: Umagillidae) in Jamaican sea urchins. J. Parasit. 70: 595-597

Ohshima, H. (1911). Note on a gigantic form of auricularia allied to A. nudibranchiata Chun. Annotnes zool. jap. 7 : $347-352$

Orihel, T. C. (1952). Entocommensal rhabdocoels from echinoids of Puget Sound. M. Sc. thesis, Univ. of Washington, Seattle

Östergren, H. (1938). Studien über die Seewalzen. Göteborgs K. Vetensk. Vitterhsamh. Handl. (B) 5 (4): 1-151

Ozaki, Y (1932). On a new genus of parasitic Turbellaria, Xenometra and an new species of Anoplodium. J. Sci. Hiroshima Univ. (B) 1: 81-83

Palombi, A. (1930). Il ciclo biologico di. Diphterostomum brusinae Stoss. (Trematode Digenetico: fam. Zoogonidae Odhner). Pubbl. Staz. zool. Napoli 10: 109-151

Pearse, J. S., Timm, R. W. (1971). Juveniles nematodes (Echinocephalus pseudouncinatus) in the gonads of sea urchins (Centrostephanus coronatus) and their effect on host gametogenesis. Biol. Bull. mar. biol. Lab., Woods Hole 140: 95-103

Pilsbry, H. A. (1956). A gastropod domiciliary in sea urchin spines. Nautilus 69: 109-110

Ponder, W. F., Gooding, R, V (1978). Four new eulimid gastropods associated with shallow-water diadematid echinoids in the western Pacific. Pacif. Sci. 32: 157-181

Popham, M. L. (1940). The mantle cavity of some of the Erycinidae, Montacutidae and Galeomatidae with special reference to the ciliary mechanisms. J. mar biol. Ass. U.K. 24: $549-587$

Powers, P. B. (1935). Studies on the ciliates of sea-urchins. Pap. Tortugas Lab. 29: 293-326

Prévot, G. (1966a). Sur deux trématodes larvaires d'Antedon mediterranea Lmk (Echinoderme). Annls Parasit. hum. comp. 41: 233-242

Prévot, G. (1966b). Metacercania sp. Prévot, 1966, d'Antedon mediterranea L.mk (Echinoderme), forme larvaire de Monorchis monorchis (M. Stossich) A. Looss, 1902 (Trematoda: Digenea). Annls Parasit. hum comp. 41: 367-369

Rader, D. N. (1982). Orthonectid parasitism: effects on the ophiuroid. In: Lawrence, J. M. (ed.) Proc. 4th int. Echinoderm Conf., Tampa Bay. Balkema, Rotterdam, p. 395-401

Randall, J., Heath, H. (1911). Asterophila, a new genus of parasitic gastropod. Biol. Bull. mar biol. Lab., Woods Hole 22: $98-106$

Risbec, J. (1953). Observations sur les Eulimidae (Gastéropodes) de Nouvelle-Calédonie. Bull. Mus. Hist. nat., Paris 26: 109-117 
Ritchie, J. (1910). Worm parasitic in sea-urchin. Naturalist. Hull 1910: 94

Rosén, N. (1910). Zur Kenntnis der parasitischen Schnecken. Lunds Univ. Arsskr (2) 6 (4): 1-67

Rubstov, I. A. (1977). A new genus and species of parasitic nematode, Ananus asteroideus (Nematoda, Marimermithidae), from the asteroid Diplopteraster perigrinator Bull. Mus. Hist. nat., Paris (3) 496: 1113-1117

Rubstov, I. A. (1985). A new species of the genus Thalassonema (Nematoda). Zool. Zh. SSSR 64: 446-448. (Russian; English summary)

Rubstov, I. A., Platonova, T. A. (1974). A new family of marine parasitic nematodes. Zool. Zh. SSSR 53: 1445-1458. (Russian; English summary)

Sarasin, P., Sarasin, F. (1887). Über zwei parasitische Schnecken. Ergebn. Naturw. Forsch. Ceylon 1884-1886 2: 21-32

Schepman, M. M., Nierstrasz, H. F. (1914). Parasitische und kommensalistische Mollusken aus Holothurien. Voeltzkow Reise in Ostafrika. Wiss. Ergebn. 4: 383-416

Schneider, A. (1858). Über einige Parasiten der Holothuria tubulosa. Arch. Anat. Physiol. 1858: 323-329

Schurig, W (1906). Anatomie der Echinothuriden. Deutsche Tiefsee-Exped. 5: 291-350

Schwanwitsch, B. N. (1914). Preliminary note on Entocolax ludwigi Voigt. Trudy imp. St. Petersb. Obshch. Estest. 45 (4): 146-158. (Russian; French summary)

Shasky, D. R. (1961). Notes on rare and little known panamic mollusks. Veliger 4: 22-24

Shimazu, T (1979). A metacercaria of a digenic trematode of the genus Protoeces (Fellodistomidae) parasitic to the sea urchin, Strongylocentrotus intermedius. Zool. Mag., Tokyo 88: $318-320$

Shimazu, T., Shimura, S. (1984). Paralepidapedon g. n. (Trematoda: Lepocreadiidae), with descriptions of metacercariae of Paralepidapedon hoplognathi (Yamaguti, 1938) comb. n. and of two other species from sea urchins. Zool. Sci., Tokyo 1: 809-817

Shinn, G. L. (1980). Reproduction of Syndisyrinx franciscanus, a flatworm symbiont of sea urchins. Am. Zool. 20: 892

Shinn, G. L. (1981). The diet of three species of umagillid neorhabdocoel turbellarians inhabiting the intestine of echinoids. Hydrobiologia 84: 155-162

Shinn, G. L. (1983a). Anoplodium hymanae sp. n., an unmagillid turbellarian from the coelom of Stichopus californicus, a northeast Pacific holothurian. Can. J. Zool. 61: 750-760

Shinn, C. L. (1983b). The life history of Syndisyrinx franciscanus, a symbiotic turbelarian from the intestine of echinoids, with observations on the mechanism of hatching. Ophelia 22: 57-79

Shinn, G. L. (1985a). Reproduction of Anoplodium hymanae, a turbellarian flatworm (Neorhabdocoela, Umagillidae) inhabiting the coelom of sea cucumbers; production of egg capsules, and escape of infective stages without evisceration of the host. Biol. Bull. mar. biol. Lab., Woods Hole 169: $182-198$

Shinn, G. L. (1985b). Infection of new hosts by Anoplodium hymanae, a turbellarian flatworm (Neohabdocoela, Umagillidae) inhabiting the coelom of the sea cucumber Stichopus californicus. Biol. Bull. mar. biol. Lab., Woods Hole 169: 199-214

Shinn, G. L. (1986a). Egg capsules of a parasitic turbellarian flatworm: ultrastructure of hatching sutures. J. Morph. 188: $15-28$

Shinn, G. L. (1986b). Life history and function of the secondary uterus of Wahlia pulchella, an umagillid turbellarian from the intestine of a northeastern Pacific sea cucumber (Stichopus californicus). Ophelia 25: 59-74

Shipley, A. E. (1901). On some parasites found in Echinus esculentus. J. microsc. Sci. 44: 281-290

Shipley, A. E. (1903). On the ento-parasites collected by the 'Skeat Expedition' to Lower Siam and the Malay Peninsula in the years 1899-1900. Proc. zool. Soc. Lond. 2: 145-156

Silliman, W. A. (1881). Sur un nouveau type de turbellariés. C. r. hebd Séanc. Acad. Sci. Paris 93: 1087-1089

Skarlato, O. A. (1951). Entocolax chirodotae nov. sp., a new mollusk parasite in holothurian. Zool. Zh. SSSR 30: 358-362. (Russian)

Sloan, N. A., Clark, A. M., Taylor, J. D. (1979). The echinoderms of Aldabra and their habitats. Bull. Br Mus. nat. Hist. (Zool.) 37 (2): 81-128

Smirnov, I. S., Stepanyants, S. D. (1980). Symbiosis of the hydroid Hydractina vallini Jaederholm and brittle stars of the family Ophiolepididae in the Antarctic waters. In: Naumov, D. V., Stepanyants, S. D. (ed.) The theorical and practical importance of the Coelenterates. Akademia Nauk SSSR, Leningrad, p. 105-108. (Russian)

Smith, N. S. (1973). A new desciption of Syndesmis dendrastrorum (Platyhelminthes, Turbellaria) an intestinal rhabdocoel inhabiting the sand dollar Dendraster excentricus. Biol. Bull. mar. biol. Lab., Woods Hole 145: 598-606

Smith, T. B. (1984). Ultrastructure and function of the proboscis of Melanella alba (Gastropoda: Eulimidae). J. mar. biol. Ass. U.K. 64: 503-512

Snyder, R. D. (1980). Commensal turbellarians from Bermuda holothurians. Can. J. Zool. 58: 1741-1744

Spärck, R. (1931). Cycladoconcha amboinensis n. gen. n. sp., a commensalistic lamellibranch. Vidensk. Meddr dansk naturh. Foren. 91. 227-240

Stunkard, H. W. (1938). Distomum lasium Leidyg, 1892 (Syn. Cercariaeum lintoni Miller and Northup, 1926), the larval stage of Zoogonus rubellus (Olsson, 1868) (Syn. Z. mirus Looss, 1901). Biol. Bull. mar. biol. Lab., Woods Hole 75: 308-334

Stunkard, H. W (1941). Specificity and host-relations in the trematode genus Zoogonus. Biol. Bull. mar biol. Lab., Stunkard, H. W., Corliss, J. O. (1950). Parasitic turbellarians from echinoderms. J. Parasit. 36 (Suppl.): 91

Stunkard, H. W., Corliss, J. O. (1951). New species of Syndesmis and a revision of the family Umagillidae Wahl, 1910 (Turbellaria: Rhabdocoela). Biol. Bull. mar. biol. Lab. Woods Hole 101 - 319-334

Tauson, A. (1917). Adolescaria ophiurae, a parasite of Ophiura sarsi. Zool. Zh. SSSR 2: 149-218. (Russian; English summary)

Thiele, J. (1925). Gastropoda. Deutsche Tiefsee-Expedition $17: 38-372$

Tikasingh, E. S. (1961). A new genus and two new species of endoparasitic gastropods from Puget Sound, Washington. J. Parasit. 47: 268-272

Tikasingh, E. S. (1962). The microanatomy and histology of the parasitic gastropod, Comenteroxenos parastichopoli Tikasingh. Trans. Am. microsc. Soc. 81: 320-327

Tikasingh, E., Pratt, I. (1961). The classification of endoparasitic gastropods. Syst. Zool, 10: 65-69

Timon-David, J. (1933). Contribution à l'étude du cycle évolutif des Zoogonies (Trématodes). C.r. hebd. Séanc. Acad. Sci., Paris 196: 1923-1924

Timon-David, J. (1934). Recherches sur les trématodes parasites des oursins en Méditerranée. Bull. Inst. océanogr. Monaco 652: 1-16

Timon-David, J. (1936). Sur l'évolution expérimentale des métacercaires de Zoogonus mirus Looss 1901 (Trématodes, 
Famille des Zoogonides). C.r. Ass. Franç. Avanc. Sci. 60: $274-276$

Timon-David, J. (1938). On parasitic trematods in echinoderms. In: Livr. jubil. Prof. L. Travassos. Publ. Inst. Oswaldo Cruz, Rio de Janeiro, p. 467-473

Tullis, R. E., Cheng, T. C. (1971). The uptake of ${ }^{14} \mathrm{C}$ by Stylifer linckiae (Mollusca: Prosobranchia) from its echinoderm host, Linckia multifora. Comp. Biochem. Physiol. 40 B: $109-112$

Vaney, C. (1913). La pénétration des gastéropodes parasites dans leur hôte. C.r Séanc. Soc. Biol. 74: 598-601

Vaney, C. (1915). L'adaptation des gastéropodes au parasitisme. Bull. scient. Fr. Belg. 47: 1-87

Voeltzkow, A. (1890). Entovalva mirabilis, eine schmarotzende Muschel aus dem Darm einer Holothurie. Zool. Jb. (Abt. Syst. Geogr. Biol.) 5: 619-628

Voigt, W (1888). Entocolax ludwigii, ein neuer seltsamer Parasit aus einer Holothurie. Z. wiss. Zool. 47: 658-688

Voigt, W. (1901). Entocolax schiemenzii n. sp. Zool. Anz. 24: 285-292

Wahl, B. (1906). Untersuchungen über den Bau der parasitischen Turbellarien aus der Familie der Dalyelliden (Vorticiden). I. Die Genera Anoplodium, Graffilla und Paravortex. SBer Akad. Wiss. Wien 115: 417-473

Wahl, B. (1909). Untersuchungen über die parasitischen Turbellarien aus der Familie der Dalyelliden (Vorticiden). II. Die Genera Umagilla und Syndesmis. SBer Akad. Wiss. Wien 118: 943-965

Ward, H. B. (1933). On Thalassonema ophioctenis, a nematode parasitic in the brittle star Ophiocten amitinum. J. Parasit. 19: 262-268

Warén, A. (1980a). Revision of the genus Thyca, Stylifer, Scalenostoma, Mucronalia and Echineulima (Mollusca, Prosobranchia, Eulimidae). Zool. Scr. 9: 187-210

Warén, A. (1980b). Descriptions of new taxa of Eulimidae (Mollusca, Prosobranchia), with notes on some previously described genera. Zool. Scr 9: 283-306

Warén, A. (1981a). Eulimid gastropods parasitic on echinoderms in the New Zealand region. N. Z. J. Zool. 8: 313-324

Waren, A. (1981b). Revision of the genera Apicalia A. Adams and Stilapex Iredale and description of two new genera (Mollusca, Prosobranchia, Eulimidaej. Zool. Scr 10 : 133-154

Warén, A. (1981c). Bloodsucking snails: the Eulimidae. Conchiglie 13: 7-10

Waren, A (1984). A generic revision of the family Eulimidae (Gastropoda, Prosobranchia). J. mollusc. Stud. 13: 1-96

Warén, A., Camey, R. S. (1981). Ophiolamia armigeri gen et sp. n. (Mollusca, Prosobranchia) parasitic on the abyssal ophiuroid Ophiomusium armigerum. Sarsia 66: 183-193

Warén, A., Sibuet, M. (1981). Ophieulima (Mollusca, Prosobranchia), a new genus of ophiuroid parasites. Sarsia 66: 103-107

Westblad, E. (1926). Parasitische Turbellarien von der Westküste Skandinaviens. Zool. Anz. 68: 212-216

Westblad, E. (1930). Anoplodiera voluta und Wahlia macrostylifera, zwei neue parasitische Turbellarien aus Stichopus tremulus. Z. Morph. Ökol. Tiere 19: $397-426$

Westblad, E. (1948). Studien über skandinavische Turbellaria Acoela. V. Ark. Zool. $41 \mathrm{~A}(7)$ : 1-82

Westblad, E. (1949). On Meara stichopi (Bock) Westblad, a new representative of Turbellaria Achoophora. Ark. Zool $1(5): 43-57$

Westblad, E. (1953). New Turbellaria parasites in echinoderms. A.r. Zool. 5: 269-288

Wright, L. (1974). The biology of Thyonicola americana parasitic in holothuroideans of the genus Eupentacta. Ann. Rep. west. Soc. Malacol. 7: 32

Yamaguchi, M., Lucas, J. S. (1984). Natural parthenogenesis, larval and juvenile development, and geographical distribution of the coral reef asteroid, Ophidiaster granifer Lütken. Mar. Biol. 83: 33-42

Zirpolo, G. (1926). Di una nuova silicospugna del Golfo di Napoli (Microcordyla asteriae n.g., n. sp.). Nota preliminare. Boll. Soc. nat. Napoli 38: 287-290

Editorial responsibility: Managing Editor; accepted for printing on April 2, 1987 